\title{
Nutrigenomics of Neuradaptogen Amino-Acid-Therapy and Neurometabolic Optimizers: Overcoming carbohydrate bingeing and overeating through neurometabolic mechanisms
}

\begin{abstract}
Kenneth Blum ${ }^{1,3,4,7,8,9^{*}}$, Debasis Bagchi ${ }^{2}$, Abdalla Bowirrat ${ }^{3}$, B. William Downs ${ }^{4}$, Roger L. Waite $^{4}$, John Giordano ${ }^{5}$, Siohban Morse ${ }^{5}$, Margaret Madigan ${ }^{4}$, Jaclyn M. Downs, ${ }^{4}$ Eric R. Braverman, ${ }^{6,7}$ Margaret Polanin $^{7}$, Debmayla Barh ${ }^{8}$, Frank Fornari ${ }^{9}$, Thomas Simpatico ${ }^{10}$

${ }^{1}$ Department of Psychiatry, University of Florida, College of Medicine, Mcknight Brain Institute, Gainesville, Florida, USA; ${ }^{2}$ Inovative Research and Clinical Trials, Iovate Inc., Toronto, Canada. ${ }^{3}$ Clinical Neuroscience and Population Genetics, Ziv Government Medical Center, Israel; ${ }^{4}$ Department of Personalized Medicine, Reward Deficiency Solutions, LLC, San Diego, California, USA; ${ }^{5}$ Deaprtment of Holistic Medicine, G and G Hoistic Addiction Treatment Center, North Miami Beach, USA; ${ }^{6}$ Department of Clinical Neurology, Path Foundation NY, New York, New York, USA; ${ }^{7}$ Department of Neurological Surgery, Weill Cornell College of Medicine, New York, New York; ${ }^{8}$ Centre for Genomics and Applied Gene Technology, Institute of Integrative Omics and Applied Biotechnology (IIOAB), Nonakuri, Purba Medinipur, West Bengal 721172, India; ${ }^{9}$ Dominion Diagnostics Inc. North Kingstown, Rhode Island, ${ }^{10}$ Community Mental Health Institute, Center for Clinical \& Translational Science, University of Vermont and Department of Psychiatry, University of Vermont College of Medicine, Burlington, Vermont, USA
\end{abstract}

Corresponding author: Kenneth Blum, PO Box: 100256, Gainesville, FL, USA

Submission date: August 12, 2011; Acceptance date: September 29, 11; Publication date: September 29, 2011

\begin{abstract}
Despite progress that has been made in the treatment of obesity, the epidemic continues to rise worldwide. While pharmacological treatment of obesity may be effective, medications may have significant side effects and can be potentially fatal. This review will provide significant evidence to substantiate the existence of Reward Deficiency Syndrome in Obesity and the role of catecholaminergic pathways in aberrant substance seeking behavior, in particular cravings for carbohydrates. The genetic basis for generalized craving behavior will be established. Evidence to support the augmentation of precursor amino acid therapy and enkephalinase, MOA and COMT inhibition leading to enhanced levels of neurotransmitters: serotonin, enkephalins, GABA and dopamine/norepinephrine as well increasing insulin sensitivity (affecting dopamine neuronal synthesis regulation) through the use of certain neurometabolic optimizers will also be provided. This review article cites many published studies to support a conceptual paradigm shift
\end{abstract}


towards the use of this proposed nutrigenomic formula. The analysis and research preceding this formulation is outlined. This formulation has a generalized anti-craving effect and can inhibit carbohydrate bingeing, inducing significant healthy fat loss and prevention of relapse. This is the first time that components of this formula have been combined, at the dosage levels indicated with the goal of promoting successful and sustainable body recomposition. We are encouraging other laboratories to further evaluate Neuroadtagen Amino-Acid Therapy (NAAT)/Nurometabolic optimizers as a putative anti-obesity complex in larger controlled blinded studies and await interpretation of must these needed studies.

Keywords: NAAT, Dopamine, Genes, Polymorphisms, Obesity, Craving Behavior, Overeating, Reward Deficiency Syndome, Nutrigenomics.

\section{Background}

It is well-known that there is indeed an obesity epidemic worldwide. To alter this trend, new strategies and programs for weight maintenance as well as weight reduction must become a high public health priority. Our take on this, is that programs which promote the "just say no policy" will be doomed to fail. We must first begin to understand how the brain controls eating behavior and what are the genetic antecedents to abnormal "sugar cravings". In this rather large review we have attempted to provide a coherent detailed account accompanied with many data driven references to carefully frame these new but important concepts.

"Weight loss," "weight gain" and "weight management" are the most common terms used to express changes in body composition, particularly regarding fat mass. However, this review will present evidence showing that the focus on "weight" as the main criteria for measurment is in contradiction to the natural sequence of processes in recompositional metabolism. Given that fat is the lightest of pertinent macro molecules and more importantly, fat is usually the last to go in the body recomposition process talking about "weight loss" creates inappropriate expectations and does not provide an accurate perspective for evaluating healthy changes in body composition. Fat metabolism is influenced by many factors from genetics to lifestyle and the efficiency of energy metabolism. Existing "weight loss" tactics for the most part have failed to provide successful means to achieve sustainable healthy body composition and improve healthy fat loss. Commercialized "weight loss" programs, even medically supervised versions, do not consider the "bi-phasic" [1] nature of genetically regulated set point "defense response" mechanisms that mandate preservation of body fat stores against famine and survival threats simulated by aggressive weight loss tactics during phase 1 . Further, existing tactics place an erroneous emphasis on caloric intake to the exclusion of considering nutrient quality and density of those calories, a factor far more important to metabolic competence than calories alone. This review provides support for a novel body recomposition and healthy body mass management technology. A unique formula and method to safely and naturally induce effective body recomposition and achieve healthy body mass management objectives is presented. This novel technology contrasts with existing tactics to manipulate body composition in that it is based on the fact that sufficient nutrition (as opposed to just calories) is required to fund a wide range of 
factors involved in achieving healthy and efficient metabolic function. This technology combines synergistic nutraceutical ingredients necessary to simultaneously address symbiotic mechanisms that promote healthy metabolism in the energy management system, stress and inflammation management system, the pleasure/food craving management system (controlled by the brain), the immune management system and the neuroendocrine system. Importantly, these five systems are homeostatic and intimately interactive and interdependent in ensuring optimal metabolic function. This novel nutraceutical technology optimizes genetically programmed energy expenditure and storage functions, without inducing "Yo Yo" rebound weight gain consequences. In contrast to conventional short term expectations, "weight loss" might not be expected since the need to improve the health of the cellular energy producing apparatus might first result in increased muscle density and weight "gain" that is needed to promote healthy and permissible fat oxidation and loss. In fact, a more normal and expectable sequence of events might include initial water weight loss, increased muscle density and weight (muscle is heavier than fat and water) followed by permissible fat loss, which could take many months to achieve. Such a sequence could and has contributed to disappointment with short term "weight loss" results and abandonment of more intelligent programs that would lead to sustainable fat loss useing the healthy body recomposition dynamic.

Various minerals have been shown to be important in funding events leading up to and promoting healthy carbohydrate metabolism, insulin function, energy production, fat oxidation, serotonin release and availability in the brain, blood lipid metabolism and improving the success of fat loss and body composition management efforts.

Figure 1 Nutrigenomics of Neuradaptogen and Amino-Acid-Therapy (NAAT) ${ }^{\mathrm{TM}}$ as a putative anti-obesity complex.

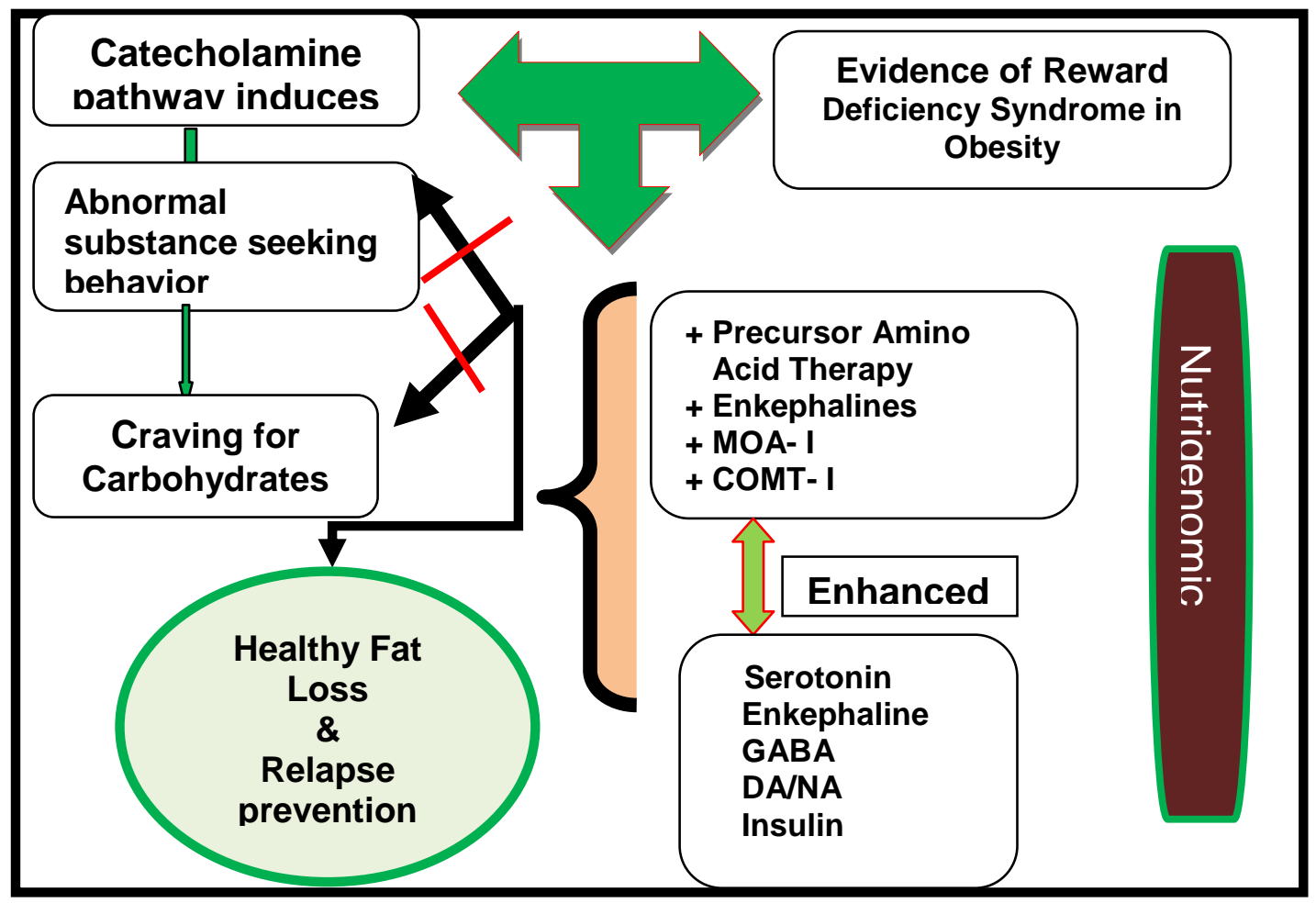


Based on the premise of this review, the novel nutraceutical technology presented herein provides ample evidence that the term "weight loss" is a misnomer. This term "weight loss" (or any terms using the "weight" language reference) is deliberately misused herein to emphasize the point of how conventional tactics (and language) contribute to erroneous, but unquestionably accepted, dogma. Current "weight loss" tactics, for the most part, are based on inducing calorie intake deprivation and artificially stimulate, deprive or inhibit the body's genetically programmed energy expenditure, storage, regulatory and management processes (see table 1).

Table 1 Current "weight loss" tactics

\begin{tabular}{|l|}
\hline $\begin{array}{l}\text { Central Nervous System Stimulants (CNSS) that artificially stimulate the rate of calorie } \\
\text { burning (Basal Metabolic Rate [BMR]). }\end{array}$ \\
\hline Appetite Suppressants \\
\hline Fat Blockers \\
\hline Starch Blockers \\
\hline Diuretics (Water Pills) \\
\hline Low Calorie Diets \\
\hline Low Food Diets \\
\hline Meal Replacement Programs (Diet Shakes, bars, etc.) \\
\hline High Protein Diets \\
\hline High Carbohydrate Diets \\
\hline Low/No Carbohydrate Diets \\
\hline Low Fat Diets \\
\hline Pre-Meal Fiber/Water "Fill-You-Up" Programs \\
\hline Fruit and Fruit juice "Rapid "weight loss"”' Programs \\
\hline Over Night "weight loss" Programs \\
\hline Vegetable Soup Diet Programs \\
\hline Liposuction \\
\hline Radical Digestive Tract Surgeries \\
\hline Acupuncture \\
\hline Laxatives \\
\hline
\end{tabular}

Many of these tactics are used individually or in combination to achieve rapid "weight loss" results. As stated, the primary goal of these tactics is "weight loss" and/or image enhancement. These objectives are usually pursued without regard for or knowledge of the impact on health, the bodys' natural genetically mandated homeostatic response to such tactics, or the fact that depriving the body of resources essential to maintain health is counterproductive. Essentially, these types of tactics simulate the circumstances of a famine and induce genetically programmed energy conservation responses. In addition, at some point in the energy conservation sequela, increased appetite can result. Alarmingly, many of these tactics are approved, administered and/or supervised by medical or health professionals. While initially appearing to promote "weight loss" (phase 1), such tactics are destined to fail as gene-induced recalibration of energy management and storage instructions homeostatically adjusts to the artificially imposed influence of such tactics, generally by lowering the basal metabolic rate, increasing energy storage requirements and promoting increased fat retention (phase 2) [1, 2]. Chronic and repeated attempts to lose weight with such tactics are referred to as the yo-yo weight gain rebound effect. 
This phenomenon is responsible for ever-increasing frustration, anxiety and a sense of helplessness caused by the out-of-control "weight loss"/gain juggernaut.

Ultimately, obesity is an energy-balance and nutrient deficiency-induced famine disorder characterized by a survival gene induced increase in fat storage, lowering of the Basal Metabolic Rate (to conserve energy) and increase in appetite. Following circumstances when a simulated famine is induced, certain genes, programmed to resist loss of body fat, prevail [3]. This programmed genetic predisposition is responsible for down-regulating the resting metabolic rate (RMR) in response to dietary and caloric restriction, which is significantly disrupted following rapid "weight loss" regimens, like those tactics indicated above. Over-consumption of food, especially nutritionally deficient high calorie food (excess energy intake), is a normal consequence contributing to weight gain and obesity. A resistance to the hormone leptin also characterizes common obesity. Insulin has been shown to increase leptin secretion by $25 \%$. Ample evidence demonstrates that insulin resistance is also a primary contributor to obesity, suggesting that insulin resistance induced hyperinsulinemia can provoke leptin resistant hyperleptinemia with a consequential increase in fat synthesis and storage in adipocytes, characteristic sequela of Syndrome X or Metabolic Syndrome. Further, adipocytes from fatter animals secrete more leptin and a correlation between intracellular ATP concentration and the rate of leptin secretion appears to exist. As such, leptin concentration correlates positively with percent body fat. A low resting metabolic rate for a given body size and composition, a low rate of fat oxidation, and low levels of physical activity are risk factors for weight gain and common traits of obese individuals. It has been shown that a decrease in body weight as fat mass and fat free mass is accompanied by a greater decrease in resting energy expenditure and fat oxidation $[4,5,6]$.

Effective fat loss and body recomposition strategies addressing the energy management pathways should simultaneously improve insulin, serotonin and fat oxidation metabolism; potentiate a healthy increase in resting metabolic rate and energy expenditure; and blunt excessive appetite cravings, given proper adequate nutrient and energy intake. The technology of the present invention replenishes the nutritional needs of at least five important systems, which are essential to healthy weight management as follows: 1 . The biochemical mechanisms involved in nutrition and energy management regulating intake, expenditure and storage controls and feedback; 2. Attenuation of the effects of chronic stress and inflammation (which overburden the endocrine system and can cause things like excessive cortisol production) reducing fat storage; 3.The pleasure seeking needs and reward circuitry of the brain, influencing psychological and emotional need-induced food cravings; 4. Promotion and support of healthy immune system function (involved in catalyzing survival response to metabolic threats; and 5. Supporting and maintaining optimal health of the neuroendrocrine system through which the majority of metabolic signaling is processed. Nutritional and gene expression deficiencies in the Reward neurochemical pathway limit the brain's reward resources (specific neurotransmitters) and are responsible for a condition called "Reward Deficiency Syndrome, (RDS)" which causes excessive cravings [7].

The Reward Deficiency Syndrome (RDS) results from a dysfunction in the Brain Reward Cascade, which directly links abnormal craving behavior with a defect in the $\mathrm{DRD}_{2}$ Dopamine 
Receptor Gene as well as other dopaminergic genes (D1, D3, D4, D5). Dopamine is a very powerful neurotransmitter in the brain, which controls feelings of well-being. This sense of wellbeing is produced through the interaction of dopamine and neurotransmitters such as serotonin, the opioids, and other powerful brain chemicals. Low serotonin levels are associated with depression. High levels of the opioids (the brain's opium) are associated with a sense of wellbeing. The complex interactions of these powerful neurotransmitters, ultimately regulating the Dopaminergic Activity in the Reward Center of the Brain, have been termed by Blum et al., "The Brain Reward Cascade" (See Figure 2 for anatomy) [8].

In individuals possessing an abnormality in the DRD2 Dopamine Receptor Gene, the brain lacks enough Dopamine receptor sites to use the normal amount of Dopamine in the Reward Center of the brain and thus reduces the function of Dopamine in this area of the brain. Individuals possessing the variant in the Dopamine Receptor Gene tend to be serious cocaine abusers, may have unhealthy appetites that can lead to obesity or overeating.

The overall effect is inadequate Dopaminergic Activity in the Reward Center of the Brain. This defect drives individuals to engage in activities, which will increase brain Dopamine function. Consuming large quantities of alcohol or carbohydrates (carbohydrate bingeing) stimulate the brain's production of and utilization of Dopamine. So too does the intake of crack/cocaine and the abuse of nicotine. Also, it has been found that the genetic abnormality is associated with aggressive behavior, which also stimulates the brain's use of Dopamine.

Figure 2 Anatomy of the Meso-limbic system of the brain reward site.

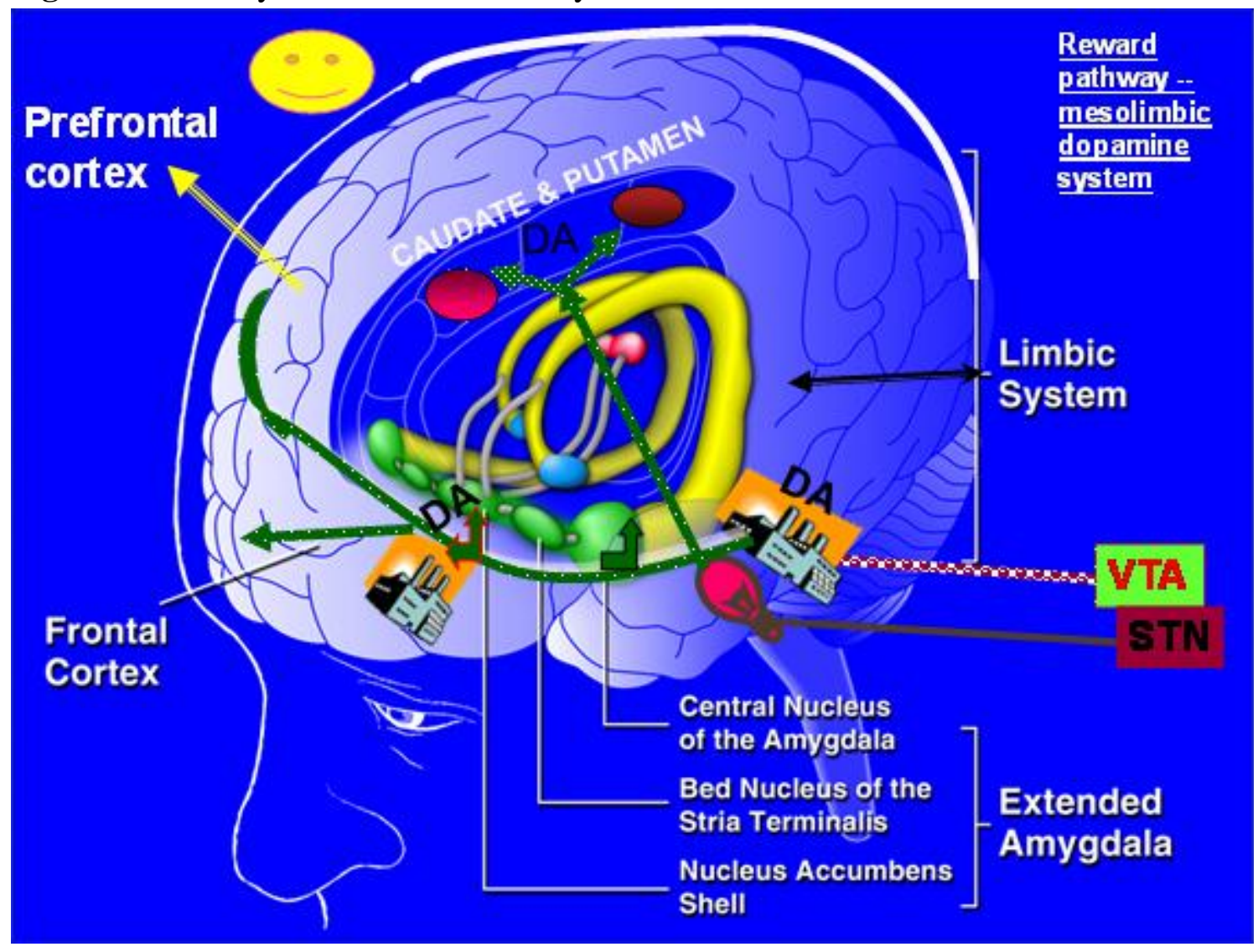


The Reward Deficiency Syndrome involves a form of sensory deprivation of the brain's reward or pleasure mechanisms. The Reward Deficiency Syndrome can be manifested in relatively mild or severe forms that follow as a consequence of an individual's biochemical inability to derive reward from ordinary, everyday activities. We believe that we have discovered at least one genetic aberration that leads to an alteration in the reward pathways of the brain. It is a variant form of the gene for the dopamine $\mathrm{D}_{2}$ receptor, called the $\mathrm{A} 1$ allele. This genetic variant also is associated with a spectrum of impulsive, compulsive, and addictive behaviors. The concept of the Reward Deficiency Syndrome unites those disorders and may explain how simple genetic anomalies give rise to complex aberrant behavior (See Figure 3, The Reward Deficiency Syndrome).

\section{Evidence for the existence of RDS in Substance Use Disorder:}

In 1990, Blum and colleagues, using the Taq1 polymorphism of the dopamine D2 receptor gene locus (DRD2), for the first time reported a strong association between a virulent form of alcoholism and the minor allele (A1) of the Drd2 gene in this population [8,9]. Other more recent studies further support an association of the A1 allelic form of the DRD2 gene with substance abuse vulnerability and other compulsive behaviors [10, 11, 12, 13, 14,15]. This association serves as the cornerstone of the biogenetic disease model and could ultimately lead us to better diagnosis and targeted treatment [16]. A complete review of this work can be found in the Journal of Psychoactive Drugs [17].

Figure 3: The Reward Defiency Syndrome.

\begin{tabular}{|l|l|l|l|}
\hline \hline $\begin{array}{l}\text { Addictive } \\
\text { Behaviors }\end{array}$ & $\begin{array}{l}\text { Impulsive } \\
\text { Behaviors }\end{array}$ & $\begin{array}{l}\text { Compulsive } \\
\text { Behaviors }\end{array}$ & $\begin{array}{l}\text { Personality } \\
\text { Disorders }\end{array}$ \\
\hline $\begin{array}{l}\text { severe alcoholism } \\
\text { polysubstance } \\
\text { abuse }\end{array}$ & $\begin{array}{l}\text { Tourette } \\
\text { disorder } \\
\text { hyperactivity }\end{array}$ & $\begin{array}{l}\text { Internet } \\
\text { gaming } \\
\text { behavior }\end{array}$ & $\begin{array}{l}\text { conduct disorder } \\
\text { personality }\end{array}$ \\
\hline smoking & autism & $\begin{array}{l}\text { pathological } \\
\text { gambling }\end{array}$ & aggressive behavior \\
\hline obesity & & & \\
\hline
\end{tabular}

This treaties will highlight the importance of a new concept, which provides a clearer understanding of impulsive, addictive, and compulsive behaviors. It is our notion that the real genesis of all behavior, whether so-called normal (socially acceptable) or abnormal (socially 
nonacceptable) behavior, derives from an individual's genetic makeup at birth. This predisposition due to multiple gene combinations and polymorphisms is expressed differently based on numerous environmental elements including family, friends, educational status, economical position, environmental pollutants, and availability of psychoactive drugs including food. We believe the core of predisposition to these behaviors is a set of genes, which promote a feeling of well-being via neurotransmitter interaction at the "reward site" of the brain (located in the meso-limbic system), leading to normal dopamine release. We also subscribe to the notion that at least one major gene, the dopamine D2 receptor gene, is responsible for the synthesis of dopamine D2 receptors. And further depending on the genotype (allelic form A1 versus A2), the dopamine D2 receptor gene dictates the number of these receptors at post-junctional sites.

A low number of dopamine D2 receptors suggest a hypodopaminergic function, as described by Eliot Gardner in a series of published works [18, 19]. When there is a paucity of dopamine receptors the person will be more prone to seek any substance (including glucose) or behavior that stimulates the dopaminergic system as a form of self-healing. In this regard we know that substances such as alcohol, cocaine, heroin, nicotine and glucose, as well as a number of behaviors like gambling and sex, preferentially release dopamine at the $\mathrm{n}$. accumbens (the reward site). Understanding this preamble allows us to introduce the concept of reward deficiency syndrome into the field of addictive behavior, which will serve as a model to explain the commonality of a number of seemingly diverse addictions based on shared genetics and neurochemistry. In this regard, most recently, Qing-Shan Yan reported that ethanol, at a peak concentration within five to 10 minutes after interparenteral administration, significantly increased both extracellular dopamine and serotonin in the n. accumbens, supporting the role of these two neurotransmitters in the reinforcing properties of ethanol [20]. Moreover, Honkanen and associates also found low basal dopamine release in alcohol accepting (AA) compared to alcohol non-accepting (ANA) rats, showing that dopamine plays a role in high alcohol preference of AA rats [21].

One important study from Nora Volkow's group further provides support for the role of the dopamine D2 receptor gene in alcohol intake in rats. Utilizing a cDNA construct of the dopamine D2 receptor gene implanted into the $\mathrm{n}$. accumbens of rats, they found that following a four-day treatment, the dopamine D2 receptors increased to $150 \%$ above pretreatment level and alcohol drinking was reduced by $50 \%$. After a period of eight (8) days, the D2 receptor density returned to pretreatment level and so did alcohol drinking. Twenty-four days later, second injections of the same construct caused a similar increase in density with a two-fold decrease in drinking [22]. The same group has now confirmed this work in mice.

We will now turn our attention to the pharmacologic and genetic aspects of the inter relationship between Obesity, carbohydrate bingeing, glucose receptor sensitivity and dopamine.The intent of this work is to share with the scientifically informed, interested reader the basic scientific evidence which explains why people overeat and become overweight in a society where "thin is in". In order to accomplish this goal we first must consider the relationship between eating behavior and "brain chemistry" and the interaction of both genetic and environmental elements. 


\section{Weight gain: A prehistoric look}

In consideration of the ability of our bodies to gain weight, we must review a few simple facts. Without our ability to gain weight, we as humans would have never survived. Ironically, whereas today the quantity of food is plentiful (although quality of nutrition is questionable), our goal is to turn away from food. In contrast, in the time of our prehistoric ancestors, the hunter-gatherers did not have a plentiful food supply. For example, when pristine sources of nutrient-rich berries and roots were in season and when wild animals were not hibernating, our ancestors ate well and "they fattened up". However, when these foods were not available, they relied on the stored fat to see them through the lean times.

To help us understand the importance of weight gain, two biological functions assisted our prehistoric ancestors as they struggled to survive this perpetual cycle known as "feast" and "famine". When there is an abundant supply of pristine quality food, our bodies efficiently store fat, and during times of a lack of food, our metabolism slows down. Scientists believe that abundant food induced efficient fat storage in our ancestors and when there was less fat their metabolism slowed to adjust to the smaller quantities programmed to adapt their metabolic rates to food intake. Those who survived were "blessed" with "fat-storage" genes, while those who lacked these genes perished. This suggests that the survivors passed their "thrifty" genes on to future generations-to you and me. Within the realm of modern times these ancient genes evolved over thousands of years and ultimately forced our bodies to store energy from nutrient-deficient concentrated sugars, processed carbohydrates, and adulterated fats to survive the famine that chronic intake of these types of low quality "foods" simulate [3].

Today we are faced with an obesity epidemic, which contributes to an estimated 300,000 deaths in people who die prematurely from this disease. In fact, obesity is a contributing risk factor for four of the seven leading causes of death. The Center for Disease Control has stated that Obesity is the number one health risk, greater than a lifetime of smoking, drinking and poverty [23]. Obesity in the United States is doubling every five years and the Institute of Medicine has declared war on the nation's "obesity epidemic".

To make sense out of all of this, we must understand that in today's modern world, no longer do we struggle through periods with very little food. Instead, we live in a perpetual calorie rich nutrient deficient food feast with a fast-food chain virtually around the corner for all Americans. This means that our bodies always are on "store mode"; except when we go on "lowfat diets", our brain loses control and there is an overwhelming call to "eat". Thus, in all of us, there is a rebound effect, which reacts by quickly regaining the lost weight in preparation for the next food shortage, just as it did for our prehistoric ancestors.

An article in Obesity Research 1996 sums up the problem;

"[The] modern western lifestyle appears to provide the social and environmental conditions that favor maximum expression of underlying individual genetic differences in susceptibility to becoming overweight."[3]

This is an important view because we now know that in today's society, with its highly processed foods, chemicals and pollution, with regard to metabolic effects, the body's instinct is to prepare for and defend against famine, but there is even a more important facet to the genetic propensity to gain excess weight and it does not reside in genes which control fat storage, and/or 
resting metabolic rates. Instead it is in the genes, which control our desire "To Binge or Not to Binge" [24]. These genes are termed "reward genes".

\section{The biology of reward:}

The pleasure and reward system in the brain was discovered by accident in 1954. The American psychologist James Olds was studying the rat brain's alerting process, when he mistakenly placed the electrodes in a part of the limbic system, a group of structures deep within the brain that generally are believed to play a role in emotions [25]. When the brain was wired so the animal could stimulate this area by pressing a lever, Olds found that the rats would press the lever almost nonstop, as much as 5,000 times an hour. The animals would stimulate themselves to the exclusion of everything else except sleep. They would even endure tremendous pain and hardship for an opportunity to press the lever. Olds clearly had found an area in the limbic system that provided a powerful reward for these animals.

Research on human subjects revealed the electrical stimulation of some areas of the brain (medial hypothalamus, which is in the limbic system) produced a feeling of quasi-orgasmic sexual arousal [25]. If certain other areas of the brain were stimulated, an individual experienced a type of light-headedness that banished negative thoughts. These discoveries demonstrated pleasure is a distinct neurological function that is linked to a complex reward and reinforcement system [26].

It is useful to think of the brain's reward system as a cascade in which one reaction triggers another. At the level of individual neurons, the reward cascade is catalyzed by a number of neurotransmitters [27]. Each neurotransmitter binds to certain types of receptors and serves a specific function. The binding of the neurotransmitter to a receptor on a neuron, like a key in a lock, triggers a reaction that is part of the cascade. Disruption of these intercellular cascades results in one form or another of the Reward Deficiency Syndrome.

\section{The Cascade Theory of Reward: A blueprint for mapping obesity genes:}

During the past four decades, considerable attention has been devoted to the investigation of neurochemical and neuroanatomical systems underlying chemical dependency. The research on the neuropharmacological basis of dependence (on alcohol, opiates, cocaine and glucose) points to the involvement of common biochemical mechanisms [28, 29]. It appears as if a limbicaccumbens-pallidal circuit is the critical substrate for the expression of drug reward [30]. However, while each substance of abuse appears to act on this circuit at a different step, the end result is the same, the release of dopamine the primary chemical messenger of reward at such reinforcement sites as the nucleus accumbens and the hippocampus [31].

In a normal person, neurotransmitters (the messengers of the brain) work together in a pattern of stimulation or inhibition, the effects spreading downward from complex stimuli to complex patterns of response like a cascade, leading to feelings of well-being: the ultimate reward (Cascade Theory of Reward) [27,28,33]. Although the neurotransmitter system is too complex and still not completely understood, the main central reward areas in the human brain's meso-limbic system are summarized in figure $4 \mathrm{a}$ and $4 \mathrm{~b}$. 
Figure 4a. Neurotransmitter Relations in the Reward Cascade

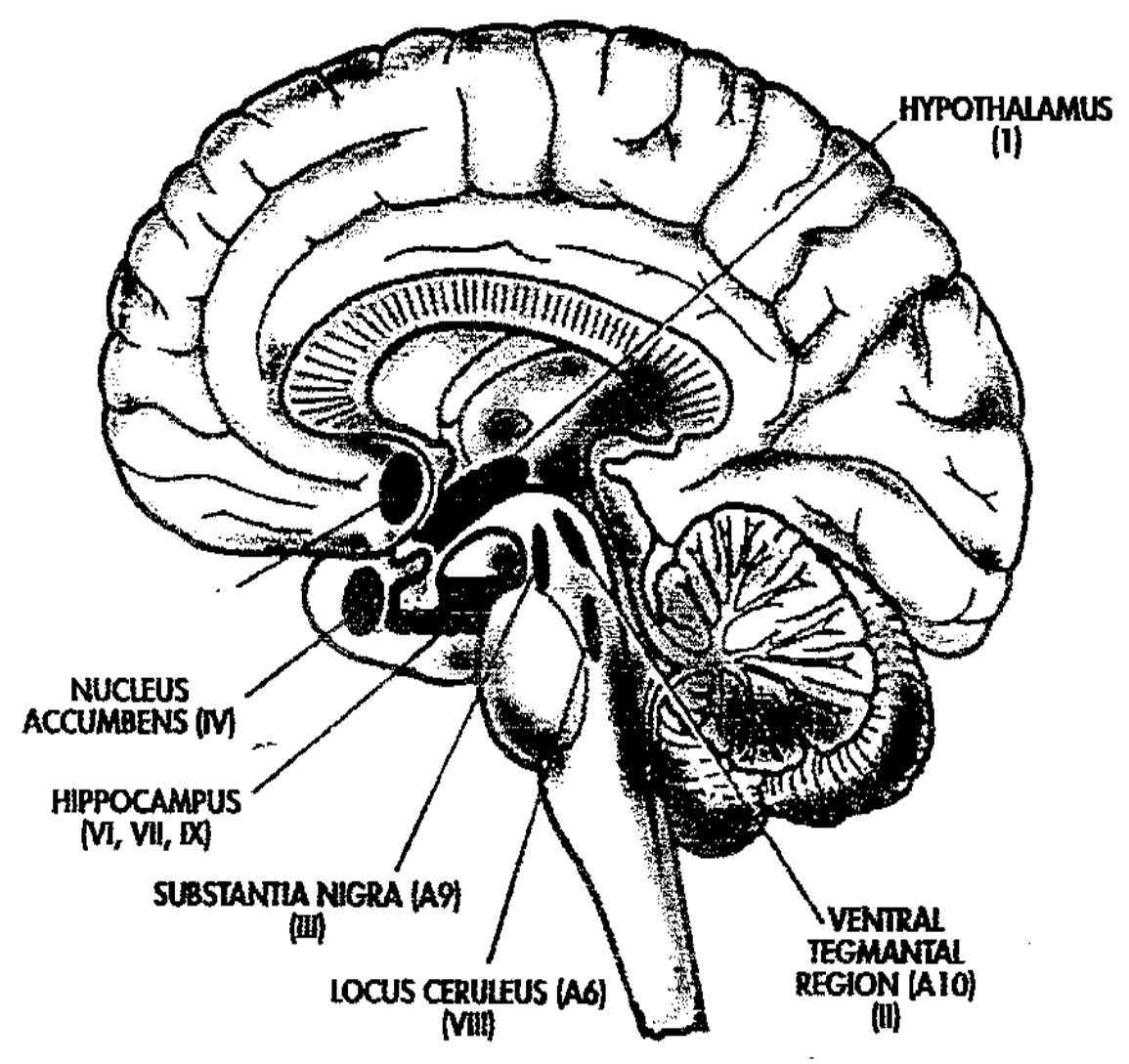

K.Blum (with J. Payne) Alcohol and the Addictive Brain. The Free Press, with permission p199 [276]

In the reward areas the following interactions take place [29,32]:

Serotonin (1) in the hypothalamus (I) indirectly activates opiate receptors (2) and causes the release of enkephalins, in the ventral tegmental region A10 (II). The enkephalins inhibit the firing of GABA (3) which originates in the substantia nigra A9 region (III);

GABA's normal role, acting through GABA B receptors (4), is to inhibit and control the amount of dopamine (5) released at the ventral tegmental regions (II) for action at the nucleus accumbens (IV). When the dopamine is released in the nucleus accumbens it activates dopamine $\mathrm{D}_{2}$ receptors (6), a key reward site [there are at least five dopamine receptors, including $\mathrm{D}_{2}$ ]. This release also is regulated by enkephalins (7) acting through GABA (8). The supply of enkephalins is controlled by the amount of the neuropeptidases (9) which destroy them.

Dopamine also may be released into the amygdala (V). From the amygdala, dopamine (10) reaches the hippocampus (IV) and the CA, cluster cells (VII) stimulates dopamine $\mathrm{D}_{2}$ receptors (11), another reward site.

Norepinephrine involves an alternate pathway (12) in the locus of ceruleus A6 (VIII) whose fibers project into the hippocampus at a reward area centering around cluster cells which have not been precisely identified, but which have been designed a CAx (IX). When GABA A 
receptors (13) in the hippocampus are stimulated, they cause the release of norepinephrine (14) at the CAx site (Figure 4b).

Figure 4b Neurotransmitter Relations in the Reward Cascade

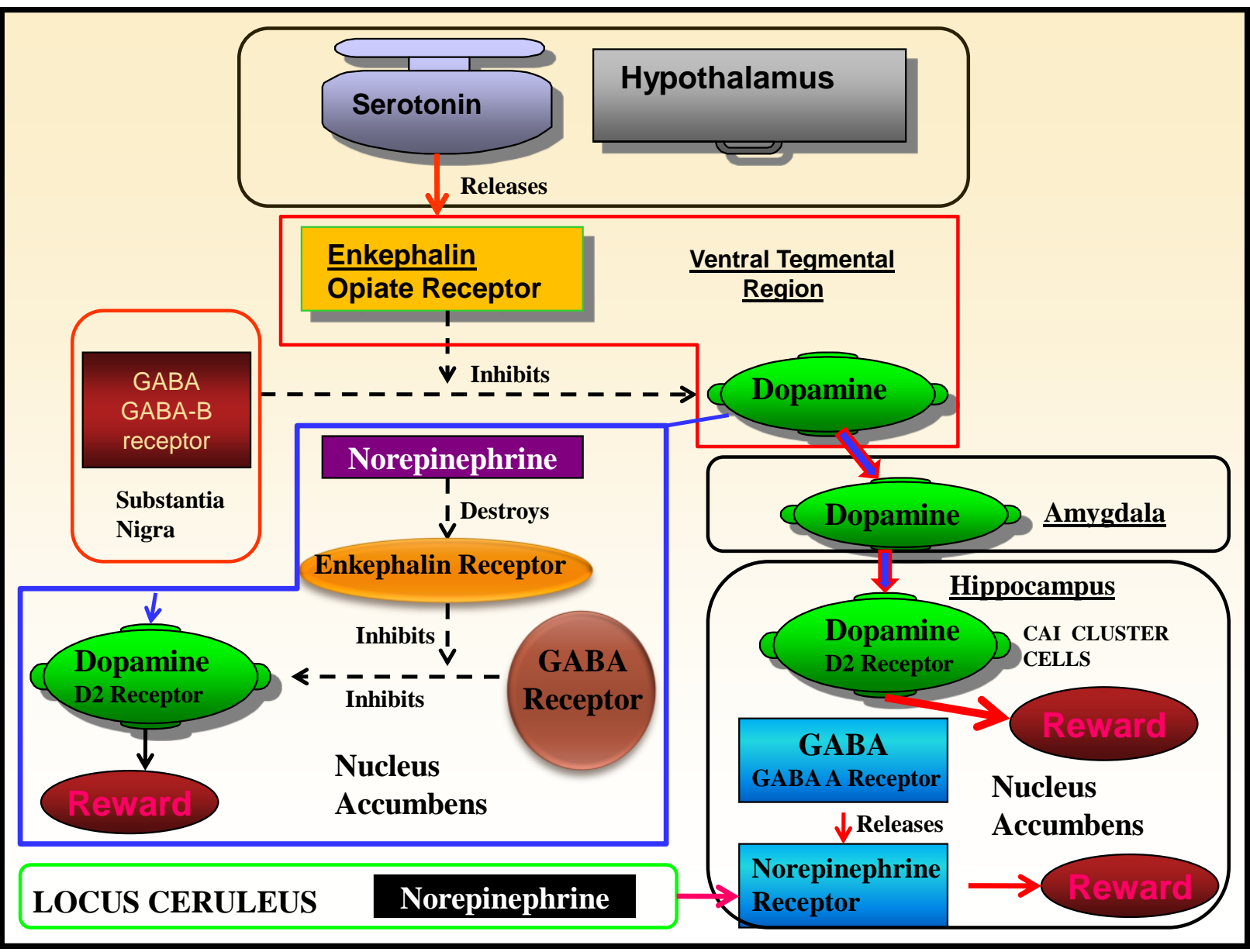

It is to be noted that the glucose receptor (GR) in the hypothalamus is intrically involved and "links" the serotonergic system with opioid peptides leading to the ultimate release of dopamine at the $n$. accumbens.

In the "cascade theory of reward", these interactions may be viewed as activities of subsystems of a larger system, taking place simultaneously or in sequence, merging in cascade fashion toward anxiety, anger, low self-esteem, or other "bad feelings" or toward craving for a substance that will make these bad feelings go away, for example sugar (Cascade Theory for Carbohydrate Bingeing). Certainly, many overweight individuals also cross abuse other psychoactive substances (e.g. alcohol, cocaine, and nicotine) [27].

Alcohol activates the norepinephrine fibers of the mesolimbic circuitry through a cascade of events, including the interaction of serotonin, opioid peptides, and dopamine. In a more direct fashion, through the subsequent formation of the neuroamine condensation products TIQs, alcohol may either interact with opioid receptors or directly with dopaminergic systems [33, 27]. In fact we sowed the important relationship between dopaminergic activation through our novel natural agonist SYN (a KB220 variant) and the narcotic antagonist Naltrexone[34]. 
In the cascade theory of carbohydrate bingeing, genetic anomalies, long-continued stress, or long-term abuse of sugar can lead to a self-sustaining pattern of abnormal craving behavior in both animals and humans. Animal model support for the cascade theory can be derived from a series of experiments carried out by T.K. Li et al. [35-40] upon their substance-preferring (P) [seek carbohydrates, alcohol, opiates, etc.] and nonpreferring (NP) rat lines. They found that $\mathrm{P}$ rats have the following neurochemical profile:

- lower serotonin neurons in the hypothalamus;

- $\quad$ higher levels of enkephalin in the hypothalamus (due to a lower release);

- $\quad$ more GABA neurons in the nucleus accumbens;

- $\quad$ reduced dopamine supply at the nucleus accumbens;

- $\quad$ reduced densities of dopamine $\mathrm{D}_{2}$ receptors in the meso-limbic areas.

This suggests a four-part cascade sequence leading to a reduction of net dopamine release in a key reward area. This was further confirmed when it was found that administering substances which increase the serotonin supply at the synapse, or by stimulating dopamine $\mathrm{D}_{2}$ receptors directly, craving behavior could be reduced [39]. Specifically, $\mathrm{D}_{2}$ receptor agonists reduce alcohol intake in high alcohol preferring rats whereas $\mathrm{D}_{2}$ dopamine receptor antagonists increase alcohol drinking in these inbred animals [41].

In thinking about the causes of obesity and possible ways in which traditional and nontraditional treatments might be improved, we must turn our attention to "neurotransmitters" and the enzymes that control them. We now know as discussed above, there are at least four important neurochemical systems involved in the natural process of "reward" or the achievement of pleasurable states; serotonin, opioids, GABA, and catecholamines. Consideration of the various neurotransmitters and their individual effects on macro-selection of food is important if we want to understand the root causes of overeating (see figure 4).

Figure 5. Schematic of Brain reward Cascade: Normal and abnormal representation.

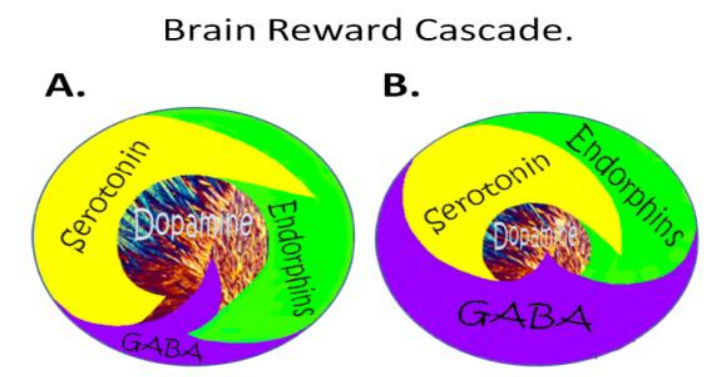

Figure 5(A) Represents the normal physiologic state of the neurotransmitter interaction at the mesolimbic region of the brain. Briefly, serotonin in the hypothalamus stimulates neuronal projections of methionine enkephalin in the hypothalamus that, in turn, inhibits the release of GABA in the substania nigra, thereby allowing for the normal amount of Dopamine to be released at the Nucleus Accumbens (NAc); reward site of the brain.

Figure 5 (B) Represents hypodopaminergic function of the mesolimbic region of the brain. The hypodopaminergic state is due to gene polymorphisms as well as environmental 
elements, including both stress and neurotoxicity from aberrant abuse of psychoactive drugs (i.e. alcohol, heroin, cocaine etc) and genetic variables.

The genetic variables include serotonergic genes (serotonergic receptors [5HT2a]; serotonin transporter 5HTIPR); endorphinergic genes (the mu OPRM1 gene; proenkephalin (PENK); PENK polymorphic 3' UTR dinucleotide (CA) repeats \}; GABergic genes (GABRB3); and dopaminergic genes (including ANKKI Taq A; DRD2 C957T, DRD4 7R, COMT Val/met substitution, MAO-A uVNTR, and SLC6A3 9 or 10R). Any of these genetic and or environmental impairments could result in reduced release of dopamine and or reduced number of dopaminergic receptors [42].

\section{Neurotransmitters and obesity: Animal studies}

The literature on eating is very complex. The same chemical element or neurotransmitter commonly will have different effects when administered in low doses versus high doses, centrally versus peripherally, in short-term versus non-predisposed, in overweight versus normal weight versus anorectic animals, as function of paradigm, and so on. Detailed reviews have been published previously $[4,5,6,43,44]$.

\section{Eating-stimulatory neurotransmitters}

The eating-stimulatory neurotransmitters include the catecholamine norepinephrine, acting through noradrenergic receptors, GABA, and three classes of neuro-peptides the opioids (endorphins, enkephalins, and dynorphins); the pancreatic polypeptides (neuro-peptide $\mathrm{Y}$ and YY), and galanin. These substances, when administered directly into the rat hypothalamus, potentiate eating in satiated animals [45].

Furthermore, chronic administration of certain monoamines (norepinephrine [NE]) and neuropeptides significantly alter daily food intake and weight gain [46, 47].

The eating-inhibitory neurotransmitters in the brain include the monoamines, dopamine, serotonin, and gut-brain peptides cholecytokinin-8 (CCK-8), neurotensin, calcitonin, glucogen, and corticotropin-releasing factor [48-54].

The effects of these neurotransmitters on eating are characterized primarily by a specific change in macro-nutrient selection, rather than an increase or decrease in total food intake. Many peptides, including CCK-8, bomesin, calcitonin, corticotropin-releasing factor, neurotensin, somatostatin, glucagon, and methionine-enkephalin have selective inhibitory actions on macronutrients [55, 56]. Leibowitz and associates [57-59] reported that medial para-ventricular nucleus (PVN) injections of NE in the rat induce a selective increase in carbohydrate ingestion with little or no change in fat and suppression of protein intake. Carbohydrate-craving behavior is observed consistently with chronic stimulation of NE and neuropeptide Y [49,60]. With regard to the all important monoamine Dopamine (released at the reward center), mixed effects have been observed with regard to the selective actions on macro-nutrient intake [51,61].

In contrast, serotonin, in the medial hypothalamus, may selectively suppress carbohydrate intake, while sparing protein intake [51,62,63]. Direct serotonergic agonists (e.g., quipazine), indirect serotonergic agonists (e.g., d-fenfluramine), or selective inhibitors of serotonin uptake into serotonergic neurons (e.g., fluoxine) decrease food ingestion in animal studies [64- 67] 
reported that d-fenfluramine $\left(\operatorname{Redux}^{\mathrm{R}}\right)$ reduced the consumption of a sucrose solution in nondeprived rats. Leander demonstrated that fluoxitine suppresses the ingestion of saccharin solutions in normal rats [68]. A similar finding was true for alcohol intake in preferring rat lines (animals genetically bred to prefer alcohol over water [69]. All the above indicates that direct and indirect serotonergic agonists depress a feeding response activated by sweet taste.

\section{Opioid peptides and macro-nutrient selection}

Current evidence suggests that the pharmacology of the opioidergic system on eating behaviors is very complex and it would therefore be difficult to a ascribe a generalized role, particularly in view of different effects observed with specific opioid peptides on macro-nutrient selection. In support of the above observation, both increases in food intake [70-72] as well as decreases in food intake $[73,74]$ have been observed under a variety of experimental conditions. In short-term experiments, administration of agonists, centrally or peripherally, results in feeding increases.

The results have been far more complicated than expected. In general, chronic administration of antagonists has been disappointing. Naltrexone caused some reduction in binge-eating in bulimics; however, it produced weight gain in anorexic patients [75]. Shimomura et al. observed increased food intake with chronic naloxone treatment and decreased food intake with chronic morphine [76]. Dhatt et al. had similar observations with chronic administration [55]. These observations suggest that while in acute situations opioid agonists increase and antagonists decrease food intake, in chronic situations opposite effects prevail. In this regard, it is noteworthy that the opioid peptides, as well as opiates acting through $m u$, delta, and kappa receptors, augment ingestion of fat and protein, while actually suppressing the relative proportion of carbohydrates ingested $[56,62,76]$.Tepperman and Hirst showed that upon inducing neonatal reduction of endorphins, rats become overweight. Compared with control animals, these overweight rats chose a greater percentage of their daily calories as carbohydrates and lower percentages as fat and protein [77].

\section{Inhibitors of Enkephalinase(s) and craving behavior}

As stated earlier, although it is known that opiates and/or opioids reportedly increase food intake in animals and humans, some papers suggest the opposite-suppression of food intake, especially when one considers macro selection of food sources (i.e., sugar/carbohydrates) $[62,70,75,76,78$ 80]. Moreover, Broekkamp et al. reported that infusion of enkephalin into the ventral tegmental A10 area of the brain induces a short-term latency behavioral stimulant effect reminiscent of effects produced by stimulation of the meso-limbic dopamine pathway; this effect is blocked by pretreatment of the opiate receptor antagonist naloxone [81]. This takes on importance in terms of feeding behavior, as feeding has been shown to increase dopamine levels in various brain structures such as the posterior hypothalamus, the nucleus accumbens, and the amygdala.

It is well known that dopamine in sufficient concentration can inhibit food intake [82]. Gilman and Lichtigfeld proposed as an appropriate therapeutic for carbohydrate bingeing (i.e., bulimia) a selective $\mathrm{D}_{2}$ agonist such as bromocriprtine [or natural released dopamine], providing $\mathrm{D}_{2}$ occupancy [83]. In this regard, using a push-pull cannula technique, Chesselet et al. were able to induce dopamine release in the "brain reward center" after local application of enkephalin, 
which suggests regulation by delta receptor stimulation [84]. Indeed Kelotorphan (an inhibitor of the opioid peptide degrading enzyme) may protect against possible CCK-8 degradation by brain peptidiases. This important satiety neuropeptide is co-localized with dopamine in the nucleus accumbens, and there is a close interaction between CCK-8, dopamine, and endogenous opioid peptides (like enkephalins) [85].

The opioid peptides are involved not only in macro-nutrient intake, but have been implicated in substance seeking [86- 88], as well as brain self-stimulation behavior [89,90]. In essence, there are a substantial number of animal experiments which support not only the "Brain Reward Cascade" but the subsequent sequale induced by a defected reward cascade leading to a number of addictive, compulsive and impulsive behaviors-defined as the "Reward Deficiency Syndrome"[91].

In this regard, Blum et al. reversed alcohol-seeking behavior in genetically preferring C57B1/6J mice with the chronic administration of an enkephalinase inhibitor [87]. In other work by George $e t a l$, they concluded that a relative lack of enkephalin peptides trans-synaptically, possibly resulting from enhanced enkephalin degradation, may contribute to increased alcohol consumption in C57B1/6J mice [92]. Moreover, others showed that intracranial self-stimulation by rats was reduced by nucleus accumbens microinjections of kelatrophan, a potent enkephalinase inhibitor. In terms of food intake, Riviere and Bueno reported that central injections of the enkephalinase inhibitor, thiorphan, also reduced daily food intake in sheep [93]. These results suggest that human carbohydrate bingeing might be critically mediated by differences in patterns of endogenous peptides.

\section{D2 Receptors and animal models:}

Hamdi et al. studied the specific binding of [3H] YM -09151-2 to investigate the possible differences in age-associated changes in striatal D2 dopamine receptor properties in genetically obese (fa/fa) Zucker rats and their lean littermates. The maximal binding sites of D2DA receptors were found to decline with age in both obese and lean rats: the rate of decline in receptor Bmax was slightly higher in lean than obese rats. However, the Bmax of D2DA receptor in 6-, 12- and 18-month old obese rats was significantly lower compared to the age matched lean rats. The very important interpretation by the authors further supports the role of dopamine in obesity. According to the authors, their data indicate that obesity decreases the number of striatal D2DA receptors without affecting the rate at which receptor number decreases with age [94].

Hypothalamic neuropeptide Y (NPY) and corticotropin - releasing hormone (CRH) influence feeding and levels of plasma glucose, insulin, free fatty acids, and triglycerides. Treatment of genetically obese, ob/ob mice, with D1/D2 agonists normalizes hyperphagia, body weight gain, hyperglycemia, and hyperlipidemia. Bina and associates examined whether levels of NPY and CRH immunoreactivity in discrete hypothalamic nuclei are altered in ob/ob mice, and whether dopaminergic treatment reverses this alteration [95]. Such dopaminergic treatment, while normalizing body weight gain and hyperglycemia, also significantly reduced elevated brain levels of NPY and CRH. These findings suggest that dopaminergic D1 /D2 coactivation may improve hyperphagia, hyperglycemia, and obesity in the ob/ob mouse, in part by normalizing elevated levels of both NPY and CRH in obese mice. Additionally, the work of Kuo 
revealed that injection of NPY anti-sense unto brain could modify the anorectic action of repeated S1/S2 agonists, indicating the involvement of NPY. Taken together the present knowledge suggests that both subtypes of D1 and D2 receptors and cerebral NPY are involved in the anorectic action of the dopamine releasing agent amphetamine [96].

Scislowski and associates reported that a two week treatment with SKF 38393 (a dopamine D1 receptor agonists) plus bromocryptine (a D2 agonist) [BC] acted synergistically to normalize overeating, body fat, hyperglycemia and hyperlipidaemia in ob/ob mice. In a more recent study they found that the $\mathrm{BC} / \mathrm{SKF}$ treatment also increased serum dehydroepiandrosterone (DHEA) sulfate concentrations, an inhibitor of body fat store accumulation. The authors conclude that their findings demonstrate that dopaminergic treatment not only normalizes overeating (hyperphagia) of ob/ob mice, but also redirects several metabolic and endocrine activities, independent of its effects on feeding to improve the obese -diabetic syndrome in ob/ob mice $[97,98]$.

Long term administration of the antipsychotic drugs known to block D2 receptors such as sulpiride, haloperodol, etc increased body weight in rats. This effect was found to be sex dependent that is, while female rats were prone to gain weight, male rats did not. In a study conducted by Baptista et al. a linear relationship between dose of sulpiride and body weight gain was found. Also sulpiride increased caloric intake, and both actions were counteracted by the specific D2 agonist bromocriptine. These results confirm that antipsychotic drugs affect feeding and body weight and suggest that hyperphagia and body weight gain might be mediated by blockade of dopamine D2 type receptors [99]. More recently, Freeman et al. studied the effect of glucose on anti-psychotic drug-induced changes in dopamine neuronal activity and suggested that caloric intake may influence antipsychotic drug-induced changes in the population activity of midbrain dopaminergoc neurons. In fact, glucose significantly reduced the number of spontaneously active A9 and A10 dopaminergic cells per track in control rats, but significantly attenuated the chronic haloperidol- and clozapine -induced reductions in dopaminergic cells per track [100]. For a review of animal models of food addiction see Blum et al. [101].

\section{Brain hypodopaminergic function and the self-healing process}

Since deficits have been found in neurotransmitter functions underlying craving behavior, and since these deficits may be alleviated by facilitated dopamine release consequent to the use of drugs, nicotine, alcohol, and food, the studies mentioned above indicate enkephalinase inhibition may similarly compensate for neurotransmitter imbalance (i.e., opioids, thereby attenuating craving behavior).

In an attempt to understand that carbohydrate craving is a subset of generalized craving behavior ("Reward Deficiency Syndrome"), due to hypodopaminergic function (an impaired "reward cascade"), scientists believe individuals self-heal through biochemical (licit or non-ilicit) attempts to alleviate the low dopaminergic brain activity via drug-receptor activation (alcohol, heroin, cocaine, and glucose). It is conjectured this will subsitute for the lack of reward and yield a temporary sense of well-being. In order to help explain this so called self-healing process, it is germane that the reinforcing properties of many drugs of abuse may be mediated through activation of common neurochemical pathways, particularly with regard to the meso-limbic 
dopamine system. In this regard, glucose, opiates, nicotine, cocaine, tetrahydracannabinol (THC), and ethanol have been shown to directly or indirectly enhance release or block re-uptake of dopamine in at least one of the primary terminal sites for the limbic dopamine neurons, the nucleus accumbens [31,102-104].

A number of studies of genetically bred animal models support the $D_{2}$ dopamine receptor involvement in substance-seeking behavior due to lower $\mathrm{D}_{2}$ receptor sites in preferring compared to non-preferring animals [38,105,106-108]. One inference from these observations is that ethanol intake, as well as the self-administration of other substances (i.e., glucose), might be altered by manipulation of dopamine receptors. Of interest is that further confirmation of the "Reward Deficiency Syndrome" in generalized substance-behavior involving slow dopamine release in the nucleus accumbens in polysubstance seeking Lewis animals has been observed recently by Gardner (1997)[17, 18].

\section{Reward Deficiency Syndrome: Human studies}

Human support for the Reward Deficiency Syndrome can be derived from a series of clinical trials with neuronutrients (precursor amino acid loading technique and enkephalinase inhibition) indicating :

- reduced alcohol and cocaine craving

- reduced stress rates

- reduction of leaving treatment against medical advice (AMA)

- facilitated recovery

- reduced relapse rates

- reduction in carbohydrate bingeing

- loss of body weight

- prevention of weight regain

- reduction of glucose craving

- enhancement of insulin sensitivity

- reduction of cholesterol

- enhancement of memory and focus

There are a number of studies using precursor amino-acids and enkephalinase inhibition which have been shown to affect various aspects of RDS [109- 119, 23] [see Table 1 and below].

Most recently, the notion of dopamine as the "final common pathway" for a number of diverse drugs of abuse such as cocaine, morphine, and alcohol [as well as glucose] is supported by Ortiz and associates at Yale University School of Medicine and the University of Connecticut Health Services Center. This support demonstrates that chronic treatment of cocaine, morphine, or alcohol similarly results in several biochemical adaptations in the meso-limbic dopamine system, which may "underlie prominent changes in the structural and functional properties of the neuronal pathway" related to the above. [120,121].

The brain reward cascade schematic (Figure 3), since then, became the blueprint for the search for "reward genes". We propose that the Reward Deficiency Syndrome gives rise to a wide range of disorders that can be classified as impulsive-addictive-compulsive diseases. 
Impulsive diseases include attention deficit disorder and Tourette's Disorder. Addictive diseases include substance-seeking behavior involving alcohol, drugs, nicotine, and most importantly food. Compulsive diseases include pathological gambling and excessive sexual activity. In terms of personality disorders it includes conduct disorder, oppositional defiant disorder, antisocial personality disorder, schizoid/avoidant behavior, violent aggressive behaviors (See Figure 1) [122-125].

\section{Compulsive Bingeing Dopamine \& Other Genes}

Obesity is a disease that comes in many forms. Once thought to be primarily environmental, it now is considered to have both genetic and environmental components. In a Swedish adoption study, for example, the weight of the adult adoptees was strongly related to the BMI of the biological parents and to the BMI of the adoptive parents. Other studies of adoptees and twins suggest heredity is an important contributor to the development of obesity, whereas childhood environment has little or no influence. Moreover, the distribution of fat around the body also has been found to have heritable elements. The inheritance of subcutaneous fat distribution is genetically separable from body fat stored in other compartments (among the viscera in the abdomen, for example). It has been suggested there is evidence for both single and multiple gene anomalies [126]. In fact according to our laboratory, in conjunction with David Comings of the City of Hope National Medical Center, at least twelve different genes have been associated with obesity providing a 33 per cent contribution to the overall variance.

Given the complex array of metabolic systems that contribute to overeating and obesity, it is not surprising that a number of neurochemical defects have been implicated. Indeed at least three such genes have been found: one associated with cholesterol production, one with fat transport and one related to insulin production [126]. Other genes include human chromosome 2, uncoupling protein 2 and the APO-D genes. The $o b$ gene and its product the leptin protein have also been implicated in regulating long-term eating behavior [127]. Another protein, glucagonlike peptide 1(GLP-1) has been found to be involved in the regulation of short-term eating behavior [128]. The regulation between leptin and GLP-1 is not known. The $o b$ gene may be involved in the animal's selection of fat. But perhaps not in the ingestion of carbohydrates, which appears to be regulated by the dopaminergic system. It may be that the $o b$ gene is functionally linked to the opioid peptodergic system involved in reward.

Whatever the relation between these systems the complexity of compulsive eating disorders suggests that more than one defective gene is involved. Indeed, the relation between compulsive overeating and drug and alcohol addiction is well documented [129, 130, 91]. Neurochemical studies show that pleasure-seeking behavior is a common denominator of addiction to alcohol, drugs, and carbohydrates [8].

Variants of the dopamine $D_{2}$ receptor gene appear to be risk factors in obesity. The $A_{1}$ allele was present in 45 percent of overweight subjects as compared to 19 percent of nonoverweight subjects [131]. Furthermore, the $A_{1}$ allele was not associated with a number of other metabolic and cardiovascular risks, including elevated levels of cholesterol, and high blood pressure. In contrast, when the subject's profile included factors such as parental obesity, a later onset of obesity and carbohydrate preference, the prevalence of the $A_{1}$ allele rose to 85 percent. 
There also is an increased prevalence of the $A_{1}$ allele in overweight subjects who have severe alcohol and drug dependence [91]. When obesity, alcoholism, and drug addiction were found in a patient, the incidence of the $A_{1}$ allele rose to 82 percent. In contrast, the allele had an incidence of zero percent in non-overweight patients who also were not substance abusers and did not have a family history of substance abuse. In an unpublished study Blum and associates also found the $A_{1}$ allele of the dopamine $D_{2}$ receptor gene significantly contributes to percent body fat in morbidly overweight subjects. The percent contribution was found to be as much as 45.9 percent of the overall variance, when compared with "super" controls (highly assessed controls-no "reward deficiency" behaviors). Additionally, Comings et al (1996) found that the Dopamine $\mathrm{D}_{2}$ receptor $\mathrm{A}_{1}$ allele also associated with overweight young females [132]. Both the $o b$ and the Dopamine $\mathrm{D}_{2}$ receptor gene are additive in contributing to the overall variance of obesity ( 22 per cent in young females). Thus, the presence of the dopamine $\mathrm{D}_{2}$ receptor gene variants increase the risk of obesity and related behaviors along with other polymorphic genes, some of which have not as yet been identified. In order to investigate the prevalence of the Taq1A1 allele of the dopamine receptor gene in obesity with and without comorbid SUD, a total of 40 patients, from an outpatient clinic were studied. In this sample with a mean BMI of 32, the A1 allele of the DRD2 gene was present in 52\% of these obese subjects. Furthermore, it was found that in the 23 obese subjects possessing comorbid SUD, the prevalence of the DRD2 A1 allele was present in $73.9 \%$ of the obese subjects compared to only $23.5 \%$ in obese subjects without comorbid SUD.

Moreover, when they assessed severity of substance usage (alcoholism, cocaine dependence, etc.) increasing severity of drug use increased the prevalence of the Taq1 DRD2 A1 allele: where $66.7 \%$ of less severe probands possessed the A1 allele compared to $82 \%$ of the most severe cases. Linear trend analyses showed that increasing use of drugs was positively and significantly associated with A1 allelic classification.

\section{Dopaminergic genes and obesity}

In a study by F. Yasuna from Japan, personality is a behavioral pattern, which differs among individuals. E. Kretchmer (see Yasuna) categorized personality variants according to the concept of fundamental body types. Several lines of evidence suggest that the central dopamine system may underlie the regulation of weight and personality trait. In this study, the authors examined the dopamine $\mathrm{D} 2$ receptor (D2R) binding together with body mass index (BMI) and personality trait on the temperament and character inventory in 16 subjects. The data demonstrates a significant relation among the D2R binding in the amygdala, BMI and personality trait of harm avoidance (this is in agreement with other work by Blum et al. showing significant association with D2RA1 variants and harm avoidance). The authors conclude that variation of dopaminergic activity in the amygdala underlies the personality variants related to body type [133].

In a study by Jenkinson and associates, the association of the dopamine D2 receptor polymorphisms Ser311cys and Taq1A with obesity or type diabetes mellitus in Pima Indians was evaluated. They found that heterozygotes at the Ser311CysDRD2 polymorphism had a higher BMI than homozygotes. [134] 
Moreover, the atypical antipsychotics have been shown to have superior efficacy compared with typical antipsychotics such as haloperidol, particularly in the treatment of negative symptoms of schizophrenia. However, following clinical use, marked bodyweight gain has been frequently observed with some of the atypical antipychotic drugs. A careful review of the literature from 1966- 2000, revealed that relative receptor affinities of the atypical antipsychotics for 5-HT2 and dopamine D2 receptors appear to be most robust correlate of body weight gain. This makes sense because if one blocks dopaminergic sites at the receptor it will increase carbohydrate bingeing. Wetterling suggests that if obesity is a problem in a patient other modalities must be considered for the long term treatment [135].

In a study, G.N. Thomas evaluated the potential relationship between blood pressure and obesity and dopamine D2 receptor Taq1 polymorphism. Pharmacological data suggest that obesity and blood pressure (BP) may be modulated through the dopamine D2 receptor (DR2R), which may represent and underlying mechanism that links these conditions. Thomas et al. found that the A1 was decreased in hypertensives compared with controls. In the combined population, systolic, diastolic, and mean arterial BP's were lower in subjects with the A1A1 genotype relative to the A2A2 genotype. However, the DRD2A1 allele frequency increased with increased markers of "gynoidal" or peripheral subcutaneous obesity [136].

\section{Brain dopamine receptors and obesity risk}

Moreover, dopamine plays a major in the regulation of appetite and growth hormone. Dopaminergic agonists are known to suppress appetite and dopamine D2 receptor antagonists enhance it. Comings found that DRD2 polymorphisms significantly associated with high BMI as well as height [137].

In another study, Wang and associates found that striatal dopamine D2 receptor availability was significantly lower in ten obese individuals than in lean controls. The availability of the D2 receptors was decreased in obese individuals in proportion to their BMI. Dopamine modulates motivation and reward circuits and hence dopamine deficiency in obese subjects may perpetuate pathological eating as a means to compensate for decreased activation of these circuits. The authors conclude that strategies aimed at improving dopamine function may be beneficial in the treatment of obese individuals [138].

\section{Other dopaminergic reward gene risk taking behavior and overeating}

Although we believe the gene for the $\mathrm{D}_{2}$ receptor plays a critical role in Reward Deficiency Syndrome behaviors, other dopaminergic receptor genes (such as the dopamine transporter genes, dopamine-beta-hydroxylase genes and the D3 and D4 dopaminergic receptor genes) undoubtedly are involved in the different manifestations of the syndrome, but, for example, both the dopaminergic transporter and the dopamine-beta-hydroxylase genes are not associated with obesity. It is noteworthy, that some have suggested one type of overeating might reside in individuals who are high-risk takers and switch their addictive risk taking dopamine-linked neuronal release to carbohydrate bingeing. This is not surprising in light of recent molecular genetic findings. 
George Koob and Associates from Scripts Institute in La Jolla, California found evidence for the $\mathrm{D}_{3}$ locus and suggested it as a primary site of cocaine effects [31]. The exact effect of cocaine is unknown regarding gene expression; however, we do know that $\mathrm{D}_{2}$ receptors are decreased by chronic cocaine administration and this may induce severe cocaine craving and possibly cocaine dreams [139] and the dopamine $\mathrm{D}_{2}$ receptor gene has been associated with severe cocaine addicts [14]. The likelihood of carrying the $A_{1}$ allele increases as the number of risk factors increases among cocaine-dependent people. Three risk factors are especially significant: parental alcoholism and drug abuse, the potency of the cocaine used by the addict and early childhood deviant behavior, such as conduct disorder.

Most recently scientists from Israel and the National Institutes of Mental Health confirmed a genetic variation of the dopamine $\mathrm{D}_{4}$ receptor gene to associate with novelty (or sensation) seekers. Both of these studies set out to test the hypothesis advanced by Cloninger of Washington University that novelty seeking behavior is affected by the way brain cells process dopamine. Epstein and his colleagues at the Herzog Memorial Hospital in Jerusalem found this association in 124 unrelated Israeli subjects. Specifically he found that subjects who scored highest on novelty seeking tended to be compulsive, exploratory, fickle, excitable, quick tempered, and extravagant. They were much more likely to have the longer version of the receptor gene than other subjects. Subjects with the shorter version of the gene scored lower and tended to be reflective, rigid, loyal, stoic, slow tempered, and frugal. In the second study conducted by Benjamin of the laboratory of clinical science, National Institute of Mental Health found similar results in his sample of 315 American subjects, most of them male siblings and other family members $[140,141]$. The $\mathrm{D}_{2}$ receptor gene and the $\mathrm{D}_{4}$ receptor gene are fairly close in gene homology and may have similar physiological functions.

In an unpublished work scientists at UCLA found an association between the $\mathrm{DRD}_{2} \mathrm{~A}_{1}$ allele and agitation marked by impulsivity, excitability, "hot temper". These subjects were classified as "sensation seekers." The recent work of Benjamin and Epstein provide additional confirmation of the relationship between the Reward Deficiency Syndrome behaviors characterized by Blum and associates and the dopaminergic system. Additionally Benjamin and Epstein provide support of the earlier work of Susan George and associates (1993) at the University of Toronto who found a strong association between the $\mathrm{D}_{4}$ gene variance and alcoholism and nicotine dependence again showing the interchangeable nature of this syndrome [13]. Therefore adding another element to the "binge or not to binge?" equation.

In this regard, Poston et al. carried out an association study of the D4 dopamine receptor and obesity risk. Many genes have been identified that may play a role in increasing susceptibility to obesity. Reduced dopamine function appears to play a role in dysfunctional eating patterns and may predispose some individuals to obesity. The long version of the D4 dopamine receptor gene (D4DR) has been shown to alter receptor function and reduce intracellular response to dopamine. It also has been associated with novelty-seeking - related personality traits that are found with greater frequency in obese individuals. Poston and associates examined the association between the D4DR and obesity in 115 obese patients participating in a weight management program. They constructed four models of increased obesity that included combinations of traditional risk factors (i.e. history of obesity, parental 
obesity, a body mass index > 40) and novelty elevations on the Karolinska Scales of Personality. There was a significant increase in the frequency of the D4DR long alleles in individuals defined as high risktaking using the combination of novelty -seeking - related personality traits, severe obesity ( i.e. BMI > 40), and any other traditional risk factor, but not with the traditional risk factors alone. These preliminary data suggest a potential role for the DR4D gene in increasing obesity susceptibility [142].

\section{What is the neuronal inter-relationship between glucose and dopamine release mechanisms: Are there close ties?}

To understand the important relationship between dopamine and glucose, it is of utmost importance to realize that in the meso-limbisc system the glucose receptor is in close proximity with the enkephalinergic neurons. There are also other important connections in the substania nigra (SN), tuberoinfundibular neurons, globus pallidus, and other important brain regions.

It is well known that glucose modulates SN dopamine neuronal activity and GABA terminal transmitter release by the actions of an ATP-sensitive potassium channel. In a study by Levin et al. the effect, on striatal dopamine release, of altering SN glucose levels was assessed by placing microdialysis probes into both the SN and striatum of male rats. During $50 \mathrm{mM}$ glucose infusion, striatal DA efflux increased transiently by $50 \%$ and returned to baseline after 60 minutes. Moreover, efflux increased by a further $30 \%$ when GABA (A) antagonist bicuculline was added. Furthermore, at basal glucose levels, nigral bicuculline alone raised striatal dopamine efflux by $31 \%$ suggesting the well-known tonic GABA inhibitory input to the DA neurons. Thus striatal dopamine release is affected by changing SN glucose levels. According to Levin and associates, this response may reflect the known effect of glucose on K(ATP) channel activity on both SN Dopamine neurons and GABA axon terminals in the SN. These interactions could provide a mechanism whereby glucose modulates motor activity involved in food intake [143].

Koshimura et al. found that long -term incubation with high concentration of glucose increased the capacity of calcium uptake to enhance depolarization-induced dopamine release from Pheochromocytoma -12 cells. These data taken together suggest that a high concentration of glucose induced activation of the calcium channel to stimulate dopamine release from P12 cells [144].

Bello et al. found that restricted feeding with scheduled sucrose access results in an upregulation of the rat dopamine transporter in the $n$. accumbens and ventral tegmental area of the brain [145]. Moreover, Lee et al. (1998) found that dopamine can activate $\mathrm{B}_{3}$ adrenoreceptor to lower glucose uptake into rat white adipocytes which lack dopaminergic receptors [146]. It is of interest that intrastriatal injection of $\mathrm{D}_{1}$ and $\mathrm{D}_{2}$ dopamine agonists affects glucose utilization in both the direct and indirect pathways of the rat basal ganglia [147]. Moreover, dopamine receptor antagonism can influence fat intake in rats dependent upon dosage and time after treatment. In this regard, both $D_{1}$ and $D_{2}$ receptor co-activation significantly reduced body weight, body fat, food consumption and serim concentrations of glucose, triglycerides, free fatty acid and insulin while increasing protein mass [99]. Furthermore, studies on blood glucose found blood glucose concentrations to be significantly correlated with cerebrospinal fluid concentrations if the dopamine metabolite, homovanillic acid [148]. 
With regard to the concept that within the RDS concept genetic commonality exist between a number of dopaminergic activating substances such as alcohol and opiates and possibly even glucose, evidence now exists that intermittent, excessive sugar intake causes endogenous opioid dependence. In rats, repeated, excessive intake of sugar created a state in which an opioid antagonist caused behavioral and neurochemical signs of opioid withdrawal. The indices of anxiety and DA/Ach imbalance were qualitatively similar to withdrawal from morphine or nicotine, suggesting that rats have become sugar-dependent [149]. In terms of understanding the brain reward cascade, there is evidence that serotonergic activation may also influence dopamine D2 receptor function. This is important when we consider the so called "sweet tooth" which has been associated with serotonin predominantly. Therefore the work by Kogan et al. confirms that the drug DR4004, a putative 5- $\mathrm{HT}_{7}$ receptor antagonist, also has functional activity at the dopamine D2 receptor [150]. It is of interest that neuroanatomical data suggest a potentially interactive role between accumbens acetylcholine and dopamine. There is evidence that nucleous accumbens. Acetylcholine is apparently related to neural processes underlying not only psychostimulant reward but also natural consummatory behavior i.e. feeding. In this regard, Hajnal et al. found that accumbens cholinergic interneurons play a role in the regulation of body weight and metabolism. In this context both stress and the role of dopamine play an important part in the Ach response [151].

It is well known well known that pharmacologic doses of the glucose analogue, 2deoxyglucose (2DG) cause acute glucoprivation and are associated with enhanced dopamine turnover in preclinical studies. In fact, lines of evidence indicate that a variety of metabolic stressors, including acute glucose deprivation are associated with dopamine release. Using PET Adler et al. found that 2DG administration enhanced synaptic dopamine concentrations [152]. The administration of 2DG is associated with significant striatal dopamine release even in healthy volunteers. These data are important because it further closely ties glucose levels to dopaminergic activity. Moreover, there is even a relationship between insulin levels and dopamine release in the tuberonfundibular neurons. The insulin effect is dependent on CA++ ions, protein kinase $\mathrm{C} \mathrm{Na}(+)-\mathrm{H}+$ exchange system. Additionally when there is lowered glucose in the brain leading to cerebral global transient ischemia, monamine release especially dopamine is inhibited. In this regard, Trugman et al. showed D1 antagonists lowered glucose utilization by $24-28 \%$ in the globus pallidus, entopeduncular nucleus, subthalmic nucleus, substania nigra, and even the motor cortex, suggesting that stimulation of the D1 receptor by endogenous dopamine contributes to basal metabolism in these regions [153]. In contrast both D1 and D2 agonists increase glucose utilization. These results suggest that feeding behavior is tied into the stimulation of both $\mathrm{D} 1$ and $\mathrm{D} 2$ receptors and provides metabolic evidence for the importance of D1 and D2 functional linkage in the brain, which relates to hyperphagia or overeating.

The direct effect of dopamine on glucose release from primary cultured rat hepatocytes were studied in Japan by Shiroyama et al. [154]. In this regard, dopamine is known to induce hyperglycemia in both animals and man. The authors investigated whether dopamine has any direct effect on glucose release from hepatocytes through the glcogenlytic and/or gluconeogenic pathways, and at the same time determined the main type of adrenergic receptor involved in 
glucose release. The notion, increasing glucose release from tissue would reduce cravings for glucose and carbohydrates. Glycogen -rich and gluconeogenic -depleted hepatocytes were prepared in order to study glycogenolytic and gluconeogenic -depleted glucose release, respectively. Dopamine caused release of glucose which was inhibited by the beta blocker propranolol. The authors conclude that dopamine has a direct effect on heptocytes, increasing glucose release via both glycogenolytic and gluconeogenic pathways and mediated by beta adrenergic receptors.

\section{Other obesity genes}

Twin and family studies suggest that genetic factors potentially influence energy and nutrient intake. In this regard, the Heritage Group utilizing a genome-wide scan for dietary energy and nutrient intakes have determined that in whites, the strongest evidence of linkage appeared for dietary energy and nutrient intakes on chromosomes Ip21.2 and 20q14.1. The linkage evidence on chromosomes 20 related to total energy intake rather than to the intake of specific macronutrients. In blacks, promising linkages for macronutient intakes occurred on chromosomes 12q23-q24.21, Oq32.1, and 7q11.1. Several potential candidate genes are encoded in and around the linkage regions on chromosomes Op21.2, 12q14.1 and 20q13.13 [155].

\section{Pharmacologic mechanisms of the drug Meridia: Comparison to proposed KB220 anti- craving formula.}

Meridia is an approved FDA drug for "weight loss" and weight management. The major effect of this drug is an anti-craving action derived from its effect to inhibit the reuptake of serotonin (5HT), dopamine (DA) and norepinephrine (NE). This inhibition of neurotransmitter reuptake results in an increase in the length of time 5HT, DA, and NE are available to act in the synaptic junction, and ultimately in an amplification of the neurotransmitter effects to reduce sugar /glucose cravings.

In its simplest form, the ingredients in the patented composition proposed for anti-craving effects mirrors the Meridia mechanism and should produce similar anti-craving effects. In this section we will point out the potential of the ingredients in the proposed formula, based on a large body of neurochemical evidence concerning precursor amino-acids; the role of chromium as a tryptophan enhancing substance; D-amino acid inhibition of enkephalinase; Rhodiola as a suspected inhibitor of catechol-O-methyl transferase (COMT) as well as Synephrine, a substance that can minic some of the effects of catecholamines. Thus it is anticipated that since the same three neurotransmitters affected by Meridia® (sibutramine) could potentially be affected by certain ingredients, it should produce similar effects. It could be hypothesized that by increasing precursor (i.e. phenylalanine, tyrosine, and chromium and or 5-hydroxytryptophane or any other neurotransmitter enhancer even via transport blockers) intake and inhibiting enzymatic degradation by COMT, greater levels of 5HT, DA would be available at the synapse. The availability of the synapse is also increased since the D-phenylalnine causes preferential release of dopamine via opioid peptide breakdown inhibition. Thus the sum total effect is very much like Meridia and the following information will assure the scientific potential of this novel natural formula. 
Most recently, Balcioglu and Wurtman measured the effects of sibutramine given intravenously, on brain dopamine and serotonin flux intostriatal and hypothalamic dialysates of freely moving rats. While low doses of the drug had no effect, higher doses increased both serotonin and dopamine concentrations in the striatal and hypotalmic brain regions. These findings further support the neurochemical effects of sibutramine, and suggest that the drug's anti-obesity action may result from changes it produces in brain dopamine as well as serotonin metabolism [156]. The importance here is that it provides further support for the KB220 variant formula and both serotonergic and dopaminergic anti-obesity actions.

There are known limitations which will be addressed:

\section{- Competition for uptake of precursors across the blood brain barrier}

While it is well known that the ability of phenylalanine, tyrosine and tryptophan to penetrate the blood brain barrier is mediated by a shared active transport system, it is also well known that the use of Chromium could significantly assist in enhancing or concentrating blood tryptophan into the brain by its effect on insulin release and subsequent enhance glucose utulization due to increase glucose receptor sensitivity [61]. In addition, glucose has the concurent effect of increasing muscle absorption of large amino acids like leucine, valine and isomeric forms, into muscle (see below). This all works in concert to help tryptophan cross into the brain and there increase serotonin synthesis. This is the exact reason for the inclusion of chromium at a dose of $1000 \mathrm{mcg}$ 's rather than the usual lower dosage of between 200-400mcgs. Moreover, even if this was not effective to increase the synthesis of serotonin, with the formula it could bypass serotonin and work through its enkephalinase activity of D-phenylalanine. This would cause dopamine release via its inhibition of SN GABA. In Earlier work by Wurtman's group, they showed that by reducing blood glucose the brain will concentrate up to $33 \%$ more blood borne tryptophan [157]. Furthermore, it is well known that if you reduce typtophan levels in the hypothalamus you will reduce brain serotonin levels and its neuronal release. Conversely, elevating tissue tryptophan levels (accomplished by adding natural 5-hydroxytryptophan or chromium) could increase both serotonin levels and serotonin release. According to Schaechter and Wurtman, these observations demonstrate for the first time that both precursor -dependent elevations and reductions in brain serotonin levels produce proportionate changes in serotonin release, and the magnitude of the tryptophan effect is unrelated to neuronal firing frequency, suggesting the importance of precursor administration to increase serotonin levels. In essence, the data support the hypothesis that serotonin release is proportionate to intracellular serotonin levels [157].

\section{- Nutrient-Dependent Control Of Brain Catecholamine Synthesis \& Release}

While brain serotonin synthesis is affected by availability of tryptophan or 5-hydroxytryptophan under control conditions, precursor dependency of catecholamine synthesis in the brain is coupled to the firing rate of the tyrosine hydroxylase containing neuron. It has been 
demonstrated in a number of studies that a supplementation of 1-tyrosine does not augment the synthesis of catecholamines under resting non-stressed condition, while an enhanced neuronal activity will increase the synthesis and release of catecholamines, especially dopamine following tyrosine application. Of these physiological stress is the most important, in terms of enhancing neuronal activity. In essence stress is mandatory for 1-tyrosne administration to affect catecholamine synthesis. While it is well known research has demonstrated that catecholamines such as norepinephrine and dopamine can act as feedback inhibitors of tyrosine hydroxylase, the enzyme that converts tyrosine into the immediate precursor for dopamine or norepinephrine under physiological stress this mechanism is obliterated [158]. The reason for this is that the mechanisms that couple catecholaminergic neuron's firing frequency to its precursor responsiveness involve the phosphorylation of the tyrosine hydroxylase enzyme portion [159]. This enzyme's affinity for its cofactor is thereby enhanced and it becomes independent of end product inhibition, yet dependent on the availability of its precursor substrate. In essence under stress 1-tyrosine supplementation becomes similar to the 1-tryptophan (5-hydroxytryptophan) type of precursor responsiveness. Moreover, it is important to realize that this enzyme activation occurs under enhanced neuronal activity and is calcium - and calmodulin dependent. In addition, the phosphorylation of tyrosine hydroxylase can be catalyzed by several protein kinases that selectively act on different amino acids of the enzyme protein. The protein kinase enhances the enzyme activity without affecting end-product inhibition or the affinity to tyrosine or the tetrahydrobiopterin cofactor. In addition, it is well known that a different, cAMP -dependent protein kinase can also phosphorylate tyrosine hydroxylae, enhancing the affinity to the cofactor (but not to tyrosine) and reducing the regulation by end -product inhibition. In summary, these changes allow the enzyme activity to become dependent on the extent to which it is saturated with its substrate 1-tyrosine.

\section{Stress \& obesity}

The effect of excessive stress in modern life can lead to chronic states of fatique -related depression. This is an unfortunate fact yet true that about $80 \%$ of all illness can be traced back to stress and depression. According to the American Academy of Family Physicians, these factors account for about $2 / 3$ of all office visits.

The importance here is to understand that it is our position that indeed an obese individual or a carbohydrate binger is definitely subject to a stressful condition and therefore there is increased neuronal firing. There are numerous examples in the literature to support this contention. Furthermore, if an obese individual has the DRD2A1 variant, numerous studies have shown that resultant low dopamine D2 receptors caused an inability to cope with stress in the family and as an individual [160, 131,132]. In this regard, it is known that stress could even reduce D2 receptor mRNA message in the substania nigra, the lateral part of the VTA, basal ganglia especially in the "reward site" the nucleus accumbens [161].This work supports the concept that forebrain dopamine systems are involved in mediating the behavioral effects of chronic mild stress. It further supports the view that in obese subjects, with chronic mild to moderate stress, a compromised number of D2 receptor sites and reduced mRNA message, the firing frequency of a catecholaminergic neuron is enhanced and would be quite receptive to 1- 
tyrosine supplementation as proposed in the formula. Moreover, it is also known that neuronal depletion of dopamine could also induce an independent end-product inhibitory state for $\mathrm{TOH}$, which will also respond to l-tyrosine supplementation. With a slow release formula, there is constant dopamine release because of the effect of enhanced opioidergic activity via Dphenylalanine on substania nigra GABA neurons.

\section{Treatment: Role of nutrients and pharmacogenomics in obesity and overeating}

In the eating game we must first appreciate the importance of brain neurochemistry and how certain nutrients such as amino-acids could effect brain neurotransmitter status and how this could effect macro-selection. In this regard we must be cognizant of how a nutritionally unbalanced diet may lead to neurochemical processes that now induce the intake and aberrant craving for, high carbohydrate meals. The intake of macro - and micronutrients leads to characteristic changes in the serum concentration of amino -acids, in particular large neutral amino acids. The consensus of the literature suggests that changes in the concentration of large neutral amino acids lead to parallel changes in their brain concentration that, in turn, specifically influence the synthesis of their respective neurotransmitters.

While the functional impact of these neurotransmitters differs markedly, the basic metabolic processes are comparable. Most of these substances are metabolized within nerve cells from their precursor molecules that have been taken up from the extracellular brain fluid. They are stored in intraneuronal vesicles and are released following a depolarization of the neuron. They interact with either pre-or postsynaptic receptors within the synaptic cleft and are inactivated either through enzymatic degradation or through neuronal uptake. Central nervous system functions clearly depend on those mechanisms that guarantee the stability of precursor amino acid concentration. It also follows that a marked reduction in the concentration of these amino acids impairs physiological functions that are regulated and /or modulated by a respective neurotransmitter. The regulation of the synthesis of metabolic products from large neutral amino acids appears to be specific for neurotransmitters such as monamines. It is noteworthy that a similar impact on the synthesis of neurohormones (i.e opioid peptides) does not exist, since ribosomal protein synthesis does not depend on the fluctuation of amino acid concentrations. It may thus be speculated that a coupling of nutrient intake (amino-acid precursors), transmitter synthesis, and neuronal function reflects a phylogenetically relevant process.

When we consider that there are shared genes and RDS is an encompassing term which includes a number of impulsive, compulsive and addictive behaviors, we should not be surprised of the vast numbers involved in RDS. We know that at least one-third of the US alone carries the DRD2 A1 variant. This has been linked to multiple addictions including carbohydrate bingeing and other drugs of abuse (i.e. alcohol, cocaine, nicotine) and its presence at birth predicts future problems with food, drugs and certain destructive behaviors at the predictive value of $74 \%$ [43].

In the United States alone there are 60 million persons who are at least 20 percent overweight, 18 million alcoholics, 28 million children of alcoholics, six to ten million cocaine addicts, 14.9 million who abuse other substances, 25 million people addicted to nicotine, 3.5 milion school age children with attention-deficit disorder or Tourette Syndrome and about a half million compulsive gamblers. Utilizing a natural approach to attenuate compromised 
neurochemistry will ultimately lead us to a better modality that is potentially without side effects.

While we believe natural nutritional therapy could offer an important approach to prevent as well as treat reward deficit problems, especially as it relates to obesity, there is reason to believe a pharmacological approach can not be ignored. In an attempt to show the power of a new emerging field of "Pharmacogenomics" we provide the following example.

It is tempting to speculate that the pharmacological sensitivity of overeaters to dopaminergic agonists (bromocriptine, bupropion, n-propylnor-apomorphine, phentermine, and dopamine) may be determined partly by the individuals $D_{2}$ genotype. We predict that $A_{1}$ carriers should be more responsive to $\mathrm{D}_{2}$ agonists (including naturaly released dopamine), especially in stimulantdependent people. At least one study already has shown that direct microinjection of the $\mathrm{D}_{2}$ agonist n-propylnor-apomorphine into the rat nucleus accumbens significantly suppresses the animals symptoms after withdrawal of opiates [162]. A double-blind study demonstrates the utility of this approach in human subjects [15]. The $\mathrm{D}_{2}$ agonist bromocriptine or a placebo was administered to alcoholics who were carriers of the $A_{1}$ allele $\left(A_{1} / A_{1}\right.$ and $A_{1} / A_{2}$ genotypes) or who carried only the $A_{2}$ allele $\left(A_{2} / A_{2}\right)$. The greatest improvement in the reduction of craving and anxiety was found among the $\mathrm{A}_{1}$ carriers who were treated with bromocriptine. The attrition rate (relapse) was highest among the $\mathrm{A}_{1}$ carriers who were treated with the placebo. It is noteworthy, that as expected, dopamine receptor occupancy by a dopamine agonist or by dopamine itself, initiates a feedback system that produces more dopamine receptors even in $A_{1}$ carriers (low dopamine receptors) after a period of time. This is supported by the fact that the greatest effect occurred after a period of six weeks. In support of this, since 1993, Molinoff and associates using transfected kidney cells consistently showed that occupancy of $\mathrm{D}_{2}$ receptors by dopamine agonists over time results in proliferation of dopamine $\mathrm{D}_{2}$ receptors [163, 164].

Similar evidence for the role of genes in physiological response even with nutritional supplements has been accomplished with chromium picolinate by Blum et al. [165]. While there still is controversy regarding the effects of chromium salts (picolinate and nicotinate) on body composition and fat loss in general, recent unpublished work seems to support the positive change in body composition in humans (see Table 2). In consideration of the above study, Chen and Blum and others decided to genotype 130 overweight subjects for the dopamine $\mathrm{D}_{2}$ receptor gene [166]. The subjects were assessed for scale weight and for percent body fat using dual energy X-ray absorptionmetry (DEXA ${ }^{\mathrm{R}}$ ). The subjects were divided into matched placebo and chromium picolinate groups $(400 \mu \mathrm{g}$. per day). The sample was separated into two independent groups; those with either an $A_{1} / A_{1}$ or $A_{1} / A_{2}$ allele and those with only the $A_{2} / A_{2}$ pattern. In the $\mathrm{A}_{2} / \mathrm{A}_{2}$ carriers, the measures of change in fat weight, change in body weight, the percent change in weight, and the body weight change in kilograms were all significant, whereas no significance was found for any parameter for those subjects possessing a dopamine $D_{2}$ receptor $A_{1}$ allele. These results suggest the dopaminergic system, specifically the density of the $\mathrm{D}_{2}$ receptors, confers a significant differential therapeutic effect of chromium picolinate in terms of improved body mass and change in body fat. Moreover, we propose for the first time that mixed effects now observed with chromium picolinate in terms of body composition, may be resolved by 
typing the patient via dopamine $\mathrm{D}_{2}$ receptor genotyping prior to treatment with not only chromium salts, but with other nutritional supplements as well.

\section{Brain nutrition and behavior}

A detailed account of this subject is treated in the books Alcohol and the Addictive Brain [34], and To Binge or Not to Binge? [23]. In short, if genetic anomalies result in neurotransmitter imbalance, then how could we help to restore balance?

At the functional level, it seems clear that neurotransmitter imbalance may be a problem of brain nutrition: more specifically, a deficiency or excess of amino acids. In the healthy body, amino acids are in balance; if there is an excess or shortage, distortions of brain function can result [167].

As we know the brain cannot synthesize all of the amino acids involved in the formation of neurotransmitters; some are derived from food metabolism, and come to the brain via the blood supply. There are two categories of amino acids: essential and nonessential. There are five essential amino acids necessary for the manufacture of neurotransmitters, thought to play a role in obesity: methionine, leucine, phenylalanine, tyrosine, and trytophan (see above for more detail). Among the nonessential amino acids manufactured in the body, Glutamine probably plays a significant role, because it is involved in the manufacture of GABA. Two forms of amino acids are found in nature. The amino acids in the brain that make up the neurotransmitters, and the enzymes that regulate them, are all derived from the L-form. The D-form (as in Dphenylalanine) is found in a few microorganisms and in multi-cellular organisms like frog skin.

\section{Single Versus Multiple Amino acid Neuronutrients}

- First, although a single amino acid may be involved in the formation of a given neurotransmitter, it does not act alone. It needs the help of co-factors such as vitamins and minerals before the formation can take place. For example, vitamin B6 (in the alcoholic, pyridoxal -5-phosphae form is required) is needed for the manufacture of dopamine.

- Second, obesity is the result of a complex disorder that involves processes taking place in the neuron, at the synapse, and at receptors.

- $\quad$ Third, we cannot determine (until we use DNA tests) the specific defect that is producing a particular part of the problem. Therefore, in the effort to offset neurotransmitter deficits, it is not feasible to depend on single amino acids. This is why we include both serotonergic and dopaminergic precursors.

- Fourth, an odd characteristic of the blood/brain barrier actually makes treatment easier. Most overweight individuals have compounded stress and may have comorbid addictions like alcohol, smoking, and other drugs; it is known that all of these weaken the barrier facilitating the passage of restorative substances such as amino acids into the brain. This is particular important when you consider large neutral amino carrier system and competition of tryptophan, phenylalanine and tyrosine. It is equally important when you consider, as mentioned earlier, that the rate-limiting enzyme Tyrosine Hydroxylase works best under stressful conditions and the precursor tyrosine will indeed be converted to dopamine and will be subsequently released into the synapse of the n.accumbens. 
- $\quad$ Fifth, it is well known that the degradation of catecholamines by COMT plays a role, albeit only partial, in clearing these neurotransmitters from synaptic cleft. Dopamine, norepinephrine and serotonin reuptake into nerve terminals via membrane transporter is thought to play a more significant role [158].

However, it is our position that any enhancement of the neurotransmitters in the synapse is positive. In this regard, the effects of synephrine on norepinephrine receptors [168] plus the central nervous system effects of Rhodiola rosea [169, 170] could contribute to a sibutramine/D-fenfluromine-like effect. The amount of Rhodiola rosea recommended in the prposed formula herein is $240 \mathrm{mg}$ per day (based on a $3 \%$ extract standardized to rosavin) which is somewhat higher than the recommended dose for use of Rhodiola rosea as an antidepressant (200mg/day, [171], see below). Moreover, the proposed formula may also contain synephrine, derived from citrus aurantium (6\% synephrine) at a daily dose of 50mg. This amounts to only $6 \mathrm{mg}$ per day. While this is less than normal recommended dose as $\mathrm{s}$ sympathiomimetic agent, when it is combined with caffeine thermogenesis could be achieved without the stimulatory effects seen with much higher doses (104mg/day).

\section{Studies showing anti-craving efficacy of precursor amino-acids and Enkephalinase inhibitor activity}

- It is our contention that with the proposed formula as designed for anti-craving, synergistic outcomes for other comorbid addictions might be observed since the ingredients are included that could act through several different mechanisms ( see above) to enhance the activity of the neurotransmitters.

- In a number of experiments we have shown brain changes of enkephalins using Dphenylalanine $(500 \mathrm{mg} / \mathrm{kg} / \mathrm{day}$ for 18 days) and or its metabolite hydrocinnamic acid (intracerebral ventricular injection of 25 micrograms) in mice [88]. Using the same doses these known enkephalinase inhibitors significantly reduced alcohol preference in both acceptance and 14 day preference test [17].

- We have shown in healthy volunteers electrophysiological changes (enhanced memory and focus) with the combination of DL-phenylalanine (1500mg/day), L-tyrosine (900mg/day), Lglutamine (300mg/day), chromium picolinate (360 micrograms /day) and other co-factors [117].

- $\quad$ Positive effects in alcoholics in an in-patient hospital including lower building up to drink scores, required no PRN benzodiazepines (0\% vs. 94\%), ceased tremoring at 72 hours, had no severe depression on the MMPI, in contrast to 245 of control group. The ingredients included Dl-phenylalanine (2760mg/kg/day), L-tryptophan (150mg/day), L-glutamine (150mg/day), and pyridoxal -5-phosphate (30mg/day) [110].

- $\quad$ in a double -blind placebo controlled study of polysubstance abusers in an in -patient hospital, the combination of Dl-phenylalanine ( 2760mg/day), L-tryptophan (150mg/day), Lglutamine (150mg/day), and pyridoxal-5 -phosphate (30mg/day), significantly reduced stress, improved physical and emotional scores, a six -fold reduction in AMA rates, enhanced treatment recovery [111]. 
- Utilizing DL-phenylalanine (1500mg/day), L-tyrosine $(900 \mathrm{mg} /$ day), L-glutamine (300mg/day), L -tryptophan (400mg/day) and pyridoxal - phosphate (20mg/day) in inpatient treatment of cocaine abusers over a 30 day period compared to controls significantly reduced drug hunger and withdrawal against advice rate (AMA), reduced need for benzodiazepines, and facilitated retention in the treatment program [172].

- In an outpatient clinic DUI offenders (alcoholics and/or cocaine addicts) were treated with a combination of dl-phenylalanine, L-tyrosine, L-glutamine, Chromium, pyidoxyl-5phosphate over a ten-month period. Compared to a vitamin control (only B-complex and vitamin c), the experimental group significantly reduced relapse rates and enhanced recovery in these DUI outpatient offenders. The retention rates obtained for alcoholics was $87 \%$ for the experimental group compared to only $47 \%$ of the control patients and for cocaine abusers the numbers are $80 \%$ vs. only $13 \%$ [108] . For alcoholics: DL-phenylalanine (2760mg/day), L-Glutamine (150mg/day), chromium picolinate (360 micrograms/day), pyridoxal -5phosphate; For cocaine abusers: DL-phenylalanine ( $1500 \mathrm{mg} /$ day), L-Tyrosine ( $900 \mathrm{mg} /$ day), L-glutamine ( $300 \mathrm{mg} / \mathrm{day})$, pyridoxal -5 -phosphate ( $20 \mathrm{mg} / \mathrm{day})$.

- Utilizing amino acid and enkephalinase inhibitory therapy, J.A. Cold found significant improvement in both cocaine craving and withdrawal symptoms in out patient cocaine addicts [114]. The ingredients included DL-phenylalanine (1500mg/day), L-Tyrosine (900mg/day), L-glutamine (300mg/day), and pyridoxal-5-phosphate (20mg/day).

- With only chromium picolinate it was found in two double - blind placebo controlled studies that doses of either $200 \mathrm{mcg}$ or $400 \mathrm{mcg}$ resulted in a body composition improvement, loss of body fat, gain in nonfat mass [115,116];

- With DL-phenylalanine (2700mg/day), L-tryptophan (150mg/day), L-glutamine $(150 \mathrm{mg} /$ day $)$ and pyridoxal -5 phosphate $(30 \mathrm{mg} /$ day) it was also found that 27 outpatients with high carbohydrate bingeing behavior where females were assigned 800 calories total intake per day and males were assigned 1,000 to 1,200 calories per day and all withdrew from sugar use attending a supervised diet- controlled treatment program, the supplement group over a 90 day period lost an average of 26.96 pounds compared to the control group ( no supplement) lost only 10 pounds. In fact, only $18.2 \%$ of the experimental group relapsed (lost less than 15 pounds over the 90 day period) compared to $80 . \%$ in the control group [112];

- In another study where the supplement contained dl-phenylalanine $(2760 \mathrm{mg} / \mathrm{day}), \mathrm{L}-$ tryptophan $(150 \mathrm{mg} /$ day), L-glutamine $(150 \mathrm{mg} /$ day $)$, pyridoxal -5 phosphate $(30 \mathrm{mg} /$ day $)$, chromium Picolinate (200 micrograms/day), and carnitine (60 mg/day) over a 2 -year period in 247 obese patients the following results were obtained in a dual blind non-randomized open trial utilizing Centrum vitamin as a control. Compared with the Non-Phencal / Centrum group the experimental Phencal/Centrum group showed a two-fold decrease in percent overweight for both males and females; a $70 \%$ decrease in food cravings for females and a $63 \%$ decrease for males; and a $66 \%$ decrease in binge eating for females and a $41 \%$ decrease for males. Most importantly, the experimental group regained only $14.7 \%$ of the lost weight, and multiple regression modeling revealed that with Phencal treatment, morbid obesity and binge eating score were significant predictors of weight gain after 2 years. In contrast, family 
history of chemical dependence was most closely associated, although not statistically significant, with improved results with Phencal [116].

- Blum decided to test the hypothesis that possibly that, the combination of a narcotic antagonist and amino acid therapy consisting of an enkephalinase inhibitor (DPhenylalanine) and neurotransmitter precursors (L-amino -acids) to promote neuronal dopamine release, might enhance compliance in methadone patients rapidly detoxified with the narcotic antagonist Trexan ${ }^{\circledR}$. In this regard, Thanos et al. and associates found increases in the dopamine D2 receptors (DRD2) via adenoviral vector delivery of the DRD2 gene into the nucleus accumbens, significantly reduced both ethanol preference (43\%) and alcohol intake (64\%) of ethanol preferring rats, which recovered as the DRD2, returned to baseline levels [21]. This DRD2 overexpression similarly produced significant reductions in ethanol non-preferring rats, in both alcohol preference (16\%) and alcohol intake (75\%). This work further suggests that high levels of DRD2 may be protective against alcohol abuse [24, 173]. The DRD2 A1 allele has also been shown to associate with heroin addicts in a number of studies. In addition, other dopaminergic receptor gene polymorphisms have also associated with opioid dependence. For example, Kotler et al. showed that the 7 repeat allele of the DRD4 receptor is significantly overpresented in the opioid dependent cohort and confers a relative risk of 2.46 [174]. This has been confirmed by Li et al. for both the 5 and 7 repeat alleles in Han Chinese case control sample of heroin addicts [175]. Similarly Duaux et al. found a significant association with homozygotes alleles of the DRD3-Bal 1 in French Heroin addicts [176]. A study from NIAAA, provided evidence which strongly suggests that DRD2 is a susceptibility gene for substance abusers across multiple populations [177]. Moreover, there are a number of studies utilizing amino -acid and enkephalinase inhibition therapy showing reduction of alcohol, opiate, cocaine and sugar craving behavior in human trials. Over the last decade, a new rapid method to detoxify either methadone or heroin addicts utilizing Trexan ${ }^{\mathrm{R}}$ sparked interest in many treatment centers throughout the United States, Canada, as well as many countries on a worldwide basis. In using the combination of Trexan $^{\mathrm{R}}$ and amino-acids, results were dramatic in terms of significantly enhancing compliance to continue taking Trexan ${ }^{\circledR}$. The average number of days of compliance calculated on 1,000 patients, without amino-acid therapy, using this rapid detoxification method is only 37 days. In contrast, the 12 subjects tested, receiving both the Trexan ${ }^{\circledR}$ and amino-acid therapy was relapse-free or reported taking the combination for an average of 262 days $(\mathrm{P}<0.0001)$. Thus coupling amino-acid therapy and enkephalinase inhibition while blocking the delta receptors with a pure narcotic antagonist may be quite promising as a novel method to induce rapid detox in chronic methadone patients. This may also have important ramifications in the treatment of both opiate and alcohol dependent individuals, especially as a relapse prevention tool. .It may also be interesting too further test this hypothesis with the sublingual combination of the partial opiate mu receptor agonist buprenorphrine. The ingredients tested included DL-phenylalanine $(2760 \mathrm{mg} /$ day), LGlutamine (150mg/day), chromium picolinate (360 micrograms/day), pyridoxal -5phosphate(30mg/day). [34]. 
- Most recently a study was performed by Julia Ross best selling author of The Diet Cure [178], in an outpatient clinic in Mill Valley, California involving amino-acid therapy and enkephalinase inhibition based on Blum's work. At Recovery Systems, Ross has successfully utilized this approach to treat a number of RDS behaviors, especially eating disorders. In a preliminary evaluation, utilizing the following ingredients tailored made for each client, $d l$ phenylalaine, 5-hydroxytryptophan, l-tryptophan, l-tyrosine, l-glutamine, chromium, vitamin $B 6$, follow -up interviews of six randomly selected former eating disordered female clients ( three were also chemically dependent), were contracted nine months to three years post treatment to evaluate efficacy of combining targeted nutritional elements (amino-acids, vitamins, digestive enzymes, a diet low in refined carbohydrates but adequate in calories and other nutrients) with conventional counseling, education, and peer support. Follow-up confirmed significant initial benefits in mood and freedom from compulsive behavior and ideation in $100 \%$ tested. While one subject relapsed within six months, the remaining five subjects all sustained, and in some cases exceeded expectations. Following this preliminary evaluation, we also evaluated an additional 100 patients and the data collected revealed 98\% significant improvement in both mood and reduced craving for not only carbohydrates but other abusable substances as well. According to Ross this work further suggests the positive potential of adding targeted nutritional protocols to conventional treatment elements to improve outcome in an RDS intransigent population [179].

- The following results from a study in Las Vegas at an outpatient clinic has been evaluated and presented herein. Relapse rates: Clark County District:-Out of 15 patients only 2 patients dropped out, while the other 13 patients remained in the program for 12 months. Therefore, the percent relapse for this group is 13.33; County Court(Las Vegas) - Out of 43 patients 11 patients dropped out, while the other 32 patients remained in the program for 12 months. Therefore, the percent relapse for this group is 23.2.; Federal Court Sustem- Out of 10 patients only 2 dropped out, while the other 8 patients remained in the program for 12 months. Therefore, the percent relapse for this group is 20.0.; Self Referral- Out of 8 patients none dropped out, thus 8 patients remained in the program for 12 months. Therefore, the percent relapse for this group is 0.0. If we calculate the percent relapse of the entire program which included a total of 76 patients with a total of 15 patients that dropped out it is a remarkable $19.9 \%$ relapse. The majority of drop outs (11 out of 15 or $73.3 \%$ ) were methamphetamine abusers.-the ingredients include DL-phenylalanine ( $2700 \mathrm{mg} /$ day), 5 hydroxytryptophane $(20 \mathrm{mg} /$ day), L-Tyrosine ( $750 \mathrm{mg} /$ day), L-glutamine $(350 \mathrm{mg} /$ day), Rhodiola rosea ( $3 \%$ rosavin) (66mg/day), Chromium dinicotinate glycerate 1000 micrograms/day), DMAE (40mg/day), Hiperzine A ( 150 micrograms/day). Combination of vitamins (C, E, Niacin, Riboflavin, Thiamin, B6 [20\% Pyridoxal -5 phosphate and 80\% Pyridoxine], folic acid, B12, Biotin, Pantothenic acid, Calcium, Magnesium, Zinc, Manganese and a herbal calming blend, focus blend or mood enhancing blend. The ingredients and dosage was dependent on type of abusers including diagnosis of ADHD [180].

We have categorized the various benefits observed by individuals according to the following:

- Stress Reduction 
- Enhancement of Sleep

- Increased Energy Levels

- Generalized Well -Being

- Craving Behavior Reduction (sweets/carbs)

- Mental Focus/Memory

- Blood Sugar Levels

- Food Consumption Reduction

- Loss Of Inches

- Loss Of Fat

- Blood Pressure Reduction

- Improvement of Workout Performance

- Reduction of drug seeking behavior ( Alcohol, nicotine, cocaine, marijuana, opiates, etc)

- Reduction of Hyperactivity

- Reduction of Cholesterol

Fortunately, if a broad menu of amino acids is available in sufficient quantity, the brain appears to have the ability to choose from the menu the one or ones needed to manufacture more of the neurotransmitter that is deficient. Based on consistent positive research outcomes and technology, the following nutrients are scientifically formulated and have been clinically tested for over 25 years[34] and have relevance to the problem defined as Reward Deficiency Syndrome, more specifically-overeating and carbohydrate bingeing. However, the work to date supports a generalized anti-craving claim utilizing a number of important ingredients:.

- D-Phenylalanine, to inhibit enkephalinase, the enzyme that metabolizes or breakdown enkephalins, thereby increasing the availability of enkephalins and, presumably, making more dopamine available at the reward sites especially under stressful conditions.

- L-Phenylalanine, to stimulate the production of dopamine, and/ or increase norepinephrine levels in the reward area of the brain. The major problem with this amino acid is that it could compete with other amino-acids such as blood borne 1- tryptophan and l-tyrosine at the large neutral amino - acid brain carrier system [159]. However, other data demonstrates for the first time that the synthesis and release responses to some dopaminergic agents may be elicited from synaptosomal dopamine which is formed by the hydroxylation of phenylalanine. Amphetamine and Cogentin increased the release of dopamine formed from $14 \mathrm{C}-$ phenylalanine in rat caudate nucleus synaptosomal preparation and concomitantly stimulated the synthesis. Amfoelic acid also caused a net release of that dopamine. In conclusion, the results suggest that synaptosomal particles represent a unit capable of synthesizing dopamine from 1-phenylalanine and that synthesis from this precursor may be under the regulatory control of the particles [181].

- $\quad$ L-glutamine, to increase brain GABA levels at receptors associated with anxiety. Its major use is to maintain balance in case of over inhibition by D-phenylalanine.

- L-5-hydroxytryptophan (or its natural form) - The effect of systemic administration of 5-hydroxy-l-tryptophan on the release of serotonin in the lateral hypothalamus of the rat in vivo as examined utilizing brain microdialysis. Administration of 5-HTP caused an 
immediate increase of the 5-HT in dialysates, which was long lasting and dose dependent. When calcium was omitted from the perfusion medium, thereby limiting exocytosis, levels of basal 5-HT were significantly decreased and the 5-HTP- induced response of 5-HT was markedly attenuated [182].

- Pyridoxal-5-phosphate, the active ingredient of vitamin $\mathrm{B}_{6}$ to serve as a co-factor in the production of neurotransmitters and to enhance the gastrointestinal absorption of amino acids.

- Chromium Salts (Nicotinate and Picolinate), have a number of metabolic effects including : increase of insulin sensitivity; reduction of cholesterol; reduction of percent body fat; net reduction of weight; maintaining muscle mass promoting lean; enhancing body composition; promotes brain serotonin production ( see above)

- Carnitine (optional ingredient), promotes fat metabolism [183].

- Calcium, promotes neurotransmitter release based on many studies $[182,159]$.

- Rhodiola rosea - Several clinical trials with double -blind placebo controls in Russia provide evidence that R. rosea possess positive mood enhancing and anti-stress properties with no detectable levels of toxicity. Generally, R. rosea extract has been shown to have a positive influence on the higher nervous system, increasing attention span, memory, strength and mobility of the human body, and weight management. It is believed that R. rosea can act as a COMT inhibitor where brain levels of serotonin and dopamine has been observed. Studies by Saratikov and Marina suggest that R. rosea can increase the level of neurotransmitters by 30 percent and decrease COMT activity by 60 percent. In the weight management area there are double -blind studies with regard to "weight loss" and fat mobilization and central nervous system effects [184-192]. Scientists explain that Rhodiola rosea likely affects multiple body systems to promote emotional well-being, physical endurance, and mental sharpness. Pharmacological studies in vitro and in vivo have demonstrated that Rhodiola rosea stimulates neurotransmitter activity in the Central Nervous System (CNS) and may positively influence Serotonin, Norepinephrine, Dopamine and Acetylcholine availability in neuropathways that regulate mood. Further laboratory analysis has shown that Rhodiola Rosea also enhances permeability of the blood-brain barrier to specific neurotransmitter precursors of Serotonin and Dopamine. Although the exact mechanism of action is not yet fully understood, clinical and laboratory research indicate that Rhodiola rosea may help to promote a healthy neurotransmitter balance and provide positive support for a occasional nervousness, nervous tension, and anxiety as well as a depressed mood and mild to moderate mood changes caused by everyday stress.

- Gymnea Syveste (Optional Ingredient) helps to reduce undesirable fat formation by its ability to reduce cravings for sweets and control blood sugar levels. A peptide isolated from Gymnema, gurmarin, has also been shown to block the sweet taste of glucose and sucrose in animals. Gurmarin temporarily binds the sweet and bitter receptors on the tongue, thereby blocking the taste sensation and reducing sweet cravings. It is very important to consider a recent study by Preuss et al regarding the efficacy of a novel, natural extract of (-) hydroxycitric acid and a combination of niacin-bound chromium and Gymnema sylvetre extract in weight management in human volunteers. In a double blinded study, in 30 obese 
subjects for eight weeks the combination compared to controls resulted in reduction of weight loss, and reduction in BMI. Food intake was also reduced. The daily dosage of the HCA-SX was 4,667 mg, ChromeMate provided 400mcg of elemental chromium , and Gymnema sylvetre was 400mg (providing 100mg gymnemic acid) [193].

- Passiflora incarnate or passionflower is a name that has been given to several members of the genus Passiflora. There are more than 40 species in the genus whose origins are in both the tropical and subtropical regions of the western hemisphere. Passionflower was first brought to Europe from Mexico in the sixteenth century by Spanish conquerors. Its main medicinal purpose was that of a calming tea. It is now part of the medicinal herbarium in many countries throughout the world. Passion flower's long history in herbal medicine includes its use as a treatment for colic, diarrhea, dysentery, menstrual pain, skin eruptions, conjunctivitis, hemorrhoids, and myscle spasms. However, the inclusion in NAAT involves its central nervous system effects.It is well known that substances that alter meso-limbic function will ultimately influence metabolic X syndrome [194-197].

One of the problems with this subtropical plant is its identity. While there are a number of alkaloids which have been sold under the rubric of Passionflower, the most important and consistently effective candidate is Passiflora incarnata. The ethnobotanical database on the U.S. Agricultural Research Service's Web site lists the total alkaloid content P. incarnata as 100 to $900 \mathrm{ppm}$ and the total flavinoid content as $1.2-3.9$ percent which ahs been further tested by others [198]. Twenty -six components fall into two categories: 20 flavonoids (including a cyanogenic glycoside and gynocardine) and 6 alkaloids. Some researchers have ascribed the sedative effects of $p$. incarnata ip indole alkaloids such as Harmane and its relatives; harmaline and harmol. However, others have suggested that P. incarnata's alkaloid content is too small to cause this and other CNS effects and that flavonoids-such as apigenin, luteolin, or their glycosides-are more likely to account for CNS bioactivity. Most recently, scientists have isolated a highly anxiolytic, trisubstituted benzoflavone moiety from a P. incarnata extract. Reports from the literture reveal that this extract has the ability to restore libido on aging male rats [199], and those who are addicted to tetrahydrocannibinol [200] to restore fertility and libido that has been reduced by alcohol or nicotine use [201], and to reduce the anxiety arising from alcohol withdrawal [202]. There are also double -blind randomized studies which suggest that Passiflora extract is as effective substance for the management of generalized anxiety disorder comparative to the drug Oxazepam [203]. There is even evidence that Passiflora in a double -blind randomized controlled trial may be an effect adjuvant in the management of opiate withdrawal of opiates [204]. In addition Passoflora reduced benzodiazepone dependence in mice [201]. In fact, many pharmacological investigations confirm the sedative effects of Passoflora, especially in the $\mathrm{P}$. incarnata form [205]. We have formulated NAAT with the knowledge afforded EuroMed (source of the fragmented or cut, dried aerial parts of P. incarnata). According to Dhawan et al. the separated leaves afford the best possible CNS results, and in fact, the selected of the entire aerial parts excluding the flowers may prove to be the optimum approach for pocking up the bioactive plant parts of $\mathrm{P}$. incarnata. The importance of standardization of preparations of Passoflora has been actively studied especially as it relates to the anxiolytic activity [205]. 
Why Passoflora in NAAT?

In the early 70's one of us (KB) showed the importance of the brain neurotransmitter serotonin as a biological substrate of stress [206]. In fact, induction of stress in rodents was attenuated by injections of the serotonin chemical synthesis depleator Para -ChloraPhenylalanine (PCA). Others have also shown the involvement of serotonin and dopamine in stress production in both animals and humans. Moreover, work by Blum et. al. also showed that amino-acid and enkepkalinase inhibition therapy reduced stress in polysubstance abusers as measured in a double -blind -placebo randomized controlled trial in humans using skin conductance levels. These studies seem to dove tail the work reported on the anxiolytic effects of Passoflora. In fact it is very interesting that at least one phytoconstituent is indeed an indole similar to the chemical makeup of serotonin $[109,110]$.

\section{Combining KB220 Variants [NAAT] with Neuroadaptagens and Neuro-metabolic Optimizers}

There are at least four important factors that can effect weight gain; genetics, environment, diet composition and lifestlye and family society and culture. In this regard, an individual's genetic code can determine basal metabolic rate, neurotransmitter function, regulatory peptide levels, and other variables that may put someone at greater risk of increased, excessive and aberrant fat storage. There is another even more important facet to the genetic tendency for aberrant fat storage than genes that control fat storage or metabolic rates. This is in the genes that control our desire "to binge or not to binge". These are the "reward genes'. The understanding of neurochemistry, genetics, metabolic rates and energy expenditure, carbohydrate bingeing, body types, lipid anabolism and catabolism, caloric intakes and Syndrome $\mathrm{X}$ will provide the basis for polygenetic diagnosis and treatment of obesity [194-197].

NAAT $^{\text {TM }}$ is a unique, patented scientifically advanced product that provides a multi-nutritional approach to normal brain function. We are proposing herein that combining Synaptose (KB220Z) an example of NAAT with other ingredients known to optimize metabolic function (SEP711CG) through neurophysiolgical processes will ultimately provide a clinically effective novel approach to obesity.

\section{Neurometablic Optimizer (SEP711CG)}

Based on consistent positive research outcomes and technology, the following nutrients are scientifically formulated (following meticulous ingredient selections and dosage determinations), have been clinically tested, and have demonstrated profound efficacy at supporting optimal brain health; improving craving management; enhancing energy expenditure, neuroendocrine function, memory, focus, and cognition; immune competence; stress reduction; and body composition and weight management.

- Synaptose ${ }^{\mathrm{TM}}$ - A patented and patent-pending KB220/KB220Z neuroadaptogen nutraceutical complex has 24 clinical studies (at the time of this writing) demonstrating its ability to correct gene expression; help maintain dopamine in the normal range, promote optimal brain health, regulate cravings, and support focus, cognition, and neurotransmitter balance; reduce the impact of stress; enhance energy regulation, 
neuroendocrine function, immune competence, and healthy mood; and support a leaner body composition and healthy weight management (see below for benefits)..

- Cognitrim ${ }^{\text {TM}}$ - Comprised of 1-alpha-Acetyl-phosporylcholine and is a semi-synthetic derivative of Lecithin.

- CurQFen ${ }^{\text {TM }}$ - Superior to other curcumin products by up to 125 times, CurQFen is a fully reacted patent pending BR213 Curcuma galactomannosides compound that promotes: cognition, healthy cardiac function, immune competence, and a healthy gut; reduces the need to activate inflammatory cytokines; helps maintain blood sugar and blood lipid levels within the normal range; and slows the absorption of carbohydrates, cholesterol, bile acids, and improves gastric emptying.

- PhosphoLean ${ }^{\mathrm{TM}}$ NOPE2G2 is a patented, advanced, appetite regulating and weight management compound that is clinically proven to help people control binge eating, and lower depressed feelings - all keys to successful, long-term weight loss. In a recent study, PhosphoLean ${ }^{\mathrm{TM}}$ increased satiety, decreased depressive symptoms, decreased binge eating severity, and provided favorable changes in insulin resistance and lipids. The EGCG polyphenols in PhosphoLean ${ }^{\mathrm{TM}}$ NOPE2G2 act synergistically via spathetic activation of thermogenesis and increased fat oxidation, thus enhancing the compound's weight management effects. PhosphoLean also significantly improved diet compliance in a group of healthy, overweight or obese subjects, as demonstrated by reduced dropout rate.

- SH1028 Choline alphoscerate - After consumption, SH1028 Choline alphoscerate is converted to the metabolically active form of choline able to reach cholinergic synaptic endings, thus increasing acetylcholine release. Metabolically active choline prevents fat deposits in the liver and facilitates the movement of fats into the cells. SH1028 promotes significant improvement in cognition, memory, and other neuro-chemical and psychological cholinergic-dependent structures and functions, such as parasympathetic and sympathetic nervous system functions, neuromuscular junctions, basal forebrain function (considered to be the major cholinergic output of the central nervous system (CNS)), and important for healthy brain stem complexes.

In addition, acute supplementation augments growth hormone response to, and peak force production during, resistance exercise.

- GlucodOX'M is a proprietary nutraceutical ingredient complex comprised of a supercritical Commiphora mukul extract and a medium chain triglyceride (MCT) oil composed of $\mathrm{C} 8$ and $\mathrm{C} 10$ fatty acids. GlucodOX ${ }^{\mathrm{TM}}$ contains guggulsterones (standardized to $2.0 \%$ by HPLC analysis), which have been linked to several mechanisms that support lipid metabolism, glucose metabolism and cellular energy.

GlucodOX $^{\mathrm{TM}}$ is a unique blend whose properties are enhanced by MCTs, which can gain rapid access to the mitochondria (energy producing organelle in cells). Given their high energy density, rapid rate of absorption, and quick metabolic conversion into cellular energy, MCTs can be used for fueling physical exertion.

SEP711C3G is designed to: 
1. Improve the efficiency of energy metabolism and fat burning

2. Improve tolerance to stress (reduce the impact of stress on the body)

3. Promote learning, memory, cognition, healthy brain function, and longevity (anti-aging)

4. Support a happier mood

5. Promote healthy cravings

6. Reduce the time needed for and improve the quality of satiety or the satisfaction from pleasurable experiences (like eating)

7. Improve brain, nerve and glandular (neuro-endocrine) function

8. Promote competent immune function

9. Promote healthy blood sugar and blood lipid levels within the normal range

10. Promote healthy fat loss and weight management.

Table 2 SEP711CG: Proposed new set of important ingredients that have never been combined into one anti-obesity product

\begin{tabular}{|c|c|c|c|c|}
\hline Ingredient* & Description & Benefits & $\begin{array}{l}\text { Protection } \\
\text { /patents }\end{array}$ & $\begin{array}{l}\text { References } \\
\text { by claim } \\
\text { number }\end{array}$ \\
\hline CurQFen $^{\mathrm{TM}}$ & $\begin{array}{l}\text { Novel result of } \\
\text { curcuminoids } \\
\text { fully reacted } \\
\text { with } \\
\text { galactomannan } \\
\text { s from } \\
\text { Curcumin and } \\
\text { Fenugreek. } \\
\text { Provides } 13 \\
\text { times more } \\
\text { absorption of } \\
\text { powerful } \\
\text { curcumninods } \\
\text { than regular } \\
95 \% \\
\text { curcuminoid } \\
\text { supplements. } \\
\text { Delivers and } \\
\text { maintains a 10- } \\
\text { fold greater } \\
\text { blood serum } \\
\text { level }\end{array}$ & $\begin{array}{l}\text { 1.Healthy blood flow } \\
\text { 2.Healthy cardiac } \\
\text { function } \\
\text { 3. Joint health } \\
\text { 4.Immune } \\
\text { competence } \\
\text { 5. A healthy gut } \\
\text { 6.Blood sugar } \\
\text { management } \\
\text { 7.Healthy cell } \\
\text { structure \& function } \\
\text { 8. Reduce the need to } \\
\text { activate inflammatory } \\
\text { cytokines } \\
\text { 9.Cognitive } \\
\text { performance } \\
\text { 10.Hypoglycemic } \\
\text { effects } \\
\text { 11.Hypolipidemic } \\
\text { effects } \\
\text { 12.slow down the } \\
\text { absorption of } \\
\text { carbohydrates, } \\
\text { cholesterol, bile acids }\end{array}$ & $\begin{array}{l}\text { Fully reacted } \\
\text { patent pending } \\
\text { BR213 } \\
\text { Curcuma } \\
\text { galactomannosi } \\
\text { des compound. } \\
\text { LifeGen Inc has } \\
\text { exclusive to the } \\
\text { combination } \\
\text { for "My Secret } \\
\text { Formula". }\end{array}$ & $\begin{array}{l}\text { 1. }[207] \\
\text { 2. }[208] \\
\text { 3. }[209] \\
\text { 4. }[210] \\
\text { 5. }[211] \\
\text { 6. }[212] \\
\text { 7. }[213] \\
{[214],[215]} \\
\text { 8. }[216] \\
\text { 9. }[217] \\
\text { 10. }[218] \\
\text { 11. }[219] \\
\text { 12. }[220]\end{array}$ \\
\hline
\end{tabular}




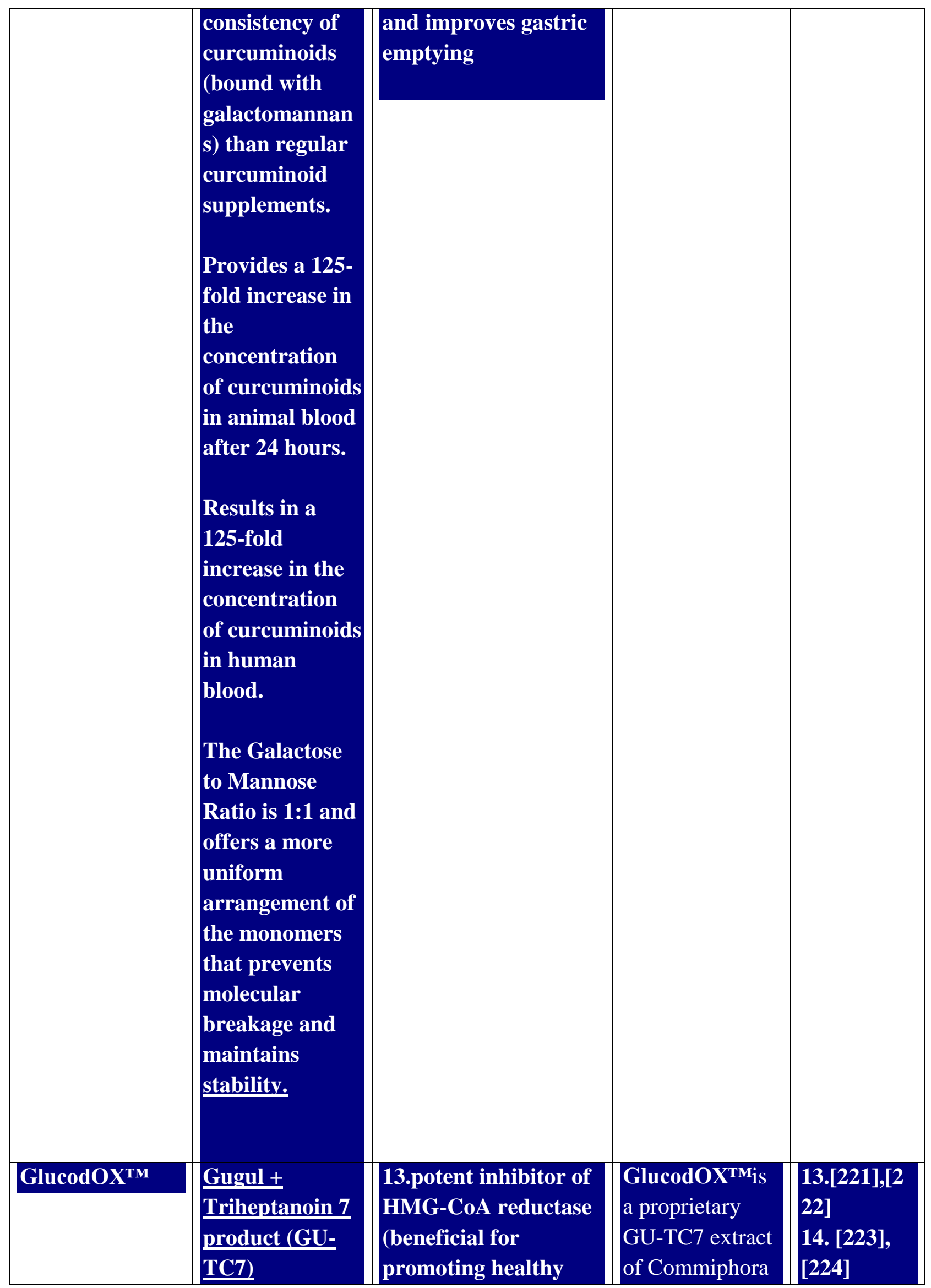




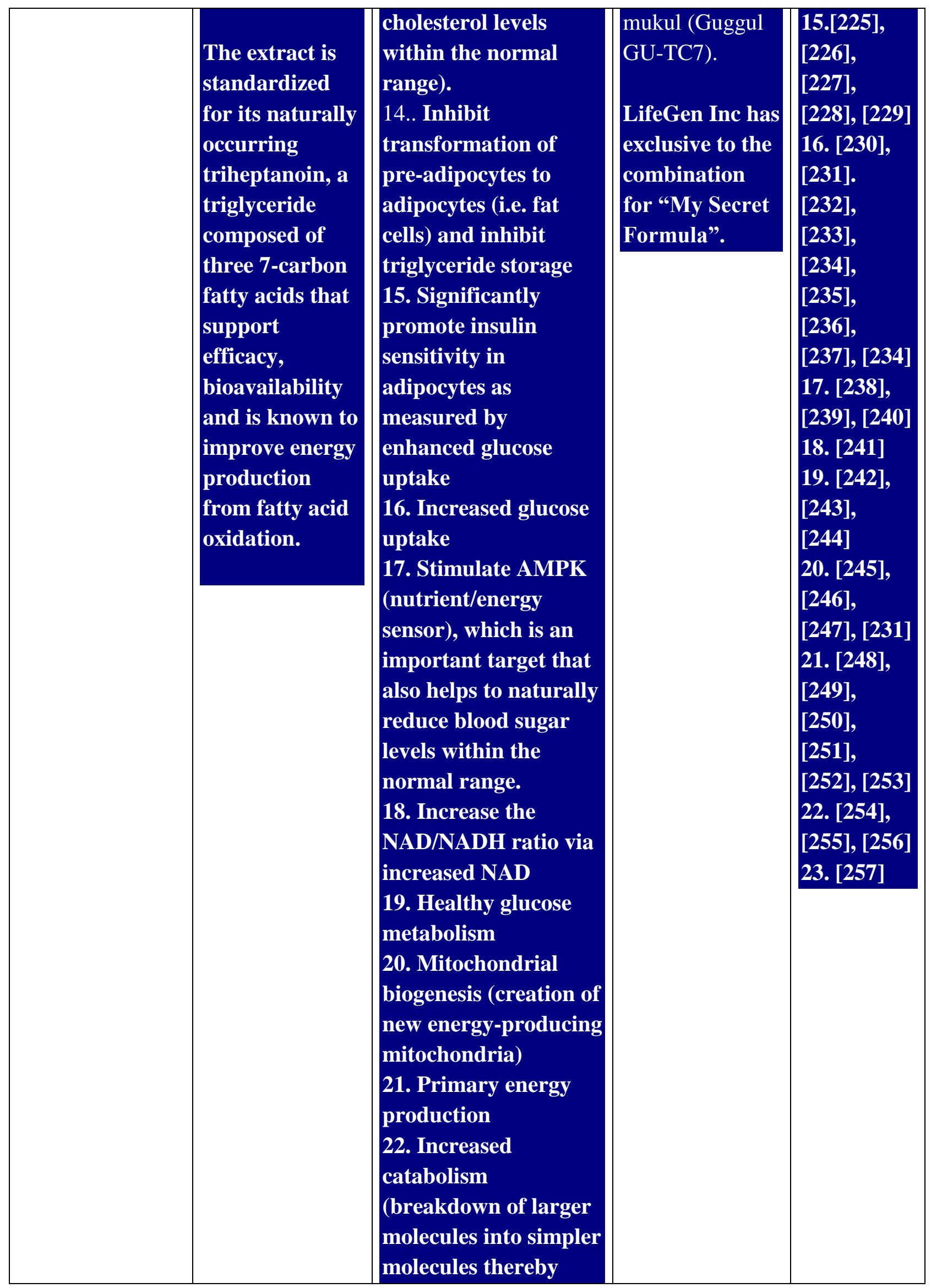




\begin{tabular}{|c|c|c|c|c|}
\hline & & $\begin{array}{l}\text { releasing } \\
\text { energy...secondary } \\
\text { energy production) } \\
\text { 23. Reduced lipid } \\
\text { production \&8. } \\
\text { Healthy blood lipid } \\
\text { metabolism }\end{array}$ & & \\
\hline $\begin{array}{l}\text { PHOSPHOLEA } \\
\frac{\mathbf{N}^{\mathrm{TM}}}{\mathrm{NOPE}+\mathrm{EGCG}} \\
\end{array}$ & $\begin{array}{l}\text { PhosphoLean } \\
\text { is a patented, } \\
\text { natural, } \\
\text { compound of N- } \\
\text { oleoyl- } \\
\text { phosphatidyl- } \\
\text { ethanolamine } \\
\text { (NOPE) and } \\
\text { EGCG, and it } \\
\text { has been } \\
\text { clinically } \\
\text { proven to help } \\
\text { dieters stay on } \\
\text { their diets. } \\
\text { Recent research } \\
\text { has shown that } \\
\text { OEA, the active } \\
\text { compound } \\
\text { liberated from } \\
\text { PhosphoLean } \\
\text { binds to a cell } \\
\text { receptor class } \\
\text { called } \\
\text { peroxisome- } \\
\text { proliferator- } \\
\text { activated } \\
\text { receptor-alpha } \\
\text { (PPAR-a) } \\
\text { found in the } \\
\text { intestinal tract. } \\
\text { This signal is } \\
\text { "hard-wired" to } \\
\text { the brain, }\end{array}$ & $\begin{array}{l}\text { 24. PhosphoLean тм } \\
\text { significantly improved } \\
\text { diet compliance in a } \\
\text { group of healthy, } \\
\text { overweight or obese } \\
\text { subjects, as } \\
\text { demonstrated by drop } \\
\text { out rate. It also } \\
\text { increased satiety, } \\
\text { decreased depressive } \\
\text { symptoms, decreased } \\
\text { binge eating severity, } \\
\text { and provided } \\
\text { favorable changes in } \\
\text { insulin resistance and } \\
\text { lipids. }\end{array}$ & $\begin{array}{l}\text { Protected } \\
\text { under US } \\
\text { Patent } \\
\text { Application: } \\
\text { US } \\
\text { 2010/0179107 } \\
\text { A1; Filed } \\
\text { September 19, } \\
\text { 2007; } \\
\text { Publication } \\
\text { Date, July 15, } \\
\text { 2010. Pistolesi } \\
\text { et al.; “N-Acyl- } \\
\text { Phosphatidyl- } \\
\text { Ethanolamines } \\
\text { And / Or } \\
\text { Mixtures Of N- } \\
\text { Acyl- } \\
\text { Ethanolamines } \\
\text { With } \\
\text { Phosphatidic } \\
\text { Acids Or } \\
\text { Lysophosphatid } \\
\text { ic Acids } \\
\text { LifeGen Inc has } \\
\text { exclusive to the } \\
\text { combination } \\
\text { for “My Secret } \\
\text { Formula". } \\
\text { (a) }\end{array}$ & 24. [258] \\
\hline
\end{tabular}




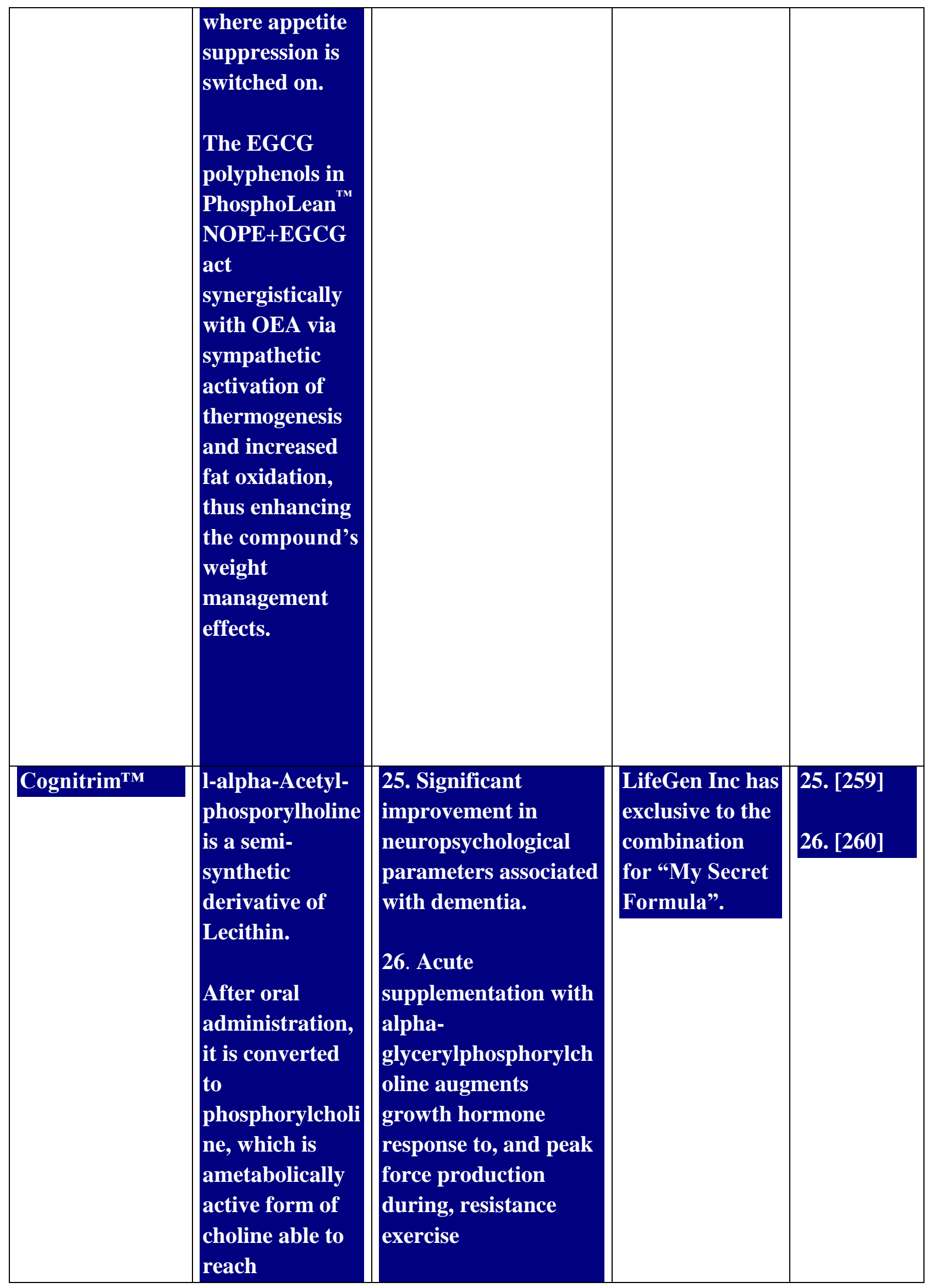




\begin{tabular}{|l|l|l|l|}
\hline & $\begin{array}{l}\text { cholinergic } \\
\text { synaptic } \\
\text { endings, thus } \\
\text { increasing } \\
\text { acetylcholine } \\
\text { and reelase. L- } \\
\text { Alpha-Acetyl- } \\
\text { phosporylholine } \\
\text { contributes to } \\
\text { anabolic } \\
\text { processes } \\
\text { responsible for } \\
\text { membrane } \\
\text { phospholipid } \\
\text { and glycerolipid } \\
\text { synthesis } \\
\text { positively } \\
\text { influencing } \\
\text { membrane } \\
\text { fluidity and } \\
\text { integrity. }\end{array}$ & & \\
\hline
\end{tabular}

\section{Benefits and Features}

In summary, $\mathbf{N A A} \mathbf{T}^{\mathrm{TM}}$ provides a unique combination of diet ingredients which include the Synapatamine $^{T M}$ composition and other natural substances like potassium glycerophosphate, citrus aurantum, and gymnema sylvestre among others helps normalize the "Reward System" in the brain by maintaining normal levels of neurotransmitters involved eating behaviors. When normal neurotransmitter function is maintained food intake, especially of carbohydrates is controlled. Potassium glycerophosphate is a compound that helps the body maintain metabolic and enhance function and increase energy levels. The product also contains thermogenic and energy supporting ingredients that will help one lose weight and increase lean muscle. To review of the clinical outcomes of many trials go to the reference Chen et al. [181].

In terms of craving behavior each neutraceuitical developed will address a specific brain dysfunction. In this regard, NAAT ${ }^{\mathrm{TM}}$ has been designed to significantly reduce carbohydrate bingeing. The mechanism for this effect involves the pharmacological principal -like treats like. In this case, the common release of dopamine at the reward site by glucose is linked to aberrant glucose seeking behavior. This compulsive drive for dopamine is affected by the use of the patented (US \# 6.132.724) Synaptose ${ }^{T M}$ composition which works on the brain reward system to mimic the action of glucose on nucleus accumbens neurons to release dopamine. Dopamine when released activates dopamine $\mathrm{D}_{2}$ receptors. When these receptors are activated by dopamine the system is driven to attain pleasure and well-being. In general, since deficits have been found 
in brain chemical functions underlying craving behavior, and since these deficits may be alleviated by facilitated dopamine release consequent to the use of substances such as glucose, combining amino- acid precursors and enkephalinase inhibition may stimulate the brain's reward system and compensate for neurotransmitter imbalance (thereby attenuating glucose craving behavior). In an attempt to understand that carbohydrate seeking behavior, is a subset of generalized craving behavior ( Reward Deficiency Syndrome) due in part to low dopamine function (an impaired reward cascade), scientists believe individuals self-heal through biochemical attempts to alleviate hypodopaminergic activity via glucose - reward site interaction. Since the brain is made up of 200 billion cells and these cells require good nutrition, which includes minerals, vitamins, trace metals and amino acids, $\mathbf{N A A T}^{\mathrm{TM}}$ is a special blend with brain stabilizing and metabolic properties. It is noteworthy, that since it is known that dopamine $\mathrm{D}_{2}$ occupancy by dopamine $\mathrm{D}_{2}$ agonists increase $\mathrm{D}_{2}$ receptors, it is the contention that the use of this product would induce a constant release of dopamine, to occupy dopamine $\mathrm{D}_{2}$ receptors, and ultimately reduce craving behavior due to a genetic deficiency of carrying the Dopamine $\mathrm{D}_{2}$ Receptor A1 allelle (expression of low $\mathrm{D}_{2}$ receptor number).

\section{Imaging studies: Genes and weight gain.}

We decided to test the acute oral $\mathbf{N A A T} \mathbf{T}^{\mathrm{TM}}$ on reward circuitry during uprotracted abstinence following psychostimulant dependence in ten subjects associated with $\mathrm{G} \&$ G Holistic Addiction Treatment Center of North Miami Beach, Florida. These subjects were diagnosed as having severe psychostimulant dependence and have been in recovery for at least two years. As part of the inclusion criteria, each patient was urine tested to determine the absence or presence of any psychoactive drug (illicit). None of the subjects tested showed a positive drug tested urine. Therefore, they were subsequently admitted to the study.

We found that a comparison of the FFT absolute Power $(\mathrm{uVSq})$ of alpha $(8-12 \mathrm{~Hz})$ demonstrated higher activity in the NAAT ${ }^{\mathrm{TM}}$ group compared to the placebo group. Similarly observing the FFT absolute Power (uVSq) of low beta (12.0 15hz), the activity is considerably larger in the $\mathbf{N A A T}^{\mathrm{T}}$ group compared to the placebo group. Finally, there was a consistent effect of $\mathbf{N A A T}^{\mathrm{TM}}$ on frontal regions when compared to placebo. The $\mathrm{p}$ values for group 1 (NAAT ${ }^{\mathrm{TM}}$ ) versus Group 2 (Placebo) for a between-group analysis of week 1 and week 2 whereby group comparisons utilizing T-tests were performed resulted in significant differences. This study is still in progress whereby we are increasing the subject population.

To date, as observed there are numerous clinical trials showing various recovery benefits from RDS behaviors using NAAT ${ }^{\text {TM }}$. However, prior to the imaging studies, a measurable magnitude of effect and the mechanism of action have been elusive. The results of these preliminary qEEG studies suggest an interaction of NAAT and meso-limbic activation leading to "normalization" of abnormal dopaminergic function in anticipation of patients carrying a number of reward gene polymorphisms [261, 100].

While NAAT ${ }^{\mathrm{TM}}$ appears to be a D2 natural non-addicting agonist, cautious interpretation must await future fMRI and PET scan analysis to determine chronic induction of D2/D3 receptors, especially in DRD2 A1 allele carriers and direct interaction at D2 receptor NAc interaction. 
Further confirmation and study expansion results of the qEEG analyses and continued demonstration that $\mathbf{N A A} \mathbf{T}^{\mathrm{TM}}$ in the oral form leads to activation of the Parietal and Frontal regions of the brain, will be important. Moreover, increasing both alpha and low Beta activity will have important clinical outcomes. If confirmed it will suggest that $\mathbf{N A A T}^{\mathrm{TM}}$ "normalizes" brain abnormalities associated with drug dependence (alcohol, heroin and psycho stimulants) induced by dopaminergic deficiency by acting as a Dopaminergic receptor agonists during protracted abstinence in polydrug abusers. This notion is supported by other studies showing enhanced treatment response in only A1 vs. A2 carriers we anticipate, that the greatest effect will have occurred with those individuals possessing the DRD2 TAq A1 allele [15,262,263].

We cautiously suggest that long-term activation of dopaminergic receptors (i.e., DRD2 receptors) will proliferate D2 receptors, leading to enhanced "dopamine sensitivity" and an increased sense of happiness. Even in carriers of DRD2 A1 allele, in psychostimulant abusers this is supported by numerous clinical trials and awaits PET scanning results to determine chronic effects of NAAT ${ }^{\text {TM }}$ on numbers of D2 receptors [15]. Positive outcomes will provide important information that could ultimately lead to significant improvement of recovery for victims of RDS having dopamine deficiency [264- 267].

Our laboratory has now published three papers on utilizing these nutrigenomic principles to target certain gene polymorphisms including but not limited to 5HT2a receptors, PPAR Gamma, MTHFMR, LEP-OB and DRD2 genes (figure 4)with significant reductions in both weight (see figure 5) and BMI (see figure 6) [ 267, 268]. In these studies we also found that there was a 2 fold better compliance with carriers of the DRD2 A1 allele compared to carriers of the DRD2 A2 allele. (see figure 7) [269].

Figure 6 Happiness gene map as proposed whereby five gene polymorphic genes (circles) were utilized for obesity nutrigenomic therapeutic targets.

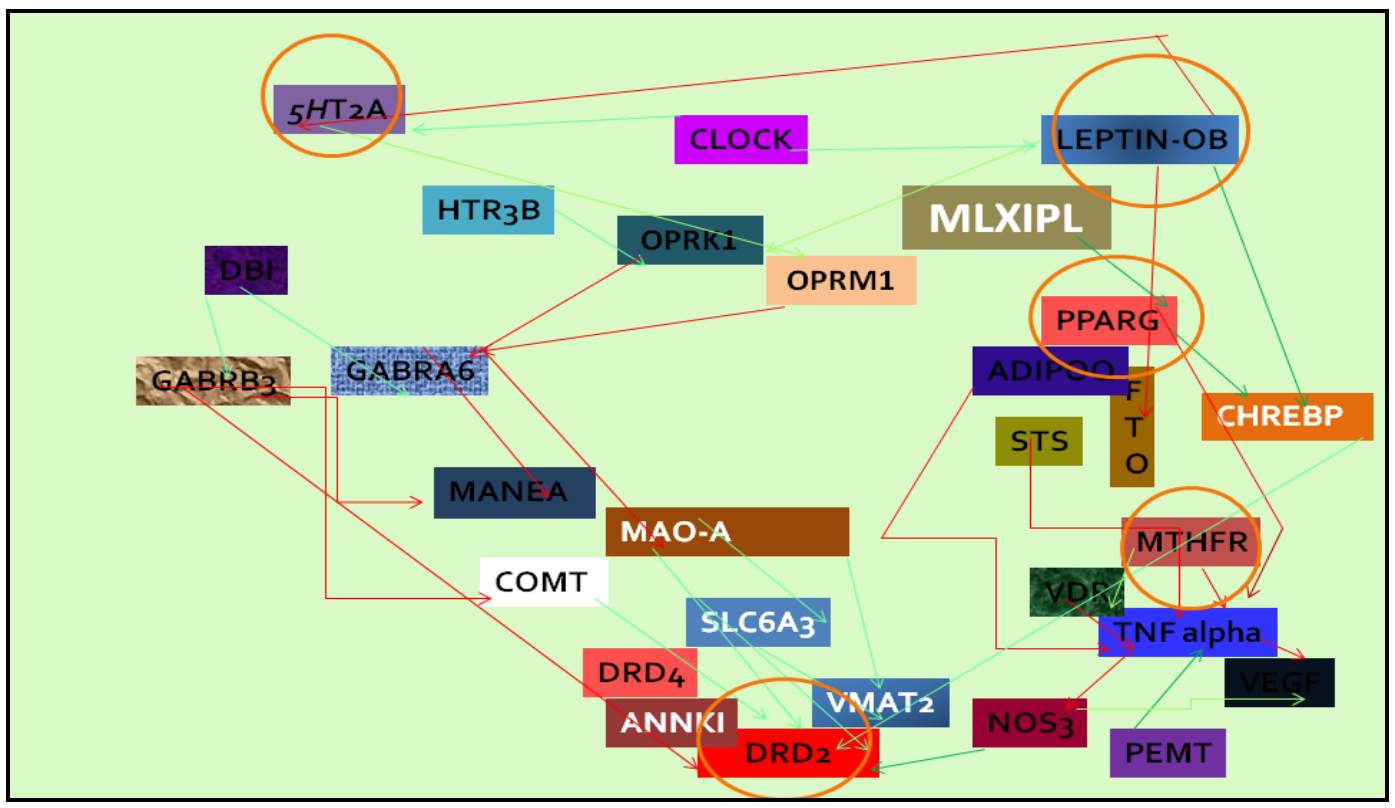


Figure 7. DNA directed KB220 (LG839 in experiment) reducs weight.Taken from reference 268 (with permission)

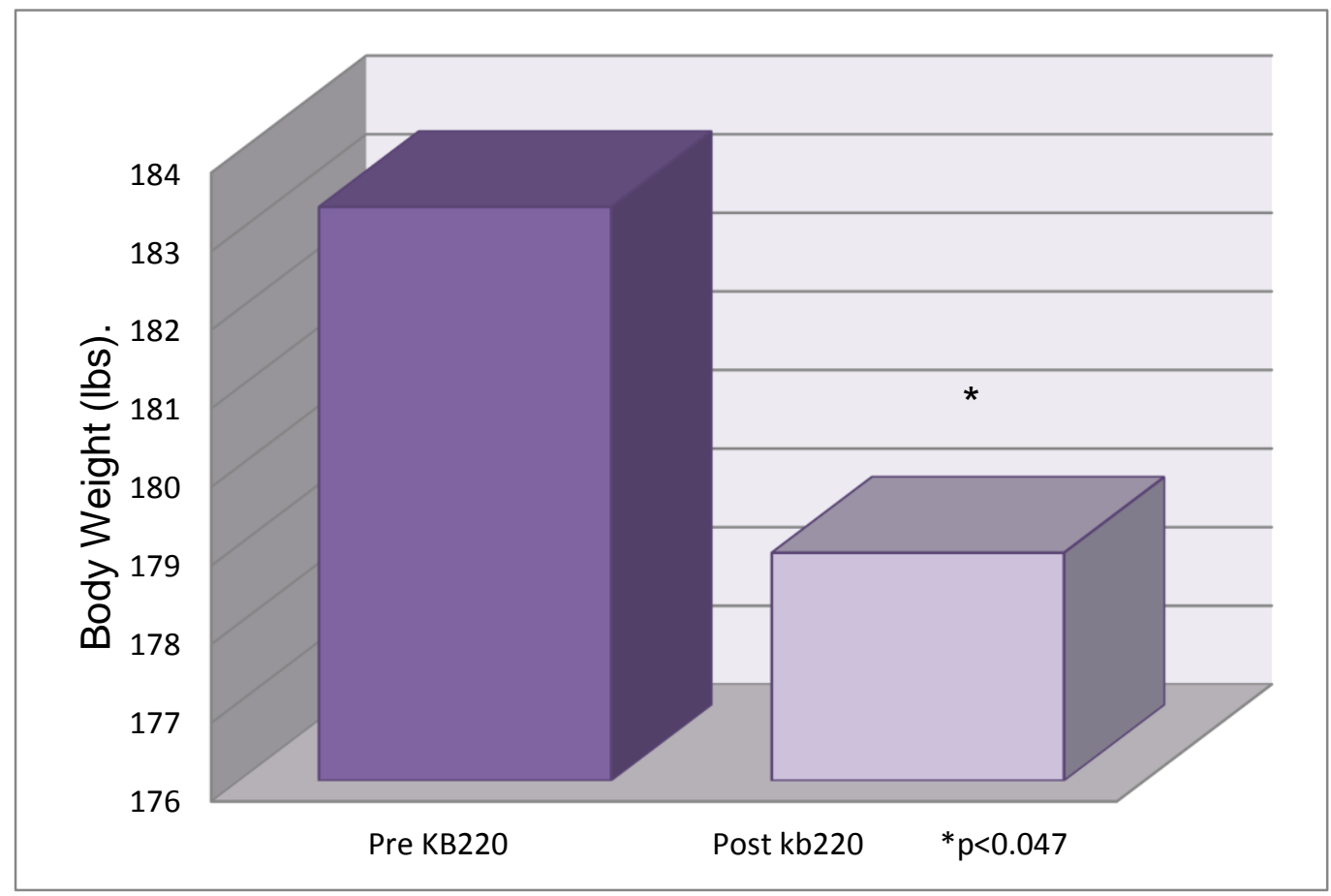

Figure 8. DNA directed KB220 reducs (LG839 in experiment) BMI. Taken from reference 268 (with permission)

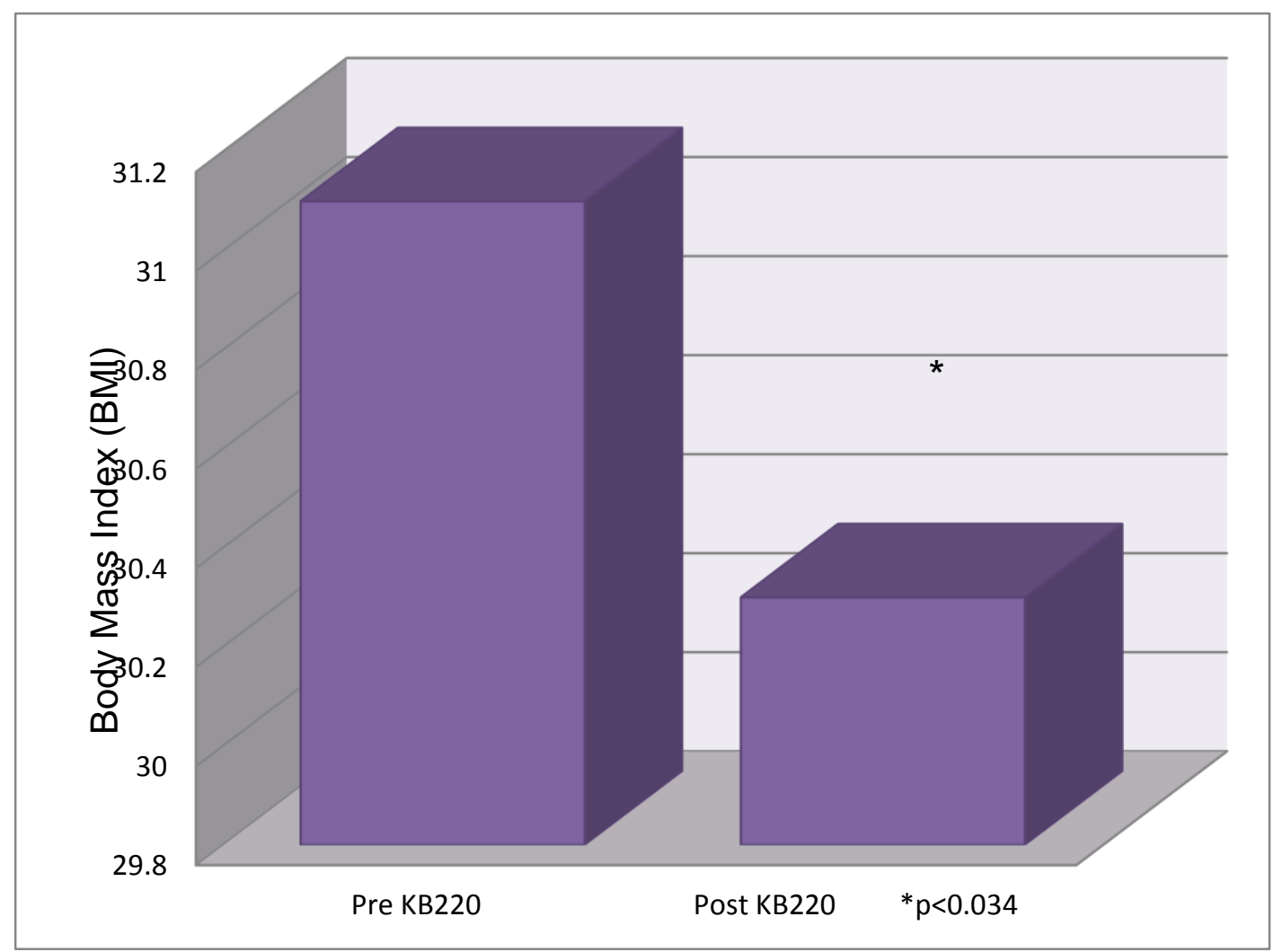


Figure 9. Treatment Compliance: Data on DNA directed KB220 (LG839 in experiment). Taken from reference 269 (with permission)

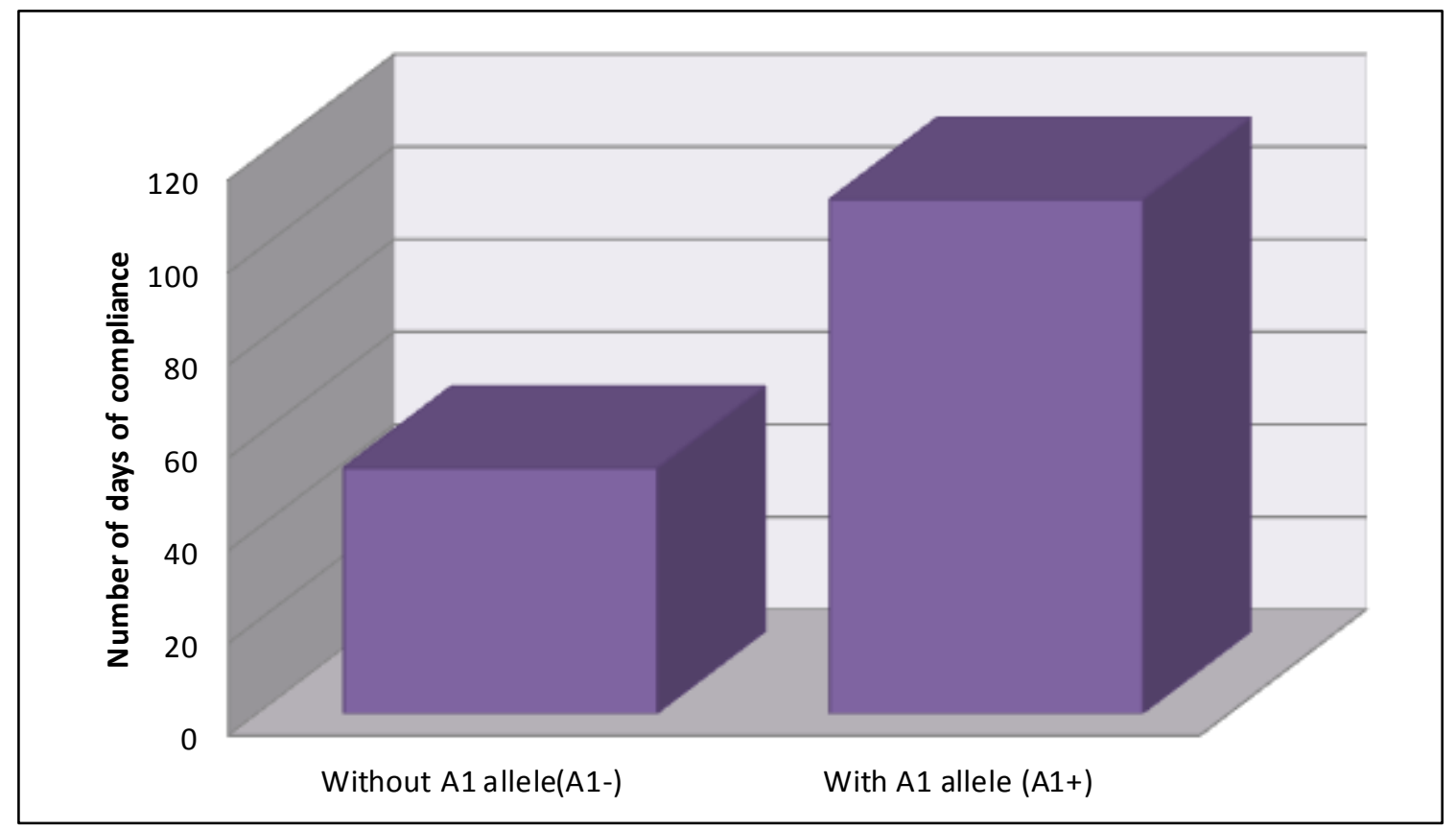

\section{Conclusion}

While we have attempted to provide a detailed comprehensive account of the need to develop nutrigenomic solutions to treat obesity and especially sugar craving behavior, a subtype of Reward Deficiency Syndrome, we are cognizant that additional large randomized double blinded -placebo studies are needed to firmly confirm these novel ideas prior to any final conclusions could be ascertained. The intent herein is to encourage our scientific peers to consider additional studies utilizing nutrigenomic solutions such as proposed with NAAT [267269].

It is well know that stress induces the preferential release of the circularitory hormone cortisol in humans [270]. It is well know that lipolysis is the major activity that is involved in the burning of fat in adipose tissue. Ottosson et al. [271] clearly showed that cortisol significantly reduced the basal rate of lipolysis $(\mathrm{p}<0.01)$ and the catecholamine lipoysis stimulators isoprenaline and noradreanline in vitro [270]. Thus, cortisol will increase rather than decrease fat burning. In addition, the patogenesis of obesity has been suggested to be intimately linked to the catechoalminegic regulation of lipolysis and the function of the sympathetic nervous system. Norepinephrine and epinephrine activate lipolysis via $\mathrm{B}_{1}$ and $\mathrm{B}_{2}$ and $\mathrm{B}_{3}$ - adrenoreceptors and inhibit it via alpha 2 adrenoreceptors, and these neurotransmitters are the most important lipolytic substances on vivo [271]. Defects of the catecholamine -induced lipolysis have been observed in a number of obese subjects, and polymorphisms of the B2- and B 3 receptors [272, 273].

By adding both Passoflora and KB220BZ (for a detailed description see [180]) a combination heretofore never combined we propose a synergistic effect on stress production and enhanced catecholamine synthesis. We further believe that these ingredients coupled together 
would induce a reduction of plasma cortisol on humans. This will indeed then enhance lipolysis and increase fat burning.

In essence, this novel formulation will promote the synthesis of the brain reward neurotransmitters like serotonin and catecholamines and through its effect on the natural opioids will by virtue of inhibiting GABA cause a significant release of dopamine at the nucleus accumbens. This constant release of possibly therapeutic amounts of dopamine (anti-stress substance) occupies dopamine $\mathrm{D}_{2}$ receptors, especially in carriers of the $A_{1}$ allele (low $D_{2}$ receptors and high glucose craving), and over time (possibly 6-8 weeks) effects RNA transcription leading to a proliferation of $\mathrm{D}_{2}$ receptors, thereby, reducing craving for carbohydrates. Evidence for anorectic actions of dopaminergic stimulators like Amphetamines I (ephedra) have been found to work via activation of both D1 ands D2 dopamine receptors [40,44]. In addition, elucidation of the composition, characteristics and properties of stabilized () HCA compounds of GcEs is essential to differentiate effective sources from ineffective and substantiate the actual active ingredients in such mineral-based complexes. Recent research demonstrates intake of $4500 \mathrm{mg} / \mathrm{d}$ of a novel IH464 GcE containing $720 \mathrm{mg}$ of $\mathrm{K}$ and $495 \mathrm{mg}$ of Ca bound by (-) HCA for 8 weeks, while consuming a $2000 \mathrm{Kcal} / \mathrm{d}$ diet, produced safe and effective loss of body fat and improved BMI without stimulating the central nervous system. Other ingredients as listed in the example will also provide important benefits such as anticraving, anti-sress, enhancement of serotonin, energy and metabolism induction, appetite suppression, starch blocking, glucose stabilization, fat burning, and general nutrition. as well as neurotransmitter rebalancing. Collateral benefits of lowered food intake and improved serotonin, insulin, lipid and leptin metabolism provide valuable evidence that this compound addresses multiple pathways in achieving sustainable healthy fat loss and improvements in body mass index while averting the consequences of rapid "weight loss" induced by CNS stimulation and/or calorie deprivation impacting many obesity genes [274,275].

Through a series of both neurogenetic and clinical experiments it is becoming increasingly clear that this novel formulation is the first neuroadaptagen known to activate the brain reward circuitry. Ongoing research repeatedly confirms the numerous clinical effects ultimately result in significant benefits for victims having genetic antecedents for all addictive, compulsive and impulsive behaviors. These behaviors are all correctly classified under the rubric of "Reward Deficiency Syndrome" (RDS). Preliminary findings in United States using qEGG and China using fMRI regarding the effects of oral $\mathbf{N A A T}^{\mathrm{TM}}$ in addicts on activation of brain reward circuitry provides potentially exciting results. It seems from this preliminary data, utilizing an fMRI 2 X2 design at resting state, NAAT ${ }^{\text {TM }}$ in comparison to placebo shows activation of the caudate brain region and potentially a smoothing out of heroin induced putamen abnormal connectivity. If further confirmed in the ongoing studies in China coupled with the qEEG results showing an increase in alpha and increase in low beta may have important treatment outcomes. Cautiously these remarkable results are in progress and must await final analysis. For a very recent review on Neuroadaptagen -Amino-Acid Therapy [NAAT ${ }^{T M}$ ] see Chen et al. [275].

Understanding that we have a worldwide epidemic of obesity coupled with substance use disorder described under the rubric of Reward Deficiency Syndrome one of us (KB) as early as 1991 sumerized it up in his book "Alcohol and the Addictive Brain"[276] 
"In the remainder of this century and the early decades of the centeury to come, I think that we will see neurobiokogy, neuropharmacology, biogenetics, psychiatry, and medicine moving forward in close coordination to reduce the devasting behavioral and social costs of faulty brain function. My vision of the future is a world in which the chemical and electrical functions of the brain are understood; the problem of chemical imbalences as they affect behavior has been solved; the role of genetic anomalies in defective brain chemistry is understood; pharmaceutical and nutrional intervention as an adjunct to twelve-step programs and professional treatment is precise and effective; and the technique of defective-gene replacement has been perfected, enabling us to break the genetic chain of inherited addiction. In this world, each individual will be able to enjoy the inborn legacy of reward and pleasure without having the need for an addictive substance [sugar], without having to pay the price of addiction and pain."

\section{Competing Interest}

Kenenth Blum, B. William Downs, Margaret A. Madigan, Roger L. Waite all own stock in LifeGen, Inc. John Giordano and Frank Fornari are partners of LifeGen, Inc. The various nutriceuticals discussed in this manuscript are based on US and foreign patents issued, awarded and pending to Blum et al.These patents have been exclusively licensed to LifeGen, Inc. There are no other conflicts of interest by any other author.

\section{Authors Contributors}

KB wrote the manuscript; AB developed the figures; BWD, RW, JG, MM, ERB, JMD, and TS contributed to the writing of the manuscript; JG and SM provided case studies; MAM edited the entire manuscript.

\section{Acknowledgements:}

The authors are grateful to the staff of the following entities: Path Foundation, NY, New York; G \&G Holistic Addiction Treatment Center, North Miami Beach, Florida; LifeGen, Inc., San Diego; and California and ElectronicWaveform Lab, Huntington Beach, California.

\section{References}

1. Jenkinson C P, Hanson R., Cray K, Wiedrich C, Bogardus C. Baiser, L: Association of dopamine D2 receptor polymorphisms Ser311Cys and Taq1 with obesity or type 2 diabetes mellitus in Pima Indians. International Journal of Obesity \& Related Metabolic Disorders. 2000, 24:12331238.

2. Tataranni PA, Baier L, Jenkinson C, Harper I, Del Parigi A, Bogardus C.: A Ser311Cys mutation in the human dopamine receptor D2 gene is associated with reduced energy expenditure. Diabetes. 2001, 50: 901-904.

3. Rivera R. and Deutsch R.D.: Your Hidden Food Allergies Are Making You Fat. Prima Health (division of Prima Publishing), Rocklin, California; 1998. 
4. Hoebel BG, Leibowitz SF, and Hernandez L.: Neurochemistry of anorexia and bulimia; In The Biology Of Feast And Famine. Edited by Andereson GH and Kennedy SH. San Diego, California, Academic Press; 1992; 21-45.

5. DeZwaan $\mathrm{M}$ and Mitchell JE.: Opiate antagonists and eating behavior in humans: a review. Journal of Clinical Pharmacology. 1992, 32:1060-1072.

6. Krueger DW: Eating Disorders. In: Substance Abuse: A comprehensive Textbook. Edited by Lowenson, JH, Ruiz P, Milman, RB, Langrod JG. 2 nd edition. 1992. Baltimore: Williams and Wilkins; 1992; 371-379.

7. Blum K, Braverman ER, Holder JM, Lubar JF, Monastra VJ, Miller D, Lubar JO, Chen TJ, Comings DE.: Reward deficiency syndrome: a biogenetic model for the diagnosis and treatment of impulsive, addictive, and compulsive behaviors. Journal of Psychoactive Drugs. 2000, 32(Suppl: i-iv):1-112.

8. Blum K and Kozlowski GP.: Ethanol and neuromodulator interactions: a cascade model of reward. In: Alcohol and Behavior. Edited by Ollat H., Parvez S. and Parvez H. Utrecht, Netherlands, VSP Press; 1990:131-149.

9. Blum K, Noble, EP, Sheridan PJ, Montgomery A, Ritchie T, Jagadeeswaran P, Nogami H, Briggs A.H, and Cohn JB.: Allelic association of human dopamine $\mathrm{D}_{2}$ receptor gene in alcoholism. Journal of the American Medical Association. 1990, 263: 2055-2060.

10. Comings DE, Gonzalez N, Wu S, Saucier G, Johnson P, Verde R, MacMurray JP.: Homozygosity at the dopamine DRD3 receptor gene in cocaine dependence. Molecular Psychiatry. 1999, 4:484-487.

11. Hill SY, Zezza N, Wipprecht G, Xu J, Neiswanger K: Linkage studies of D2 and D4 receptor genes and alcoholism. American Journal of Medical Genetics. 1999, 88:676-685.

12. Blum K, Sheridan PJ, Wood RC, Braverman ER, Chen TJ, Comings DE.: Dopamine D2 receptor gene variants: association and linkage studies in impulsive-addictive-compulsive behaviour. Pharmacogenetics. 1995, 5:121-141.

13. George SR, Cheng R, Nguyen T, Israel Y, and O'Dowd BF: Polymorphisms of the $\mathrm{D}_{4}$ dopamine receptor alleles in chronic alcoholism. Biochemical and Biophysical Research Communications. 1993, 196:107-114.

14. Noble EP, Blum K, Khalsa H, Ritchie T, Montgomery A, Wood RC, Fitch RJ, Ozkaragoz T, Sheridan, PJ, Aglin MD. Paredes A, Treiman LJ, Sparkes RS.: Allelic association of the $\mathrm{D}_{2}$ dopamine receptor gene with cocaine dependence. Drug and Alcohol Dependence. 1993, 33: 271-285.

15. Uhl G, Blum K, Noble E, Smith S.: Substance abuse vulnerability and D2 receptor genes. Trends in Neurosciences. 1993, 16:83-88.

16. Lawford BR, Young RM, Rowell J, Qualichefski BH, Fletcher K, Sundulko T, Ritchie T, Noble EP.: Bromocriptine in the treatment of alcoholics with ${ }_{\mathrm{D} 2}$ dopamine receptor $\mathrm{A}_{1}$ allele. Nature Medicine. 1995, 1: 337-341.

17. Bowirrat A, Oscar-Berman M. Relationship between dopaminergic neurotransmission, alcoholism, and Reward Deficiency syndrome. Am J Med Genet B Neuropsychiatr Genet. 2005, 132B:29-37. 
18. Gardner EL: Brain Reward Mechanisms. In: Substance Abuse: A Comprehensive Textbook .Edited by Lowenson, JH, Ruiz P, Millman RB, Langrod JG. 2 nd edition. 1992. Baltimore: Williams and Wilkins; 1997, 51-58.

19. Gardner El.: Neurobiology and genetics of addictions: Implications of "Reward Deficiency Syndrome" for therapeutic strategies in chemical dependency. In: Russell Sage Conference on Addictions: July 15, ${ }^{\text {th }} 1997$, Chaired by Jon Elston.

20. Yan QS.: Extracellular dopamine and serotonin after ethanol monitored with 5-minute microdialysis. Alcohol. 1999, 19:1-7.

21. Honkanen A, Hyytiä P, Korpi ER, Ahtee L.: Effects of morphine on metabolism of dopamine and serotonin in brains of alcohol-preferring AA and alcohol-avoiding ANA rats. Alcohol. 1999, 18:3-10.

22. Thanos PK, Volkow ND, Freimuth P, Umegaki H, Ikari H, Roth G, Ingram DK, Hitzemann R.: Overexpression of dopamine D2 receptors reduces alcohol self-administration. Journal of Neurochemistry. 2001, 78:1094-103.

23. Reither EN, Olshansky SJ, Yang Y: New Forecasting Methodology Indicates More Disease And Earlier Mortality Ahead For Today's Younger Americans. Health Affairs (Millwood). 2011, 30:1562-1568.

24. Blum K, Cull, J. G, .Miller M: To Binge or Not to Binge? Psychiatric Genetics Press 1999, San Antonio, Texas.

25. Olds ME, and Olds J: Effects of lesions in medical forebrain bundle on self-stimulation behavior. American Journal of Physiology 1969, 217: 1253-1264.

26. Hall RD, Bloom FE, Olds J: Neuronal and neurochemical substrates of reinforcement. Neuroscience Research Program Bulletin 1977, 15:131-314.

27. Blum K, Trachtenberg MC. Alcoholism: scientific basis of a neuropsychogenetic disease. Int J Addict. 1988, 23:781-96.

28. Cloninger CR.: Genetic and environmental factors in the development of alcoholism. Journal of Psychiatric Treatment Evaluation 1983, 5:487-496.

29. Blum K, Briggs AH, Trachtenberg MC.: Ethanol ingestive behavior as a function of central neurotransmission. Experientia. 1989, 4:444-452.

30. Wise RA, and Bozarth MA: Brain reward circuitry: four circuit elements "wired" in apparent series. Brain Research Bulletin. 1984, 297:265-273.

31. Koob GF, Bloom FE.: Cellular and molecular mechanism of drug dependence. Science. 1988, 242:715-23.

32. Stein L, and Belluzzi JD.: Second messenger, natural rewards, and drugs of abuse. Clinical Neuropharmacology. 1986, 9(Suppl. 4):205-207.

33. Alvakisinen MN, Saano V, Juvonene H, Huhtikangas A, Gunther J: Binding of beta-carbolines and tetrahydroisoquinolines by opiate receptors of the delta-type. Acta Pharmacologica et Toxicologica 1984, 55: 380-385.

34. Chen TJ, Blum K, Payte JT, Schoolfield J, Hopper D, Stanford M, Braverman ER. Narcotic antagonists in drug dependence: pilot study showing enhancement of compliance with SYN-10, amino-acid precursors and enkephalinase inhibition therapy. Med Hypotheses. 2004, 63:538-48.

35. Russell V, Lanin MCL, Taljaard, JF.: Effect of ethanol on ${ }^{3} \mathrm{H}$-dopamine release in rat nucleus accumbens and striatal slices. Neurochemical Research. 1988, 13:487-492. 
36. McBride WJ, Guan XM, Chernet E, Lumeng L, Li TK: Regional serotonin1A receptors in the CNS of alcohol-preferring and -nonpreferring rats. Pharmacol Biochem Behav. 1994, 49:7-12.

37. Zhou FC, Bledsoe S, Lumeng L, Li TK.: Serotoninergic immuno-stained terminal fibers are decreased in selected brain areas of alcohol-preferring $\mathrm{P}$ rats. Alcoholism: Clinical and Experimental Research. 1990, 14: 355.

38. McBride WJ, Chernet E, Dyr W, Lumeng, L, Li TK.: Densities of dopamine $\mathrm{D}_{2}$ receptors are reduced in CNS regions of alcohol preferring P rats. Alcohol. 1990, 10:387-390.

39. McBride WJ, Chernet E, Russell RN, Wong DT, Guan XM, Lumeng L, Li, TK.: Regional CNS densities of monoamine receptors in alcohol-naive alcohol-prteferring $\mathrm{P}$ and nonpreferring NP rats. Alcohol. 1997, 14:141-148.

40. Hwang BH, Lumeng L, Wu JY, Li, TK.: Increased number of GABAergic terminals in the nucleus accumbens is associated with alcohol-preferring $\mathrm{p}$ rats. Alcoholism: Clinical and Experimental Research 1990, 14:503-507.

41. Dyr W, Mcbride WJ, Lumeng, L, Li T-K. Murphy, JM.: Effects of $\mathrm{D}_{1}$ and $\mathrm{D}_{2}$ dopamine receptor agents on ethanol consumption in the high-alcohol-drinking (HAD) line of rats, Alcohol 1993, 10: 207-212.

42. Blum K, Chen TJ, Morse S, Giordano J, Chen AL, Thompson J, Allen C, Smolen A, Lubar J, Stice E, Downs BW, Waite RL, Madigan MA, Kerner M, Fornari F, Braverman ER.: Overcoming qEEG abnormalities and reward gene deficits during protracted abstinence in male psychostimulant and polydrug abusers utilizing putative dopamine $\mathrm{D}_{2}$ agonist therapy: part 2 . Postgraduate Medicine. 2010 122:214-26.

43. Blum K, Sheridan PJ, Wood RC, Braverman ER, Chen TJ, Cull JG, Comings DE. The D2 dopamine receptor gene as a determinant of reward deficiency syndrome.J R Soc Med. 1996, 89:396-400

44. Blum WF, Englaro P, Attanasio AM, Kiess W, Rascher W: Human and clinical perspectives on leptin. The Proceedings of the Nutritional Society 1998, 57:477-85.

45. Liebowitz, SF: Paraventricular nucleus: a primary site mediating adrenergic stimulation of feeding and drinking. Psychopharmacology Biochemistry Behavior. 1978, 8:163-175.

46. Stanley BG, Liebowitz SF: Neuropeptide Y injected in the paraventricular hypothalmus: a powerful stimulant of feeding behavior. Proceedings of the National Academy Of Science USA. 1985, 82:3940-3943.

47. Lichtenstein SS., Marinesccu C, Liebowitz SF.: Chronic infusion of norepinephrine and clonidine into the hypothalamic paraventricular nucleus. Brain Research Bulletin 1984, 13:591595.

48. Inokuchi A, Domura Y, Nishimura H.: Effect of intracerebro-ventricularly infused glucagon on feeding behavior. Physiological Behavior 1984, 33:397-400.

49. Blundell JE.: Problems and processes underlying the control of food selection and nutrient intake. In: Nutrition and the Brain. Edited by Wurtman, RJ. and Wurtman, JD, Raven Press; New York, 1983:163-222.

50. Blundell JL.: Serotonin and appetite. Neuropharmacology. 1984, 23:1537-1551.

51. Blundell JE.: Serotonin manipulations and the structure of feeding behavior. Appetite. 1986, 7(Suppl): 39-56. 
52. Bhakthavat-salam P, Liebowitz, SF: Morphine-elicited feeding: diurnal rhythm circulating corticosterone and macronutrient selection. Pharmacology, Biochemistry and Behavior 1986, 24:911-917.

53. Young SN. The clinical psychopharmacology of tryptophan. In: Nutrition and the Brain. Food Constituents Affecting Normal and Abnormal Behaviors. Edited by Wurtman RJ, Wurtman JJ. Raven Press, New York, 1986: 49-88.

54. Rogers LL, Pelton, RB.: Glutamine in the treatment of alcoholism : a preliminary report. Quarterly Journal Of Studies in Alcohol 1957, 18: 581-587.

55. Dhatt RK. Rattan AK, Mangat HK. Effect of chronic intracerebroventricular morphine to feeding responses in male rats. Physiological Behavior 1988, 43 : 553-557.

56. Marks-Kaufman R, Kanarch TB: Morphine selectively influences macronutrient intake in the rat. Pharmacology Biochemistry and Behavior 1980, 12: 427-430.

57. Liebowitz SF, Hor L.: Endorphinergic and alpha-noradrenergic systems in the paraventricular nucleus: effects on eating behavior. Peptides 1982, 3: 421-428.

58. Liebowitz SF, Weiss G, Yee F. , Tretter JB: Noradrenergic innervation of the paraventricular nucleus specific role in control of carbohydrate ingestion. Brain Reseach Buletin 1985, 14: 561567.

59. Liebowitz SF: Brain neurotransmitters and appetite regulation. Psychopharmacology Bulletin 1985, 21: 412-418.

60. Stanley BG, Daniel DR, Chin AS: Paraventricular nucleus injections of pepetide YY and Neuropepetide Y preferentially enhance carbohydrate ingestion. Peptides 1985, 6: 1205-1211.

61. Liebowitz SF: Brain monoamines and peptides: role in the control of eating behavior. Federation Proceedings 1986, 45: 1396-1403.

62. Shor-Posner G, Azr AP, Filart R, Tempel D, Liebowitz SF: Morphine-stimulated feeding analysis of macronutrient selection and paraventricular nucleus lesions. Pharmacology Biochemistry and Behavior 1986, 24: 931-939.

63. Wurtman JJ, Wurtman, RJ: Drugs that enhance serotonergic transmission diminish elective carbohydrate consumption by rats. Life Sciences 1979, 24: 895-904.

64. Samanin R, Bendotti C, Candelaresi G, Garattini S.: Specificity of serotonergic involvement in the decrease of food intake induced by quipazine in the rat. Life Sciences 1977, 21: 1259-1266.

65. Garattini S, Caccia S, Mennini T, Consolo S, Landisky H.: Biochemical pharmacology of the anorectic drug fenfluramine: a review. Current Medical Research and Opinion. 1979, 6(suppl. 1):15-27.

66. Goudie AJ, Thornton DW, and Wheeler TJ.: Effects of Lilly 110140, a specific inhibitor of 5hydroxytryptamine uptake on food intake and on 5-hydroxytryptophan-induced anorexia, evidence for serotonergic inhibition of feeding. Journal of Pharmacy and Pharmacology. 1976, 28: 318-320.

67. Borsini F, Bendotti C, Samanin R.: Salbutanol, d-amphetamine and d-fenfluramine reduce sucrose intake in freely fed rats by acting on different neurochemical mechanisms. International Journal of Obesity. 1985, 9:277-283.

68. Leander JD: Fluoxetine suppresses palatability-induced ingestion. Psychopharmacology. 1987, 91:2885-2887. 
69. Murphy JM, Waller MB, Gatto W, McBride WJ, Lumeng L, Li T-K.: Effects of Fluoxitine on the intragastric self administration of ethanol in the alcohol preferring P line of rats. Alcohol. 1988, 5:283-286.

70. Atkinson RL.: Familial subtypes of childhood hyperactivity. Journal of Nervous and Mental Disease 1987, 171: 362-368.

71. Bado A, Roze C, Lewin MJM, and Dubrasquet M: Endogenous opioid peptides in the control of food intake in cats. Peptides. 1989, 10:967-971.

72. Gosnell BA, Grace M, Levine AS.: Effects of B-chlonaltrexamine on food intake, body weight and opioid-inducing feeding. Life Sciences. 1987, 40:1459-1467.

73. Morley JE, Levine AS.: Corticotropin releasing factor, grooming and ingestive behavior. Life Sciences. 1982, 31: 1459-1464.

74. Morley JE, Parker S, Levine AS.: Effect of butorphanol tartrate on food and water consumption in humans. American Journal of Clinical Nutrition 1985, 42: 1175-1178.

75. Jonas JM, Gold MS.: The use of opiate antagonists in treating bulimia: a study of low-dose versus high-dose Naltrexone. Psychiatry Research 1987, 24: 195-199.

76. Shimomura. Y, Oku J, Glick Z, Bray, GA.: Opiate receptors, food intake and obesity. Physiology and Behavior 1982, 28: 441-445.

77. Tepperman FS, and Hirst M: Concerning the specificity of the hypothalamic opiate receptor for food intake in the rat. Pharmacology Biochemistry and Behavior 1982, 17: 1141-1144.

78. Bakshi VP, Kelly AE.: Striatal regulation of morphine-induced hyperphagia: An anatomical mapping study. Psychopharmacology. 1993, 111:207-214.

79. Gosnell BA, Levine AS, Morley JE.: The stimulation of food intake by selective agonists of mu, kappa and delta opioid receptors. Life Sciences. 1986, 38:1081-1088.

80. Drewnowski A, Krahn DD, Demitrack MA, Nairn K, Gosnell BA.: Naloxone, an opiate blocker, reduces the consumption of sweet high-fat foods in obese and lean female binge eaters. American Journal of Clinical Nutrition 1995, 6:1206-1212.

81. Broekkamp CLE, Phillips AG, Cools R.: Stimulant effect of enkephalin microinjection into the dopaminergic A10 area. Nature. 197, 278:560-562.

82. Hoebel BG: The psychopharmacology of feeding. In: Handbook of Psychopharmacology Edited by Iversen LF, Iversen SD, Snyder SH. New York: Plenum Press. 1977, 1-53.

83. Gillman MA, Lichtigfeld FJ.: The opioids, dopamine, cholecystokinin, and eating disorders. Clinical Neuropharmacology. 1986, 9:91-97.

84. Chesselet MF, Chéramy A, Reisine TD, Glowinski J.: Morphine and delta-opiate agonists locally stimulate in vivo dopamine release in CA1 caudate nuclei. Nature. 1981, 291: 320-322.

85. Koob GF.: Drug abuse: Anatomy, Pharmacology and function of reward pathways. Trends in Pharmacological. Science. 1992, 13:177-184.

86. Lynch WC, Burns G.: Enhancement of sucrose intake by the kappa opioid agonists U-50, 4888H persists beyond the period of drug exposure. Society of Neuroscience 1987, 13: 878.

87. Blum K, De Lallo L, Briggs AH, Wallace JE.: Ethanol acceptance as a function of genotype amounts of brain (met) enkephalin. Proceedings of the National Academy of science USA. 1983, 80:6510-6512. 
88. Blum K, Wallace JE, Trachtenberg MC.: Enkephalinase inhibition: regulation of ethanol intake in genetically predisposed mice. Alcohol 1987, 4:449-456.

89. Banks WA, Kastin, AJ: Inhibition of the brain to blood transport system for enkephalins and Tyr-mif-1 in mice addicted or genetically predisposed to drinking ethanol. Alcohol. 1989, 6:5357.

90. Heidbreder C, Roques B, Vanderhaeghen JJ, De Witte, P.: Kelotorphan, a potent enkephalinase inhibitor, presents opposite properties when injected intracerebroventricularly or into the nucleus accumbens on intracranial self-stimulation. Neurochemistry International. 1988, 12:347-350.

91. Blum K, Braverman ER, Wood RC, Gill J, Li C, Chen TJH, Taub M, Montggomery AR, Cull JG, Sheridan PJ.: Increased prevalence of the Taq1 $A_{1}$ allele of the dopamine receptor gene in obesity with comorbid substance use disorder. Pharmacogenetics. 1996, 6: 297-305.

92. George SR, Roldan L, Lui A, Naranjo CA.: Endogenous opioids are involved in the genetic determined high preference for ethanol consumption. Alcoholism, Clinical and Experimental Research. 1991, 15: 668-672.

93. Riviere PJM, Bueno L.: Origin of the stimulation of food intake by oral administration of enkephalinase inhibitors in sheep. Life Sciences 198,. 41: 333-339.

94. Hamdi A, Porter J, Prasad, C.: Decreased striatal D2 dopamine receptors in obese Zucker rats: changes during aging. Brain Research 1992, 589: 338-340.

95. Cincotta A.H., Tozza E, Scislowski PW.: Bromocryptine/SKF38393 treatment ameliorates obesity and associated metabolic dysfunctions in obese (ob/ob) mice. Life Sciences 1997, 61:951-6, 1997.

96. Bina KG, Cincotta AH: Dopaminergic agonists normalize elevated hypothalamic neuropeptide Y and corticotropin-releasing hormone, body weight gain, and hyperglycemia in ob/ob mice. Neuroendocrinology. 2000, 71:68-78.

97. Kuo DY.: Further evidence for the mediation of both subtypes of dopamine D1/D2 receptors and cerebral neuropepetide Y (NPY) in amphetamine -induced appetite suppression. Behavioral Brain Research. 2003, 147: 149-155.

98. Scislowski PW, Tozzo E, Zhang Y, Phaneuf S, Prevelige R, Cinocotta AH.: Biochemical mechanisms responsible for the attenuation of diabetic and obese conditions in ob/ob mice treated with dopaminergic agents. International Journal Of Obesity \& Related Metabolic Disorders. 1999, 94:425-31.

99. Baptista T, Parada M, Hernandez L.: Long term administration of some antipsychotic drugs increases body weight and feeding in rats. Are D2 receptors involved? Pharmacology, Biochemistry \& Behavior. 1987, 27:399-405.

100. Freeman AS, Weddige FK, Lipinski JL Jr.: Effect of glucose on antipsychotic drug-induced changes in dopamine neuronal activity. European Journal of Pharmacology 2001, 431:43-46.

101. Blum K, Liu Y, Shriner R, Gold MS.: Reward circuitry dopaminergic activation regulates food and drug craving behavior. Cur Pharm Des. 17:1158-67.

102. Dichiara G, Impereto A: Drugs abused by humans preferentially increase synaptic dopamine concentrations in the mesolimbic systems of freely moving rats. Proceedings of the National Academy of Science USA. 1988, 84:1413-1416. 
103. Gessa Gl, Mutoni, F, Coller, M, Vargin L, Mercer G: Low doses of ethanol activate dopaminergic neurons in the ventral tegmental area. Brain Research. 1985, 348:201-203.

104. Tandra G, Pontieri FE, Dichiara G. Cannabinoid and heroin activation of mesolimbic dopamine transmission by a common mu1 opioid receptor mechanism. Science. 1997, 276:2048-2050.

105. Nakajima S: Subtypes of dopamine receptors involved in the mechanism of reinforcement. Neuroscience Biobehavior Review. 1989, 13:123-128.

106. Stefanini E, Frau M., Garau MG, Garau B, Fadda F, Gessa, GL.: Alcohol preferring rats have fewer dopamine $\mathrm{D}_{2}$ receptors in the limbic system. Alcohol and Alcoholism. 1992, 27:127-130.

107.Pffer AO, Samson HH.: Haloperidol and opomorphine effects on ethanol reinforcement in free feeding rats. Pharmacology Biochemistry Behavior. 1988, 29:343-350.

108. Boehme, RE and Ciaranello, R.: Dopamine receptor binding in inbred mice: strain differences in mesolimbic and nigrostriatal dopamine binding sites. Proceedings of the National Academy of Science USA. 1981, 78:3255-3259.

109. Brown RJ, Blum K, Trachtenberg MC.: Neurodynamics of relapse prevention: A neuronutrient approach to outpatient DUI offenders. Journal Psychoactive Drugs. 1990, 22:173-187.

110. Blum K, Trachtenberg MC, Ramsey J.: Improvement of inpatient treatment of the alcoholic as a function of neurotrient restoration: A pilot study. International Journal of Addiction. 1988, 23:991-998.

111. Blum K, Trachtenberg MC, Elliott CE, Dingler ML, Sexton RL, Samuels AI, Cataldie L.: Enkephalinase inhibition and precursor amino acid loading improves inpatient treatment of alcohol and polydrug abusers: Double-blind placebo-controlled study of the nutritional adjunct SAAVE. Alcohol. 1988, 5:481-493.

112. Blum K, Briggs AH, Trachtenberg MC.: Ethanol ingestive behavior as a function of central neurotransmission. Experientia. 1989, 45:444-4452.

113. Blum, K., Trachtenberg MC, Cook, DW.: Neuronutrient effects on weight loss in carbohydrate bingers: An open clinical trial. Current Therapeutic Research. 1990, 48: 217-233.

114. Kaats G, Blum K.: The short -term therapeutic efficacy of treating obesity with a plan of improved nutrition and moderate caloric restriction. Curr Ther Res. 1992, 51:261

115. Cold JA. NeuRecover-SA in the treatment of cocaine withdrawal and craving: a pilot study. Clinical Drug Investigation. 1996, 12:1-7.

116. Kaats GR, Blum K, Fisher JA, Adelman JA.: Effects of chromium picolinate supplementation on body composition: A randomized, double masked, placebo-controlled study. Current Therapeutic Research. 1996, 57:747-756.

117. Blum K, Cull JG, Chen JHT, Garcia-Swan S, Holder JM, Wood R, Braverman ER, Bucci, LR, Trachtenberg MC: Clinical evidence For Effectiveness of Phencal ${ }^{\mathrm{TM}}$ in maintaining weight loss in an open-label, controlled, 2-year study. Current Therapeutic Research. 1997, 58: 745-763.

118. DeFrance JF, Hymel C, Trachtenberg MC, Ginsberg LD, Schweitzer FC, Estes S, Chen TJ, Braverman ER, Cull JG, Blum K.: Enhancement of attention processing by Kantroll in healthy humans: a pilot study. Clinical (EEG) Electroencephalography. 1997, 28(2):68-75.

119. Kaats GR, Blum K, Pullin D, Keith SC, Wood R.: A randomized, double-masked, placebocontrolled study of the effects of chromium picolinate supplementation on body composition: A replication of a previous study. Current Therapeutic Research. 1998, 59:379-388. 
120. Routtenberg, A.: The reward system of the brain. Scientific American. 1978, 239:154-165.

121. Imperato A, Di Chiara G.: Preferential stimulation of dopamine release in the nucleus accumbens of freely moving rats by ethanol. Journal of Pharmacology and Experimental Therapy. 1986, 239(1):219-28.

122. England JA, Gerhard DS, Pauls DL, Sussex JN, Kidd KK, Allen CR, Hostetter AM, Housmman DE.: Bipolar affective disorder linked to DNA markers on chromosome 11. Nature. 198. 325: 783-787.

123. Cloninger CR, Bohman M, Sigvardsson S.: Inheritance of alcohol abuse; cross-fostering analysis of adopted men. Archives of General Psychiatry. 1981, 38:861-868.

124. Goodwin, DS.: Alcoholism and Heredity. Archives of General Psychiatry. 1979, 36:57-61.

125. Neiswanger K, Hill SY, Kaplan RB.: Association between alcoholism and the Taq1 A RFLP of the dopamine $\mathrm{D}_{2}$ receptor gene in samples of female and male alcoholics. Neuropsychiatric Genetics. 1995, 60:267-271.

126. Bouchard C.: Genetics of obesity: an update on molecular markers.: International Journal of Obesity. 1995, 19 (supple 3):S10-S13.

127. Zhang X, Proenca R, Barone M, Leopold L, Freedman JM.: Positional cloning of the mouse obese gene and its human homologue. Nature. 1994, 372:425-32.

128. Turton MD, O'Shea D, Gunn I, Beak SA, Edwards CM, Meeran K, Choi SJ, Taylor GM, Heath MM, Lambert PD, Wilding JP, Smith DM, Ghatei MA, Herbert J, Bloom SR.: A role for glucagon-like peptide-1 in the central regulation of feeding. Nature. 1996, 379:60-72.

129. Krahn, D.: The relationship of eating disorders and substance abuse. Journal of Studies on Alcohol. 1991, 3:239-253.

130. Newman MM, and Gold MS.: Preliminary findings of patterns of substance abuse in eating. American Journal of Drugs and Alcohol Abuse 1992, 18:207-211.

131. Noble EP, Noble RE, Ritchie T, Syndulko K, St. jeor SC, Fitch RJ, Brunner RL, Sparkes RS.: $\mathrm{D}_{2}$ dopamine receptor gene and obesity. International Journal of Eating Disorders. 1994, 15:205217.

132. Comings DE, Gade R, MacMurray JP, Muhlleman D, Johnson P, Verde R, Peters WR.: Genetic variants of the human obesity (OB) gene: association with body mass index in young women psychiatric symptoms, and interaction with the dopamine $\mathrm{D}_{2}$ receptor gene. Molecular Psychiatry. 1996, 1:325-335.

133. Yasuno F, Suhara T, Yamamoto M, Inoue M, Okubo Y, Suzuki K.: Relation among dopamine D2 receptor binding, obesity and personality in normal human subjects. Neuroscience Letters. 2001, 300(1): 59-61.

134. Jenkinson CP, Hanson R, Cray K, Wiedrich C, Knowler WC, Bogardus C, Baier L.: Association of dopamine $\mathrm{D} 2$ receptor polymorphisms Ser311Cys and TaqIA with obesity or type 2 diabetes mellitus in Pima Indians. International Journal of Obesity. 2000, 24:1233-1238.

135. Wetterling, T.: Body weight gain with atypical antipychotics. A comparative review. Drug Safety. 2001, 24(1):59-73.

136. Thomas GN, Tomlinson B, Critchley JA.: Modulation of blood pressure and obesity with dopamine D2 receptor gene Taqi polymorphism. Hypertension. 2000, 369(2): 177-82. 
137. Comings DE, Flanagan SD, Diez G, Muhlman D, Knell E, Gysin R.: The dopamine $\mathrm{D}_{2}$ receptor as a major gene in obesity and height. Biochemical Medicine and Metabolic Biology. 1993, 50: 176-185.

138. Wang GJ, Volkow ND, Logan J, Pappas NR, Wong CT, Zhu W, Netusil N, Fowler JS.: Brain dopamine and obesity. Lancet. 2001, 357( 9253):354-7.

139. Volkow ND, Fowler JS, Wang GJ, Hitzman R, Logan J, Schlyer D, Dewey S, Wolf AP.: Decreased dopamine $\mathrm{D}_{2}$ receptor availability is associated with reduced frontal metabolism in cocaine abusers. Synapse. 1993, 14:169-177.

140. Ebstein RP, Novick O, Umansky R, Peil B, Osher Y, Blaine D, Bennett E, Nemanov L, Katz M, Belmaker R.: Dopamine $\mathrm{D}_{4}$ receptor exon 111 polymorphism associated with the human personality trait of novelty seeking. Nature Genetics. 1996, 12:78-80.

141. Benjamin J, Lin L, Patterson C, Greenberg BD, Murphy DL, Hamer DH.: Population and familial association between the D4 dopamine receptor gene and measures of novelty seeking. Nature Genetics. 1996, 12:81-84.

142. Poston WS 2nd, Ericsson M, Linder J, Haddock CK, Hanis CL, Nilsson T, Aström M, Foreyt JP.: D4 dopamine receptor gene exon III polymorphism and obesity risk. Eating and Weight Disorders. 1998, 3(2):71-7.

143. Levin, B.E.: Glucose -regulated dopamine release from substantia nigra neurons. Brain Research. 2000, 874(2):158-64.

144. Koshimura K, Tanala, J, Murakami T, Kato, T.: Effect of high concentration of glucose on dopamine release from Pheochromocytoma -12 cells. Metabolism. 2002, 52: 922-926.

145. Bello NT, Sweigart, KM Lakoski, JM, Norgren, R, Hajnal, A.: Restricted feeding with scheduled sucrose access results in an upregulation of the rat dopamine transporter. American Journal of Physiology:Regulatory, Integrative, and Comparative Physiology. 2000, 284: R1260R1268.

146. Lee TL, Hsu SH, Yen SH, Lai CW. Cheng JT.: Activation of $B_{3}$ - adrenoreceptors by exogenous dopamine to lower glucose uptake into rat adipocytes. Journal of Autonomic Nervous System. 1998, 74: 86-90.

147. Conti G, Blandini F, Tassorelli, Giubilei, F, Fornai, F, Zocchi, A, Orzi, F.: Intrastriatal injection of D1 or D2 dopamine agonists affects glucose utilization in both the direct and indirect pathways of the rat basal ganglia. Neuroscience Letters. 2001, 309:161-164.

148. Umhau JC, Petrulis SG, Diaz R, Rawlings R, George DT.: Blood glucose is correlated with cerebrospinal fluid neurotransmitter metabolites. Neuroendocrinology. 2003, 78:339-43.

149. Colantuoni C, Rada P, McCarthy J, Patten C, Avena NM, Chadeayne A, Hoebel BG.: Evidence that intermittent, excessive sugar intake causes endogenous opioid dependence. Obesity Research. 2001, 10: 478-488.

150. Kogan, HA, Marsden, CA, Fone CF.: DR4004, a putative 5- $\mathrm{HT}_{7}$ receptor antagonist, also has functional activity at the dopamine D2 receptor. European Journal of Pharmacology. 2002, 449:105-111.

151. Hajnal A, Szekely M, Galosi, R, Lenard L.: Accumbens cholinergic interneurons play a role in the regulation of body weight and metabolism. Physiology and Behavior. 2000, 70:95-103. 
152. Adler CM, Elman I, Weisenfield N, Kestler L, Pickar D, Breier A.: Effects of acute metabolic stress on striatal dopamine release in healthy volunteers. Neuropsychopharmacolgy. 2000, 22(5):545-50.

153. Trugman JM, and James CL.: Dopamine agonist and antagonist effects on regional cerebral glucose utilization in rats with intact dopaminergic innervation. Brain Research. 1993, 607(12):270-4.

154. Shiroyama K, Moriwaki K and Yuge O.: The direct effect of dopamine on glucose release from primary cultured rat hepatocytes. In Vivo. 1998, 12(5):527-9.

155. Collaku A, Rankinen T, Rice T, Leon AS, Rao DC, Skinner JS, Wilmore JH, Bouchard C.: A genome-wide linkage scan for dietary energy and nutrient intakes: the health, risk factors. Exercise training, and genetics (HERITAGE) family study. American Journal of Clinical Nutrition. 2004, 79:881-886.

156. Balcioglu A. and Wurtman RJ.: Sibutramine, serotonin uptake inhibitor, increases dopamine concentrations in rat striatal and hypothalamic extracellular fluid. Neuropharmacology. 2000, 39(12) 2352-9.

157. Schaechter JD, Wurtman RJ.: Serotonin release varies with brain tryptophan levels. Brain Research. 1990, 532(1-2):203-10.

158. Cooper JR, Bloom FR, Roth RH.: The Biochemical Basis of Neuropharmacology. New York: Oxford University Press. 1996, pp 226-409.

159. Milner JD, Irie K and Wurtman RJ.: Effect of phenylalanine on the release of endogenous dopamine from rat striatal slices. Journal of Neurochemistry. 1986, 47:1444-1448.

160. Downs BW, Chen AL, Chen TJ, Waite RL, Braverman ER, Kerner M, Braverman D, Rhoades P, Prihoda TJ, Palomo T, Oscar-Berman M, Reinking J, Blum SH, DiNubile NA, Liu HH, Blum K.: Nutrigenomic targeting of carbohydrate craving behavior: can we manage obesity and aberrant craving behaviors with neurochemical pathway manipulation by Immunological Compatible Substances (nutrients) using a Genetic Positioning System (GPS) Map? Medical Hypotheses. 2009, 73(3):427-34.

161. Dziedzicka - Wasylewska M, Willner P, Papp M.: Changes in dopamine receptor mRNA expression following chronic and mild stress and chronic anti-depressant treatment. Behavioral Pharmacology. 1997, 8(6-7):607-18.

162. Harris GC, and Aston-Jones G.: Involvement of $\mathrm{D}_{2}$ dopamine receptors in the nucleus accumbens in the opiate withdrawal syndrome. Nature. 1994, 371: 155-157.

163. Filtz TM, Artymyshyn RP, Guan W, Molinoff PB.: Paradoxical regulation of dopamine receptors in transfected HEK-293 cells. Journal of Molecular Pharmacology. 1993, 44:371-379.

164. Filtz TM, Guan W, Artymyshyn RP, Pacheco M, Ford C, Molinoff PB.: Mechanisms of upregulation of $\mathrm{D}_{2 \mathrm{~L}}$ dopamine receptors by agonists antagonists in transfected HEK-293 cells. Journal of the American Society for Pharmacology and Experimental Therapeutics. 1994. 271:1574-1582.

165. Chen TJH, Blum K, Kaats, G, Braverman ER: Chromium Picolinate: a putative anti-obesity nutrient induces changes inRu body composition as a function of the Taq 1 dopamine D2 receptor polymorphisms in a randomized double-blind placebo controlled study. Gene Therapy and Molecular Biology. 2007, 11: 161-170. 
166. Blum K, Chen ALC, and Che, TJH.: Putative targeting of dopamine D2 receptor function in reward deficiency syndrome (RDS) by Synaptamine Complex Variant (KB220): Clinical trial showing anti-anxiety effects. Gene Therapy \& Molecular Biology. 2009, 13: 214-30.

167. Fischer E, Heller B, Nachon M, Spatz H.: Therapy of depression by phenylalanine. Preliminary note. Arzneimittelforschung. 1975, 25(1):132.

168. Royal Pharmaceutical Society. Oxedrine. In: Martindale. The Extra Pharmacopia. London: 1996, P 1584.

169. Wagner H, Norr H, Winterhoff H.: Plant Adaptogens. Phytomedicine. 1994, 1: 63-76.

170. Staneheva SL, and Mosharrof A.: Effect of the extract of Rhodiola rosea on the content of the brain biogenic monoamines. Comptes Rendus de 1' academie Bulgare des Sciences: 1987, 40: 85-87.

171. Germano C and Ramazanov Z.: Artic Root (Rhodiola rosea). New York: Kensington publishing Corp. 1999, pp 45-46.

172. Blum K. Allison D, Trachtenberg MC, Williams RW, Loeblich LA.: Reduction of both drug hunger and withdrawal against advice rate of cocaine abusers in a 30-day inpatient treatment program by the neuronutrient Tropamine. Current Therapeutic Research. 1988, 43: 1204-1214.

173. Blum K, Noble EP, Sheridan PJ, Finley O, Montgomery A, Ritchie T, Ozkaragoz T, Fitch RJ, Sadlack F, Sheffield D, et al.: Association of the A1 allele of the D2 dopamine receptor gene with severe alcoholism. Alcohol. 1991, 8(5):409-16.

174. Kotler M, Cohen H, Segman R, Gritsenko I, Nemanov L, Lerer B, Kramer I, Zer-Zion M, Kletz I, Ebstein RP.: Excess dopamine D4 receptor (D4DR) exon III seven repeat allele in opioiddependent subjects. Molecular Psychiatry. 1997, 2(3):251-4.

175. Lee AM, Knoll JL, Suppes T.: The atyptical anti-psychotic sertindole: a case series. Journal Of Clinical Psychiatry. 1997, 58 (9): 410-6.

176. Duaux E, Gorwood P, Griffon N, Bourdel MC, Sautel F, Sokoloff P, Schwartz JC, Ades J, Lôo H, Poirier MF.: Homozygosity at the dopamine D3 receptor gene is associated with opiate dependence. Molecular Psychiatry. 1998, 3(4):333-6.

177. Xu K, Lichtermann D, Lipsky RH, Franke P, Liu X, Hu Y, Cao L, Schwab SG, Wildenauer DB, Bau CH, Ferro E, Astor W, Finch T, Terry J, Taubman J, Maier W, Goldman D.: Association of specific haplotypes of D2 dopamine receptor gene with vulnerability to heroin dependence in 2 distinct populations. Archives of General Psychiatry. 2004. 61(6):597-606.

178. Ross, Julia. The Diet Cure. USA: Viking Press, 1999. Print.

179. Ross, J. Amino -acid precursor and enkephalinase inhibition therapy: evidence for effectiveness in treatment of "Reward Deficiency Syndrome (RDS)", with particular emphasis on eating disorders. Molecular Psychiatry. 2001, 6:(supple) S7.

180. Chen TJ, Blum K, Waite RL, Meshkin B, Schoolfield J, Downs BW, Braverman EE, Arcuri V, Varshavskiy M, Blum SH, Mengucci J, Reuben C, Palomo T. Gene INarcotic Attenuation Program attenuates substance use disorder, a clinical subtype of reward deficiency syndrome. Adv Ther. 2007, 24(2):402-14.

181. Bagchi, S.P. and Smith, T.M.: Synaptosomal dopamine from phenylalanine in brain: effects of some dopaminergic agents. Research Communications in Chemical Pathology \& Pharmacology. 1979, 26 (3): 447-58. 
182. Gartside SE, Cowan PJ, Sharp T.: Effect of 5-hydroxy -1-tryptophan on the release of 5-HT in rat hypothalamus in vivo as measured by microdialysis. Neuropharmacology. 1992, 31(1): 9-14.

183. Kaats GR, Wise JA, Blum K, Morin RA, Adelman JD, Craig J, Croft, HA.: The short-term therapeutic efficacy of treating obesity with a plan of improved nutrition and moderate caloric restriction. Current Therapeutic Research. 1992, 51:261-274, 9.

184. Blum K, Chen TJ, Meshkin B, Waite RL, Downs BW, Blum SH, Mengucci JF, Arcuri V, Braverman ER, Palomo T.: Manipulation of catechol-O-methyl-transferase (COMT) activity to influence the attenuation of substance seeking behavior, a subtype of Reward Deficiency Syndrome (RDS), is dependent upon gene polymorphisms: a hypothesis. Medical Hypotheses. 2007, 69(5):1054-60.

185. Cifani C, Micioni Di B MV, Vitale G, Ruggieri V, Ciccocioppo R, Massi M.: Effect of salidroside, active principle of Rhodiola rosea extract, on binge eating. Physiology \& Behavior. 2010, 101(5):555-62.

186. Maslova LV, Kondrat'ev BIu, Maslov LN, Lishmanov IuB.: The cardioprotective and antiadrenergic activity of an extract of Rhodiola rosea in stress. Eksp Klin Farmakol. 1994, 57(6):61-3.

187. Mattioli L, Funari C, Perfumi M.: Effects of Rhodiola rosea L. extract on behavioural and physiological alterations induced by chronic mild stress in female rats. Journal of Psychopharmacology. 2009, 23(2):130-42

188. Perfumi M, Mattioli L.: Adaptogenic and central nervous system effects of single doses of $3 \%$ rosavin and $1 \%$ salidroside Rhodiola rosea L. extract in mice. Phytotherapy Research. 2007, 21(1):37-43.

189. Sarris J, Panossian A, Schweitzer I, Stough C, Scholey A.: Herbal medicine for depression, anxiety and insomnia: A review of psychopharmacology and clinical evidence. European Journal of Neuropsychopharmacology. 2011 May 20. (in press)

190. Hung SK, Perry R, Ernst E.: The effectiveness and efficacy of Rhodiola rosea L.: a systematic review of randomized clinical trials. Phytomedicine. 2011, 18(4):235-44.

191. Dwyer AV, Whitten DL, Hawrelak JA.: Herbal medicines, other than St. John's Wort, in the treatment of depression: a systematic review. Alternative Medicine Review. 2011, 16(1):40-9.

192. Azizov AP, Seĭfulla RD. The effect of elton, leveton, fitoton and adapton on the work capacity of experimental animals. Eksp Klin Farmakol. 1998, 61(3):61-3.

193. Preuss HG, Bagchi D, Bagchi M, Rao CV, Dey DK, Satyanarayana S.: Effects of a natural extract of (-)-hydroxycitric acid (HCA-SX) and a combination of HCA-SX plus niacin-bound chromium and Gymnema sylvestre extract on weight loss. Diabetes, Obesity, and Metabolism 2004, 6(3):171-80.

194. Davy BM and Melby CL.: The effect of fiber-rich carbohydrates on features of Syndrome X. Journal of the American Dietetic Association. 2003, 103: 86-96.

195. Leeds AT.: Glycemic index and heart disease. American Journal of Clinical Nutrition. 2002, 76: 286S-289S.

196. McCullough ML, Feskanich D, Rimm EB, Giovannucci EL, Ascherio A, Variyam JN, Spiegelman D, Stampfer MJ, Willett WC.: Adherence to the Dietary Guidelines for Americans 
and risk of major chronic disease in men. American Journal of Clinical Nutrition. 2000, 72:122312231.

197. Friedman TC, Mastorakos G, Newman TD, Mullen NM, Horton EG, Costello R, Papadopoulos NM, Chrousos GP.: Carbohydrate and lipid metabolism in endogenous hypercortisolism: shared features with metabolic syndrome X and NIDDM. Endocrine Journal. 1996, 43:645-655.

198. Hansen AK, Escobar LK, Gilbert LE, Jansen RK.: Paternal, maternal, and biparental inheritance of the chloroplast genome in Passiflora (Passifloraceae): implications for phylogenetic studies. American Journal of Botany. 2007, 94(1):42-6.

199. Dhawan K, Kumar S, Sharma A.: Suppression of alcohol -cessation -oriented hyper-anxiety by the benzoflavone moiety of Passiflora incarnata Linneaus in mice. Journal of Ethnopharmacology. 2002, 81: 239-244.

200. Dhawan K, Dhawan S, Chhabra S.: Attenuation of benzoduazepine dependence in mice by a trisubstituted benzoflavone moiety of Passflora incarnata Linneaus: A non-habit forming anxiolytic. Journal of Pharmacy and Pharmaceutical Science. 2003, 6:215-222.

201. Dhawan K, Kumar S, Sharma A.: Comparative Anxiolytic activity profile of various preparations of Passiflora incarnate Linneaus: A comment on medicinal plants Standardization. The Journal of Alternative and Complementary Medicine. 2002, 8:283-291.

202. Akhondzadeh S, Naghavi HR, Vazirian M, Shayeganpour A, Rashidi H, Khani M.: Passionflower in the treatment of generalized anxiety: A pilot double -blind randomized controlled reial with oxazepam. Journal of Clinical Pharmacy \& Therapeutics. 2001, 26:363-367.

203. Akhondzadeh S, Kashani L, Mobaseri M, Hosseini SH, Nikzad S, Khani M.: Passionflower in the treatment of opiate withdrawal: a double -blind randomized controlled trial. Journal of Clinical Pharmacy \& Therapeutics. 2001, 26:369-373.

204. Krenn L.: Passion Flower (Passflora incarnata L.) - a reliable herbal sedative. Wiener Medozin. Woshenschrift. 2002, 152:404-406.

205. Dhawan K, Kumar S, Sharma A.: Anxuilytic activity of aerial and underground parts of Passflora incarnata. Fitoterapia. 2001, 72: 922-926.

206. Geller, I. and Blum, K.: The effects of 5-HTP on para-chlorphenylalanine (p-CPA) attenuation of "conflict" behavior. European Journal of Pharmacology. 1970, 9(3):319-24.

207. Srivastava LM.: Flow of couple stress fluid through stenotic blood vessels. Journal of Biomechanics. 1985, 18(7):479-85.

208. Nirmala C, Puvanakrishnan R.: Effect of curcumin on certain lysosomal hydrolases in isoproterenol-induced myocardial infarction in rats. Biochemical Pharmacology. 1996, 51(1):4751.

209. Funk JL, Frye JB, Oyarzo JN, Kuscuoglu N, Wilson J, McCaffrey G, Stafford G, Chen G, Lantz RC, Jolad SD, Sólyom AM, Kiela PR, Timmermann BN.: Efficacy and mechanism of action of turmeric supplements in the treatment of experimental arthritis. Arthritis and Rheumatism. 2006. 54(11):3452-64.

210. Deodhar SD, Sethi R, Srimal RC.: Preliminary study on antirheumatic activity of curcumin (diferuloyl methane). Indian Journal of Medical Research. 1980, 71:632-4. 
211. Holt HB, Wild SH, Wood PJ, Zhang J, Darekar AA, Dewbury K, Poole RB, Holt RI, Phillips DI, Byrne CD.: Non-esterified fatty acid concentrations are independently associated with hepatic steatosis in obese subjects. Diabetologia. 2006, 49(1):141-8.

212. Arun N, Nalini N.: Efficacy of turmeric on blood sugar and polyol pathway in diabetic albino rats. Plant Foods for Human Nutrition. 2002, 57(1):41-52.

213. Aggarwal BB, Kumar A, Bharti AC.: Anticancer potential of curcumin: preclinical and clinical studies. Anticancer Research. 2003, 23(1A):363-98.

214. Aggarwal BB.: Prostate cancer and curcumin: add spice to your life. Cancer Biology and Therapy. 2008. 7(9):1436-40.

215. Hsu CH, Cheng AL.:Clinical studies with curcumin. Advances in Experimental Medicine and Biology. 2007, 595:471-80.

216. Surh CD, Sprent J.: Regulation of mature T cell homeostasis. Seminars in Immunology. 2005, 17(3):183-91.

217. Yang F, Lim GP, Begum AN, Ubeda OJ, Simmons MR, Ambegaokar SS, Chen PP, Kayed R, Glabe CG, Frautschy SA, Cole GM.: Curcumin inhibits formation of amyloid beta oligomers and fibrils, binds plaques, and reduces amyloid in vivo. Journal of Biological Chemistry. 2005, 280(7):5892-901.

218. El-Moselhy MA, Taye A, Sharkawi SS, El-Sisi SF, Ahmed AF.: The antihyperglycemic effect of curcumin in high fat diet fed rats. Role of TNF- $\alpha$ and free fatty acids. Food and Chemical Toxicology. 2011, 49(5):1129-40.

219. Parra HJ, Arveiler D, Evans AE, Cambou JP, Amouyel P, Bingham A, McMaster D, Schaffer P, Douste-Blazy P, Luc G.: A case-control study of lipoprotein particles in two populations at contrasting risk for coronary heart disease. The ECTIM Study. Arteriosclerosisand Thrombosis 1992. 12(6):701-7.

220. Boban PT, Nambisan B, Sudhakaran PR.: Hypolipidaemic effect of chemically different mucilages in rats: a comparative study. British Journal of Nutrition. 2006, 96(6):1021-9.

221. Izzat NN, Deshazer ME, Loose-Mitchell DS.: New molecular targets for cholesterol-lowering therapy. Journal of Pharmacology and Experimental Therapy. 2000, 293(2):315-20.

222. Brown MS, Goldstein JL.: Lipoprotein receptors: therapeutic implications. Journal of Hypertension. Supplement 1990, 8(1):S33-5; discussion S35-6.

223. Yang Y, Ju D, Zhang M, Yang G.: Interleukin-6 stimulates lipolysis in porcine adipocytes. Endocrine. 2008. 33(3):261-9.

224. Rizzo G, Disante M, Mencarelli A, Renga B, Gioiello A, Pellicciari R, Fiorucci S.: The farnesoid $\mathrm{X}$ receptor promotes adipocyte differentiation and regulates adipose cell function in vivo. Molecular Pharmacology. 2006, 70(4):1164-73.

225. Shishodia S, Harikumar KB, Dass S, Ramawat KG, Aggarwal BB.: The guggul for chronic diseases: ancient medicine, modern targets. Anticancer Research. 2008, 28(6A):3647-64.

226. Gruzman A, Babai G, Sasson S.: Adenosine Monophosphate-Activated Protein Kinase (AMPK) as a New Target for Antidiabetic Drugs: A Review on Metabolic, Pharmacological and Chemical Considerations. Review of Diabetic Studies 2009, 6(1):13-36. 
227. Zhang CM, Qiu J, Chen XH, Wang B, Zhang M, Guo XR.: Effects of NYGGF4 gene overexpression on the insulin sensitivity and secretory function of adipocytes. Zhongguo Dang Dai Er Ke Za Zhi. 2009, 11(10):846-9.

228. Claudel T, Staels B, Kuipers F.: The Farnesoid X receptor: a molecular link between bile acid and lipid and glucose metabolism. Arteriosclerosis, Thrombosis, and Vascular Biology. 2005, 25(10):2020-30.

229. Stayrook KR, Bramlett KS, Savkur RS, Ficorilli J, Cook T, Christe ME, Michael LF, Burris TP.: Regulation of carbohydrate metabolism by the farnesoid X receptor. Endocrinology. 2005, 146(3):984-91.

230. Lage R, Diéguez C, Vidal-Puig A, López M.: AMPK: a metabolic gauge regulating whole-body energy homeostasis. Trends in Molecular Medicine. 2008, 14(12):539-49.

231. Long YC, Zierath JR.: AMP-activated protein kinase signaling in metabolic regulation. Journal of Clinical Investigation. 2006, 116(7):1776-83.

232. Cantó C, Pich S, Paz JC, Sanches R, Martínez V, Orpinell M, Palacín M, Zorzano A, Gumà A.: Neuregulins increase mitochondrial oxidative capacity and insulin sensitivity in skeletal muscle cells. Diabetes. 2007, 56(9):2185-93.

233. Steinberg GR, Kemp BE.: AMPK in Health and Disease. Physiological Reviews. 2009, 89(3):1025-78.

234. Hardie DG, Sakamoto K.: AMPK: a key sensor of fuel and energy status in skeletal muscle. Physiology (Bethesda). 2006, 21:48-60.

235. Fogarty S, Hardie DG.: Development of protein kinase activators: AMPK as a target in metabolic disorders and cancer. Biochimicaet Biophysica Acta. 2010, 1804(3):581-91.

236. Lim JG, Lee JJ, Park SH, Park JH, Kim SJ, Cho HC, Baek WK, Kim DK, Song DK.: Glucagonlike peptide-1 protects NSC-34 motor neurons against glucosamine through Epac-mediated glucose uptake enhancement. Neuroscience Letters. 2010, 479(1):13-7.

237. Lele RD.: Pro-insulin, C peptide, glucagon, adiponectin, TNF alpha, AMPK: neglected players in type 2 diabetes mellitus. Journal of the Association of Physicians of India. 2010, 58:30,35-40.

238. Lin SJ, Guarente L.: Nicotinamide adenine dinucleotide, a metabolic regulator of transcription, longevity and disease. Current Opinion in Cell Biology. 2003, 15(2):241-6.

239. Wu A, Ying Z, Gomez-Pinilla F.: Oxidative stress modulates Sir2alpha in rat hippocampus and cerebral cortex. European Journal of Neuroscience. 2006, 23(10):2573-80.

240. Egawa M, Kamata H, Kushiyama A, Sakoda H, Fujishiro M, Horike N, Yoneda M, Nakatsu Y, Ying G, Jun Z, Tsuchiya Y, Takata K, Kurihara H, Asano T.: Long-term forskolin stimulation induces AMPK activation and thereby enhances tight junction formation in human placental trophoblast BeWo cells. Placenta. 2008, 29(12):1003-8.

241. Pugazhenthi S, Akhov L, Selvaraj G, Wang M, Alam J.: Regulation of heme oxygenase-1 expression by demethoxy curcuminoids through Nrf2 by a PI3-kinase/Akt-mediated pathway in mouse beta-cells.American Journal of Physiology, Endocrinology, and Metabolism. 2007, 293(3):E645-55.

242. Badmaev, V. and Majeed, M.: Open Field, Physician Controlled, Clinical Evaluation of Botanical Weight Loss Formula Citrin. [Abstract] Nutriceuticals, Dietary Supplements and Functional Foods. 1995, July, Las Vegas, NV. 
243. Shen HQ, Roth MD, Peterson RG.: The effect of glucose and glucagon-like peptide-1 stimulation on insulin release in the perfused pancreas in a non-insulin-dependent diabetes mellitus animal model. Metabolism. 1998, 47(9):1042-7.

244. Svegliati-Baroni G, Saccomanno S, Rychlicki C, Agostinelli L, De Minicis S, Candelaresi C, Faraci G, Pacetti D, Vivarelli M, Nicolini D, Garelli P, Casini A, Manco M, Mingrone G, Risaliti A, Frega GN, Benedetti A, Gastaldelli A.: Glucagon-like peptide-1 receptor activation stimulates hepatic lipid oxidation and restores hepatic signalling alteration induced by a high-fat diet in nonalcoholic steatohepatitis. Liver International. 2011 Feb 15. Doi: 10.1111/j.14783231.2011.02462.x.

245. Nisoli E, Clementi E, Moncada S, Carruba MO.: Mitochondrial biogenesis as a cellular signaling framework. Biochemical Pharmacology. 2004, 67(1):1-15. Review. Erratum in: Biochem Pharmacol. 2004, 67(4):803.

246. Wilson-Fritch L, Burkart A, Bell G, Mendelson K, Leszyk J, Nicoloro S, Czech M, Corvera S.: Mitochondrial biogenesis and remodeling during adipogenesis and in response to the insulin sensitizer rosiglitazone. Molecular and Cellular Biology. 2003, 23(3):1085-94.

247. Kim JA, Wei Y, Sowers JR.: Role of mitochondrial dysfunction in insulin resistance. Circulation Research. 2008, 102(4):401-14.

248. Hardie DG.: Minireview: the AMP-activated protein kinase cascade: the key sensor of cellular energy status. Endocrinology. 2003, 144(12):5179-83.

249. Carling D.: The AMP-activated protein kinase cascade--a unifying system for energy control. Trends in Biochemical Sciences. 2004, 29(1):18-24.

250. Roe CR, Mochel F.; Anaplerotic diet therapy in inherited metabolic disease: therapeutic potential. Journal of Inherited Metabolic Disease. 2006, 29(2-3):332-40.

251. St-Onge MP, Bourque C, Jones PJ, Ross R, Parsons WE.: Medium- versus long-chain triglycerides for 27 days increases fat oxidation and energy expenditure without resulting in changes in body composition in overweight women. International Journal of Obesity Relatated Metabolic Disorders. 2003, 27(1):95-102.

252. St-Onge MP, Ross R, Parsons WD, Jones PJ.: Medium-chain triglycerides increase energy expenditure and decrease adiposity in overweight men. Obesity Research. 2003, 11(3):395-402.

253. St-Onge MP, Jones PJ.: Physiological effects of medium-chain triglycerides: potential agents in the prevention of obesity. Journal of Nutrition. 2002, 132(3):329-32.

254. Austin MA, Edwards KL, McNeely MJ, Chandler WL, Leonetti DL, Talmud PJ, Humphries SE, Fujimoto WY.: Heritability of multivariate factors of the metabolic syndrome in nondiabetic Japanese americans. Diabetes. 2004, 53(4):1166-9.

255. Chandler CE, Wilder DE, Pettini JL, Savoy YE, Petras SF, Chang G, Vincent J, Harwood HJ Jr.: CP-346086: an MTP inhibitor that lowers plasma cholesterol and triglycerides in experimental animals and in humans. Journal of Lipid Research. 2003, 44(10):1887-901.

256. Mehra R, Raman R, Bayless ML, Sivitz WI.: Antecedent caloric intake and glucose excursion following a subsequent meal in Type 1 diabetes. Journal of Diabetes. 2009, 1(4):273-7.

257. Cernkovich ER, Deng J, Bond MC, Combs TP, Harp JB.: Adipose-specific disruption of signal transducer and activator of transcription 3 increases body weight and adiposity. Endocrinology. 2008, 149(4):1581-90. 
258. Rondanelli M, Opizzi A, Solerte SB, Trotti R, Klersy C, Cazzola R.: Administration of a dietary supplement (N-oleyl-phosphatidylethanolamine and epigallocatechin-3-gallate formula) enhances compliance with diet in healthy overweight subjects: a randomized controlled trial. British Journal of Nutrition. 2009, 101(3):457-64.

259. Parnetti L, Senin U, Carosi M, Baasch H.: Mental deterioration in old age: results of two multicenter, clinical trials with nimodipine. The Nimodipine Study Group. Clinical Therapeutics. 1993. 15(2):394-406.

260. Ceda GP, Ceresini G, Denti L, Marzani G, Piovani E, Banchini A, Tarditi E, Valenti G.: AlphaGlycerylphosphorylcholine administration increases the GH responses to GHRH of young and elderly subjects. Hormone and Metabolic Research. 1992, 24(3):119-21.

261. Miller DK, Bowirrat A, Manka M, Miller M, Stokes S, Manka D, Allen C, Gant C, Downs BW, Smolen A, Stevens E, Yeldandi S, Blum K.: Acute intravenous synaptamine complex variant KB220 $0^{\mathrm{TM}}$ "normalizes" neurological dysregulation in patients during protracted abstinence from alcohol and opiates as observed using quantitative electroencephalographic and genetic analysis for reward polymorphisms: part 1, pilot study with 2 case reports. Postgraduate Medicine. 2010, 122(6):188-213.

262. Blum K, Chen AL, Chen TJ, Braverman ER, Reinking J, Blum SH, Cassel K, Downs BW, Waite RL, Williams L, Prihoda TJ, Kerner MM, Palomo T, Comings DE, Tung H, Rhoades P, Oscar-Berman M.: Activation instead of blocking mesolimbic dopaminergic reward circuitry is a preferred modality in the long term treatment of reward deficiency syndrome (RDS): a commentary. Theoretical Biology \& Medical Modeling. 2008, 12; 5:24.

263. . Ooteman W, Naassila M, Koeter MW, Verheul R, Schippers GM, Houchi H, Daoust M, van den Brink W.: Predicting the effect of naltrexone and acamprosate in alcohol-dependent patients using genetic indicators. Addiction Biology. 2009, 14(3):328-37.

264. Dackis CA, Gold MS.: New concepts in cocaine addiction: the dopamine depletion hypothesis. Neuroscience and Biobehavioral Reviews 1985, 9(3):469-77.

265. Bowirrat A, Oscar-Berman M.: Relationship between dopaminergic neurotransmission, alcoholism, and Reward Deficiency syndrome. American Journal of Medical Genetics, Part B, Neuropsychiatric Genetics. 2005. 132B (1):29-37.

266. Blum K, Liu Y, Shriner R, Gold MS.: Reward circuitry dopaminergic activation regulates food and drug craving behavior. Curr Pharm Des. 2011, 17(12):1158-67.

267. Blum K, Chen AL, Chen TJ, Rhoades P, Prihoda TJ, Downs BW, Waite RL, Williams L, Braverman ER, Braverman D, Arcuri V, Kerner M, Blum SH, Palomo T.: LG839: anti-obesity effects and polymorphic gene correlates of reward deficiency syndrome. Adv Ther. 2008, 25(9):894-913.

268. Blum K, Chen TJH, Williams L, Chen ALCH, Downs BW, Waite RL, Huntington T, Sims S, Prioda T, Rhodes P, Reinking J, Braverman D, Kerner M, Blum SH, Quirk B, Braverman ER.: A short term pilot open label study to evaluateefficacy and safety of LG839, a customized DNAdirected nutraceutical in obesity: Exploring Nutrigenomics. Gene Ther Mol Biol 2008, 12:371-382.

269. Blum K, Chen ALC, Chen TJH, Rhoades P, Prihoda TJ, Downs, BW, Bagchi, Bagchi M, Blum SH, Williams L, Braverman, ER, Kerner M, Waite RL, Quirk B, White L.: Dopamine D2 
Receptor Taq A1 allele predicts treatmentcompliance of LG839 in a subset analysis of a pilot study inthe Netherlands. Gene Ther Mol Biol. 2008, 12: 129-140.

270. Rivier C, Rivier J, Vale W.: Stress-induced inhibition of reproductive functions: role of endogenous corticotropin-releasing factor. Science 1986 231(4738):607-9.

271. Ottosson M, Lönnroth P, Björntorp P, Edén S.: Effects of cortisol and growth hormone on lipolysis in human adipose tissue. Journal of Clinical Endocrinololgy and Metabolism 2000. 85(2):799-803.

272. Large V, Hellström L, Reynisdottir S, Lönnqvist F, Eriksson P, Lannfelt L, Arner P.: Human Beta 2 adrenoreceptor gene poymorphisms are highly frequent in obesity and associate with altered Beta -2 adrenoreceptor function. Journal of Clinical Investigation 1993, 100: 1057-1091.

273. Clément K, Vaisse C, Manning BS, Basdevant A, Guy-Grand B, Ruiz J, Silver KD, Shuldiner AR, Froguel P, Strosberg AD.: Genetic variation in the Beta 3 -adrenoreceptor and an increased capacity to gain weight in patients with morbid obesity. New England Journal of Medicine 1995, 333: 352-354.

274. Dahlman I, Arner P.: Obesity and polymorphisms in genes regulating human adipose tissue. Int J Obes (Lond). 2007, 31(11):1629-41.

275. Chen, TJH, Blum K, Chen,LCH, Bowirrat A, Downs BW, Madigan MA, Waite RL, Bailey JA, Kerner M, Yelandi S, Giordano J, Morse S, Miller D, Braverman ER. : Neurogenetics and clinical evidence for the putative activation of the brain reward circuitry by amino-acid precursor-catabolic enzyme inhibition therapeutic agent (a Neuroadaptagen): Proposing an addiction candidate gene panel map. Journal of Psychoactive Drugs 2011, 42(2):108-127.

276. Blum K (with James Payne).: Alcohol and the Addcitive Brain. Simon-Schuster; (The Free Press) New York, 1991. 